\title{
A NUMERICAL STUDY OF DIFFUSION OF NANOPARTICLES IN A VISCOUS MEDIUM DURING SOLIDIFICATION
}

\author{
by
}

Kazi Mizanur Rahman

A thesis submitted in partial fulfillment of the requirements for the degree

\author{
of \\ Master of Science \\ in \\ Mechanical Engineering \\ MONTANA STATE UNIVERSITY \\ Bozeman, Montana
}

April 2016 


\section{CCOPYRIGHT}

by

Kazi Mizanur Rahman

2016

All Rights Reserved 


\section{ACKNOWLEDGEMENTS}

I would like to express my gratitude to Dr. M. Ruhul Amin for his constant guidance, encouragement and support throughout my research and thesis work. I feel fortunate to work under his guidance. I'm also grateful to Dr. Vic A. Cundy and Dr. Erick L. Johnson for their work as committee members. I am highly indebted to Dr. Ahsan Mian for his advice, expertise and care during various stages of my work.

I would also like to thank Dr. Ladean McKittrick for helping me out with computing resources and Dr. Roberta Amendola for her continuous support. I'm grateful to the Department of Mechanical and Industrial Engineering for providing me the financial support, which helped tremendously to pursue my dream. My appreciation goes to all the staff of the department, my fellow graduate students and friends at Montana State University, Bozeman.

Finally and most importantly, my infinite gratitude to my parents. Their unconditional love, endless support and constant trust helped me throughout my time in graduate school. My love and thanks to them cannot be expressed in words. 
TABLE OF CONTENTS

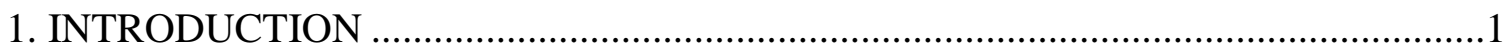

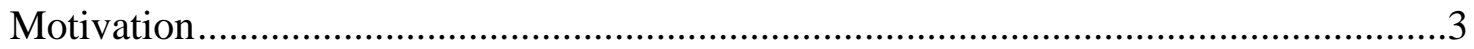

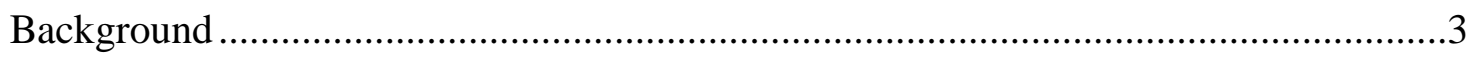

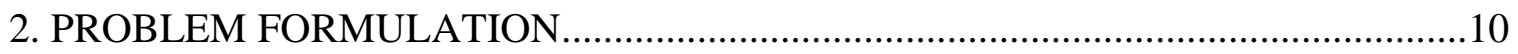

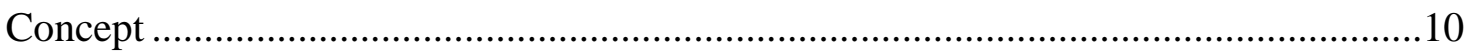

Governing Equations ....................................................................................... 12

Conservation of Mass ............................................................................... 13

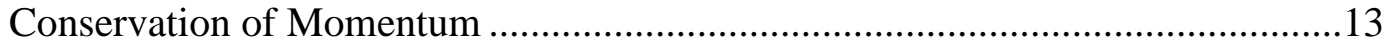

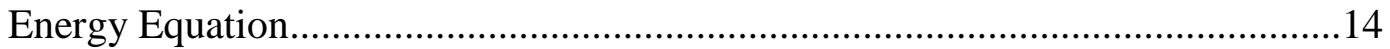

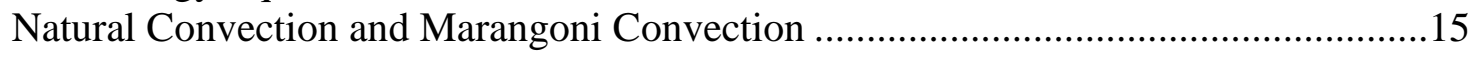

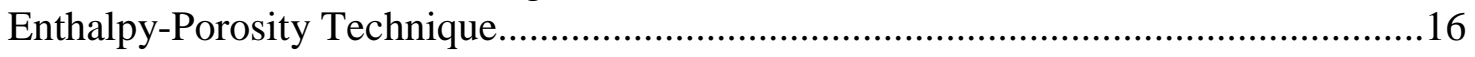

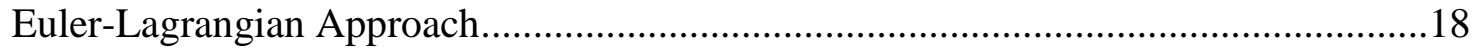

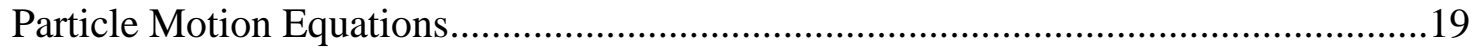

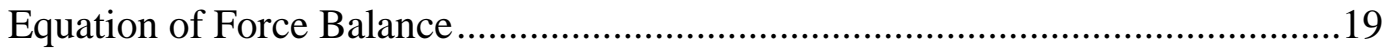

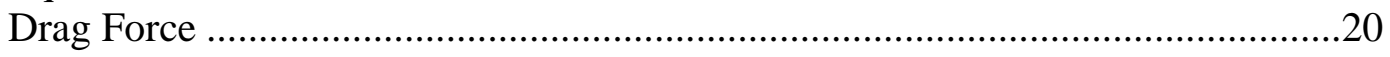

Virtual Mass and Pressure Gradient Force .......................................................20

Saffman's Lift Force .........................................................................21

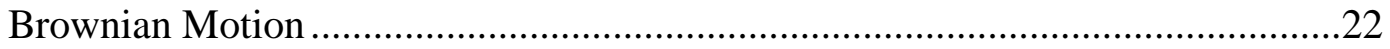

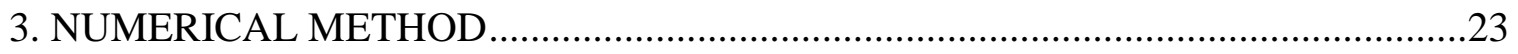

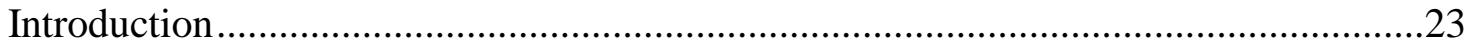

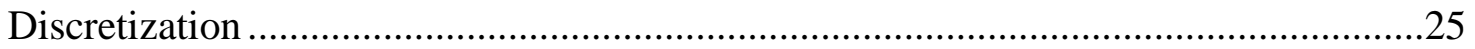

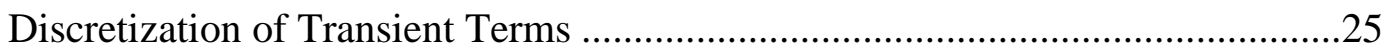

Discretization of Advection and Diffusion Terms ...........................................26

Discretization of Continuity and Momentum Equations ...................................27

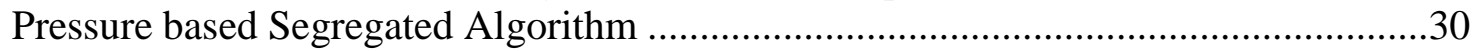

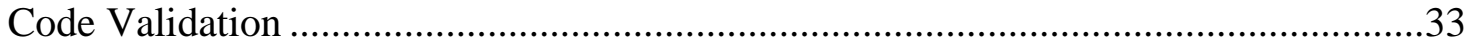

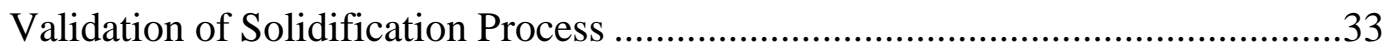

Validation of Particle Tracking Process ........................................................ 34

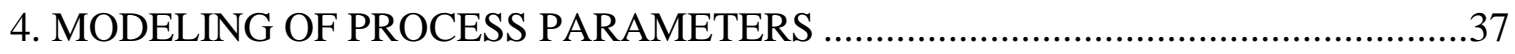

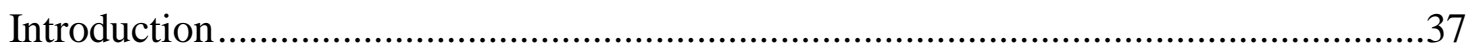

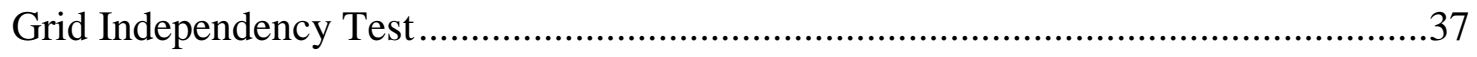

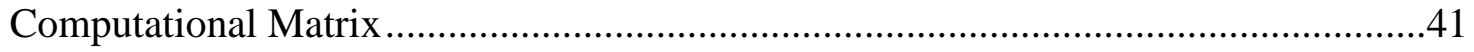




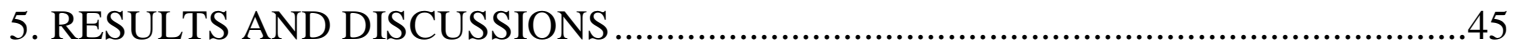

Fluid Hydrodynamics and Particle Diffusion Characteristics .................................45

Initial Distribution of Particles: Uniform..............................................................49

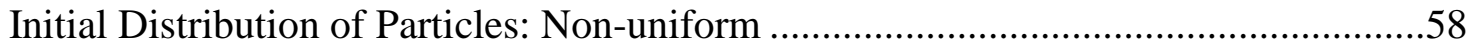

Quantitative Analysis of Different Parameters ......................................................... 77

6. CONCLUSIONS / RECOMMENDATIONS .......................................................101

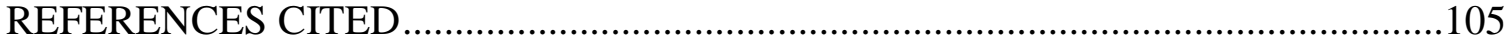




\section{LIST OF TABLES}

Table $\quad$ Page

2.1. Thermophysical properties of pure titanium ...............................................11

2.2. Thermophysical properties of Silicon carbide .......................................12

4.1. Computational matrix for the study with initially uniform particle distribution....................................................4 42

4.1. Computational matrix for the study with

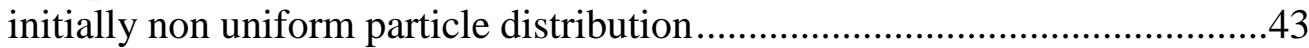




\section{LIST OF FIGURES}

Figure $\quad$ Page

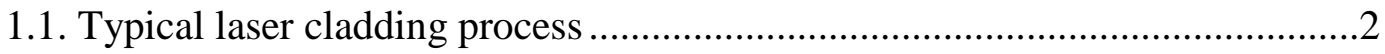

2.1. Computational domain in terms of dimensional parameters .......................10

3.1. Illustration of control volume discretizing .............................................24

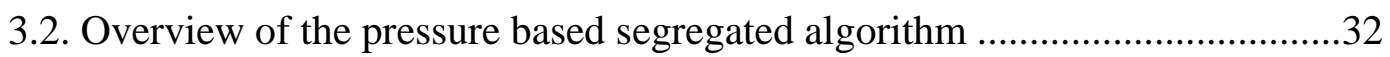

3.3. Comparison of numerically obtained solidification front positions with experimental data by Wolff and Viskanta (1988)...............................34

3.4. Comparison of numerically obtained particle distribution with numerical results from Akbar et al. (2009).

3.5. Quantitative comparison of numerically obtained particle fraction remained in the domain with numerical results from Akbar et al. (2009)......36

4.1. Comparison of temperature profile for grid independence .........................38

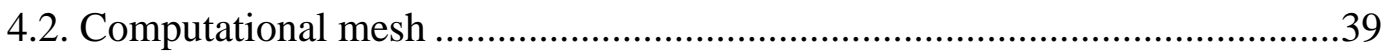

4.3. Comparison of nanoparticle distribution .............................................40

4.4. Initial uniform distribution of particles .........................................................

4.5. Initial non uniform particle distribution for different cases .........................44

5.1. Velocity profile and particle distribution at specific time steps ...................46

5.2. Final particle distribution at $\mathrm{h}=5 \mathrm{~W} / \mathrm{m}^{2} \mathrm{~K}$ :

(a) $\mathrm{Ma}=4.3 \times 10^{3}$, (b) $\mathrm{Ma}=4.3 \times 10^{4}$ (c) $\mathrm{Ma}=4.3 \times 10^{5}$

5.3. Final particle distribution at $\mathrm{h}=25 \mathrm{~W} / \mathrm{m}^{2} \mathrm{~K}$ :

(a) $\mathrm{Ma}=4.3 \times 10^{3}$, (b) $\mathrm{Ma}=4.3 \times 10^{4}$ (c) $\mathrm{Ma}=4.3 \times 10^{5}$

5.4. Final particle distribution at $\mathrm{h}=50 \mathrm{~W} / \mathrm{m}^{2} \mathrm{~K}$ :

(a) $\mathrm{Ma}=4.3 \times 10^{3}$, (b) $\mathrm{Ma}=4.3 \times 10^{4}$ (c) $\mathrm{Ma}=4.3 \times 10^{5}$ 


\section{LIST OF FIGURES - CONTINUED}

Figure

Page

5.5. Final particle distribution at $\mathrm{h}=146 \mathrm{~W} / \mathrm{m}^{2} \mathrm{~K}$ :
(a) $\mathrm{Ma}=4.3 \times 10^{3}$, (b) $\mathrm{Ma}=4.3 \times 10^{4}$ (c) $\mathrm{Ma}=4.3 \times 10^{5}$

5.6. Final particle distribution at $\mathrm{h}=300 \mathrm{~W} / \mathrm{m}^{2} \mathrm{~K}$ :

(a) $\mathrm{Ma}=4.3 \times 10^{3}$, (b) $\mathrm{Ma}=4.3 \times 10^{4}$ (c) $\mathrm{Ma}=4.3 \times 10^{5}$

5.7. Final particle distribution at $\mathrm{h}=400 \mathrm{~W} / \mathrm{m}^{2} \mathrm{~K}$ :

(a) $\mathrm{Ma}=4.3 \times 10^{3}$, (b) $\mathrm{Ma}=4.3 \times 10^{4}$ (c) $\mathrm{Ma}=4.3 \times 10^{5}$

5.8. Final particle distribution at $\mathrm{h}=600 \mathrm{~W} / \mathrm{m}^{2} \mathrm{~K}$ :

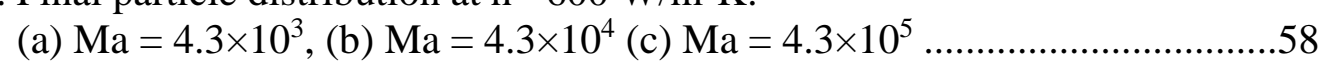

5.9. Final particle distribution at $\mathrm{h}=5 \mathrm{~W} / \mathrm{m}^{2} \mathrm{~K}, \mathrm{Ma}=4.3 \times 10^{3}$ and insulated bottom wall

5.10. Final particle distribution at $\mathrm{h}=5 \mathrm{~W} / \mathrm{m}^{2} \mathrm{~K}, \mathrm{Ma}=4.3 \times 10^{3}$ and constant temperature bottom wall

5.11. Final particle distribution at $\mathrm{h}=146 \mathrm{~W} / \mathrm{m}^{2} \mathrm{~K}, \mathrm{Ma}=4.3 \times 10^{3}$ and insulated bottom wall

5.12. Final particle distribution at $\mathrm{h}=146 \mathrm{~W} / \mathrm{m}^{2} \mathrm{~K}, \mathrm{Ma}=4.3 \times 10^{3}$ and constant temperature bottom wall

5.13. Final particle distribution at $\mathrm{h}=600 \mathrm{~W} / \mathrm{m}^{2} \mathrm{~K}, \mathrm{Ma}=4.3 \times 10^{3}$ and insulated bottom wall

5.14. Final particle distribution at $\mathrm{h}=600 \mathrm{~W} / \mathrm{m}^{2} \mathrm{~K}, \mathrm{Ma}=4.3 \times 10^{3}$ and constant temperature bottom wall

5.15. Final particle distribution at $\mathrm{h}=5 \mathrm{~W} / \mathrm{m}^{2} \mathrm{~K}, \mathrm{Ma}=4.3 \times 10^{4}$ and insulated bottom wall

5.16. Final particle distribution at $\mathrm{h}=5 \mathrm{~W} / \mathrm{m}^{2} \mathrm{~K}, \mathrm{Ma}=4.3 \times 10^{4}$ and constant temperature bottom wall

5.17. Final particle distribution at $\mathrm{h}=146 \mathrm{~W} / \mathrm{m}^{2} \mathrm{~K}, \mathrm{Ma}=4.3 \times 10^{4}$ and insulated bottom wall 


\section{LIST OF FIGURES - CONTINUED}

Figure

5.18. Final particle distribution at $\mathrm{h}=146 \mathrm{~W} / \mathrm{m}^{2} \mathrm{~K}, \mathrm{Ma}=4.3 \times 10^{4}$ and constant temperature bottom wall

5.19. Final particle distribution at $\mathrm{h}=600 \mathrm{~W} / \mathrm{m}^{2} \mathrm{~K}, \mathrm{Ma}=4.3 \times 10^{4}$ and insulated bottom wall

5.20. Final particle distribution at $\mathrm{h}=600 \mathrm{~W} / \mathrm{m}^{2} \mathrm{~K}, \mathrm{Ma}=4.3 \times 10^{4}$ and constant temperature bottom wall

5.21. Final particle distribution at $\mathrm{h}=5 \mathrm{~W} / \mathrm{m}^{2} \mathrm{~K}, \mathrm{Ma}=4.3 \times 10^{5}$ and insulated bottom wall

5.22. Final particle distribution at $\mathrm{h}=5 \mathrm{~W} / \mathrm{m}^{2} \mathrm{~K}, \mathrm{Ma}=4.3 \times 10^{5}$ and constant temperature bottom wall

5.23. Final particle distribution at $\mathrm{h}=146 \mathrm{~W} / \mathrm{m}^{2} \mathrm{~K}, \mathrm{Ma}=4.3 \times 10^{5}$ and insulated bottom wall

5.24. Final particle distribution at $\mathrm{h}=146 \mathrm{~W} / \mathrm{m}^{2} \mathrm{~K}, \mathrm{Ma}=4.3 \times 10^{5}$ and constant temperature bottom wall

5.25. Final particle distribution at $\mathrm{h}=600 \mathrm{~W} / \mathrm{m}^{2} \mathrm{~K}, \mathrm{Ma}=4.3 \times 10^{5}$ and insulated bottom wall

5.26. Final particle distribution at $\mathrm{h}=600 \mathrm{~W} / \mathrm{m}^{2} \mathrm{~K}, \mathrm{Ma}=4.3 \times 10^{5}$ and constant temperature bottom wall

5.27. Effect of convective heat transfer coefficient (h), Marangoni number (Ma), insulated (i) and constant temperature (c) bottom boundary on liquid fraction

5.28. Effect of convective heat transfer coefficient (h), Marangoni number (Ma) and insulated (i) bottom boundary on liquid fraction

5.29. Effect of convective heat transfer coefficient (h), Marangoni number (Ma) and constant temperature (c) bottom boundary on liquid fraction 


\section{LIST OF FIGURES - CONTINUED}

Figure

5.30. Effect of Marangoni number (Ma), insulated (i) and constant temperature (c) bottom boundary condition on top wall heat flux at $\mathrm{h}=5 \mathrm{~W} / \mathrm{m}^{2} \mathrm{~K}$

5.31. Effect of Marangoni number (Ma), insulated (i) and constant temperature (c) bottom boundary condition on top wall heat flux at $\mathrm{h}=25 \mathrm{~W} / \mathrm{m}^{2} \mathrm{~K}$

5.32. Effect of Marangoni number (Ma), insulated (i) and constant temperature (c) bottom boundary condition on top wall heat flux at $\mathrm{h}=50 \mathrm{~W} / \mathrm{m}^{2} \mathrm{~K}$

5.33. Effect of Marangoni number (Ma), insulated (i) and constant temperature (c) bottom boundary condition on top wall heat flux at $\mathrm{h}=146 \mathrm{~W} / \mathrm{m}^{2} \mathrm{~K}$

5.34. Effect of Marangoni number (Ma), insulated (i) and constant temperature (c) bottom boundary condition on top wall heat flux at $\mathrm{h}=300 \mathrm{~W} / \mathrm{m}^{2} \mathrm{~K}$

5.35. Effect of Marangoni number (Ma), insulated (i) and constant temperature (c) bottom boundary condition on top wall heat flux at $\mathrm{h}=400 \mathrm{~W} / \mathrm{m}^{2} \mathrm{~K}$

5.36. Effect of Marangoni number (Ma), insulated (i) and constant temperature (c) bottom boundary condition on top wall heat flux at $\mathrm{h}=600 \mathrm{~W} / \mathrm{m}^{2} \mathrm{~K}$

5.37. Power law curve fit for top wall's solidification time vs $h$ at different Marangoni number (Ma), insulated (i) and constant temperature (c) bottom wall

5.38. Power law curve fit for top wall's solidification time vs $h$ at different Marangoni number (Ma) and insulated (i) bottom wall

5.39. Power law curve fit for top wall's solidification time vs $h$ at different Marangoni number (Ma) and constant temperature (c) bottom wall 


\section{LIST OF FIGURES - CONTINUED}

Figure

Page

5.40. Power law curve fit for top wall's solidification time vs $h$ at $\mathrm{Ma}=4.3 \times 10^{3}$ along with insulated (i) and constant temperature (c) bottom wall

5.41. Power law curve fit for top wall's solidification time vs $h$ at $\mathrm{Ma}=4.3 \times 10^{4}$ along with insulated (i) and constant temperature (c) bottom wall

5.42. Power law curve fit for top wall's solidification time vs $h$ at $\mathrm{Ma}=4.3 \times 10^{5}$ along with insulated (i) and constant temperature (c) bottom wall

5.43. Linear curve fit for variation of top wall's solidification time vs the entire geometry's solidification time at different $\mathrm{Ma}$ and $\mathrm{h}$

5.44. Linear curve fit for variation of top wall's solidification time vs the entire geometry's solidification time at different $\mathrm{Ma}$ and $\mathrm{h}=5 \mathrm{~W} / \mathrm{m}^{2} \mathrm{~K}$

5.45. Linear curve fit for variation of top wall's solidification time vs the entire geometry's solidification time at different $\mathrm{Ma}$ and $\mathrm{h}=25 \mathrm{~W} / \mathrm{m}^{2} \mathrm{~K}$

5.46. Linear curve fit for variation of top wall's solidification time vs the entire geometry's solidification time at different $\mathrm{Ma}$ and $\mathrm{h}=50 \mathrm{~W} / \mathrm{m}^{2} \mathrm{~K}$

5.47. Linear curve fit for variation of top wall's solidification time vs the entire geometry's solidification time at different $\mathrm{Ma}$ and $\mathrm{h}=146 \mathrm{~W} / \mathrm{m}^{2} \mathrm{~K}$

5.48. Linear curve fit for variation of top wall's solidification time vs the entire geometry's solidification time at different $\mathrm{Ma}$ and $\mathrm{h}=300 \mathrm{~W} / \mathrm{m}^{2} \mathrm{~K}$

5.49. Linear curve fit for variation of top wall's solidification time vs the entire geometry's solidification time at different $\mathrm{Ma}$ and $\mathrm{h}=400 \mathrm{~W} / \mathrm{m}^{2} \mathrm{~K}$ 


\section{LIST OF FIGURES - CONTINUED}

Figure

5.50. Linear curve fit for variation of top wall's solidification time vs the entire geometry's solidification time at different $\mathrm{Ma}$ and $\mathrm{h}=600 \mathrm{~W} / \mathrm{m}^{2} \mathrm{~K}$

5.51. Power law curve fit for variation of top wall's solidification time vs total geometry's solidification time at different values of $h$ and $\mathrm{Ma}=4.3 \times 10^{3}$

5.52. Power law curve fit for variation of top wall's solidification time vs total geometry's solidification time at different values of $h$ and $\mathrm{Ma}=4.3 \times 10^{4}$

5.53. Power law curve fit for variation of top wall's solidification time vs total geometry's solidification time at different values of $h$ and $\mathrm{Ma}=4.3 \times 10^{5}$ 


\section{NOMENCLATURE}

\section{$\underline{\text { Symbol }}$}

A

a

Amushy

c

$\mathrm{C}_{\mathrm{C}}$

$\mathrm{C}_{\mathrm{p}}$

d

F

g

$\mathrm{h}$

$\mathrm{H}$

$\mathrm{H}_{\mathrm{E}}$

$\mathrm{h}_{\mathrm{s}}$

J

$\mathrm{k}$

$\mathrm{kB}_{\mathrm{B}}$

L

$\mathrm{L}_{\mathrm{H}}$

$\dot{\mathrm{m}}$

$\mathrm{Ma}$
Description

Area

Linearized coefficient of scalar quantity

Mushy zone constant

Cell center

Cunningham correction

Specific heat

Diameter

Force

Gravitational constant

Convective heat transfer coefficient

Height of the domain

Enthalpy of the material

Sensible heat

Mass flux

Thermal conductivity

Boltzmann constant $=1.3806488 \times 10^{-23} \mathrm{~m}^{2} \mathrm{~kg} \mathrm{~s}^{-2} \mathrm{~K}^{-1}$

Length of the domain

Latent heat of fusion

Mass flow rate

Marangoni number 


\section{xiii \\ NOMENCLATURE - CONTINUED}

$\begin{array}{ll}\mathrm{N}_{\text {Faces }} & \text { Number of faces in cell } \\ \mathrm{P} & \text { Pressure } \\ \mathrm{Pe} & \text { Peclet number } \\ \mathrm{Ra} & \text { Rayleigh number } \\ \mathrm{Re} & \text { Reynolds number } \\ \mathrm{S} & \text { Source term } \\ \mathrm{T} & \text { Temperature } \\ \mathrm{t} & \text { Time } \\ \mathrm{T}_{\infty} & \text { Ambient temperature } \\ \mathrm{u} & \text { Fluid velocity } \\ \mathrm{V}_{\mathrm{X}} & \text { X component of velocity } \\ \mathrm{V}_{\mathrm{Y}} & \text { Y component of velocity } \\ \mathrm{X}, \mathrm{y} & \text { Spatial coordinates } \\ & \end{array}$

\section{$\underline{\text { Greek Symbols }}$}

$\mu$

Dynamic viscosity

$\alpha$

Thermal diffusivity

$\beta$

Coefficient of thermal expansion

$\beta_{\mathrm{L}}$

Liquid fraction

$\Gamma$

Diffusion coefficient

$\Delta$

Mathematical operator for difference 


\section{xiv \\ NOMENCLATURE - CONTINUED}

\begin{tabular}{|c|c|}
\hline$\zeta$ & Unit variance independent Gaussian random number \\
\hline$\lambda$ & Molecular mean free path \\
\hline$v$ & Kinematic viscosity \\
\hline$\rho$ & Density \\
\hline$\sigma$ & Surface tension \\
\hline$\tau$ & Stress \\
\hline$\phi$ & Scalar quantity \\
\hline & $\underline{\text { Subscripts and Superscripts }}$ \\
\hline ' & Cell correlation value \\
\hline$*$ & Guessed values in cell \\
\hline c & Cell value \\
\hline $\mathrm{f}$ & Unit face of control volume \\
\hline $\mathrm{m}$ & Melting point \\
\hline $\mathrm{p}$ & Particle property \\
\hline ref & Reference value \\
\hline
\end{tabular}




\begin{abstract}
In the field of additive manufacturing process, laser cladding is widely considered due to its cost effectiveness, small localized heat generation and full fusion to metals. Introducing nanoparticles with cladding metals produces metal matrix nanocomposites which in turn improves the material characteristics of the clad layer. The strength of the laser cladded reinforced metal matrix composite are dependent on the location and concentration of the nanoparticles infused in metals. Hence, investigating the nanoparticle diffusion characteristics during solidification of laser cladding process is of prime interest. The governing equations that controls the fluid flow are standard incompressible Navier-Stokes and heat diffusion equation whereas the Euler-Lagrange approach has been considered for particle tracking. The mathematical formulation for solidification is adopted based on enthalpy porosity method. During the solidification process of liquid titanium, particle flow and distribution has been observed until the entire geometry solidified.

A two dimensional numerical analysis has been performed to identify and track the silicon carbide nanoparticle diffusion in titanium. A numerical model implemented in a commercial software based on control volume method has been developed that allows to simulate the fluid flow during solidification as well as tracking nanoparticles during this process. The influence of the free surface of the melt pool has a high importance on the fluid flow as well as the influence of pure natural convection. Thus both buoyancy and Marangoni convection have been considered in terms of fluid flow in the molten region. A detailed parametric study has been conducted by changing the Marangoni number, convection heat transfer coefficient, different initial distribution of particles, and thermal boundary condition of bottom wall to analyze the behavior of the nanoparticle movement. Variation in particle's initial distribution along with different Marangoni number and solidification time results in a high concentration of nanoparticles in some portion of the geometry and lack of particles in rest of the geometry. High concentration of nanoparticles decrease with a decrease in Marangoni number. Furthermore, an increase in the rate of solidification time limits the nanoparticle movement from its original position which results in different distribution patterns with respect to the solidification time.
\end{abstract}




\section{CHAPTER 1}

\section{INTRODUCTION}

The diffusion of solid particles in multiphase flow has long been a subject of interest. Thermal transport phenomena related with solidification and particle tracking plays an important role in the engineering applications especially in manufacturing. Additive manufacturing is one of the rising field in manufacturing because of the advantage of adding material rather than producing an end result by taking material away. This technique introduces the process of melting and solidification along with the movement of the particles during those processes. Laser cladding is an additive manufacturing process of depositing layers of desired solid along with different nanoparticles. The process uses solid powders which melts due to the heat exerted by laser and rapidly solidifies due to heat exchange with the substrate where the deposition happens along with the convection with air. The interaction between laser and substrate creates a melt pool consisting of liquid substrate, molten powder of desired material and solid nanoparticles. The powder used for cladding is generally of metallic nature.

Nanoparticles are inserted along with the powders or by a separate nozzle. This process is often used for improving mechanical properties of substrate material, repair worn parts (Capello et al., 2005) or fabricate a metal-matrix composite. There are many advantages of using laser cladding which are stated below:

- Great technique for introducing coating of any shape and form, which increases wear and impact resistance of parts over thermal spraying. 
- Ideal for repairing a part of the mold if the part is not available or fabrication of the complete part is time consuming.

- Strong metallurgical bond, low dilution between clad layer and substrate along with low deformation of substrate.

- Fine microstructure due to fast cooling.

- Highly flexible and compact technology which increase product design flexibility and decrease product complexity.

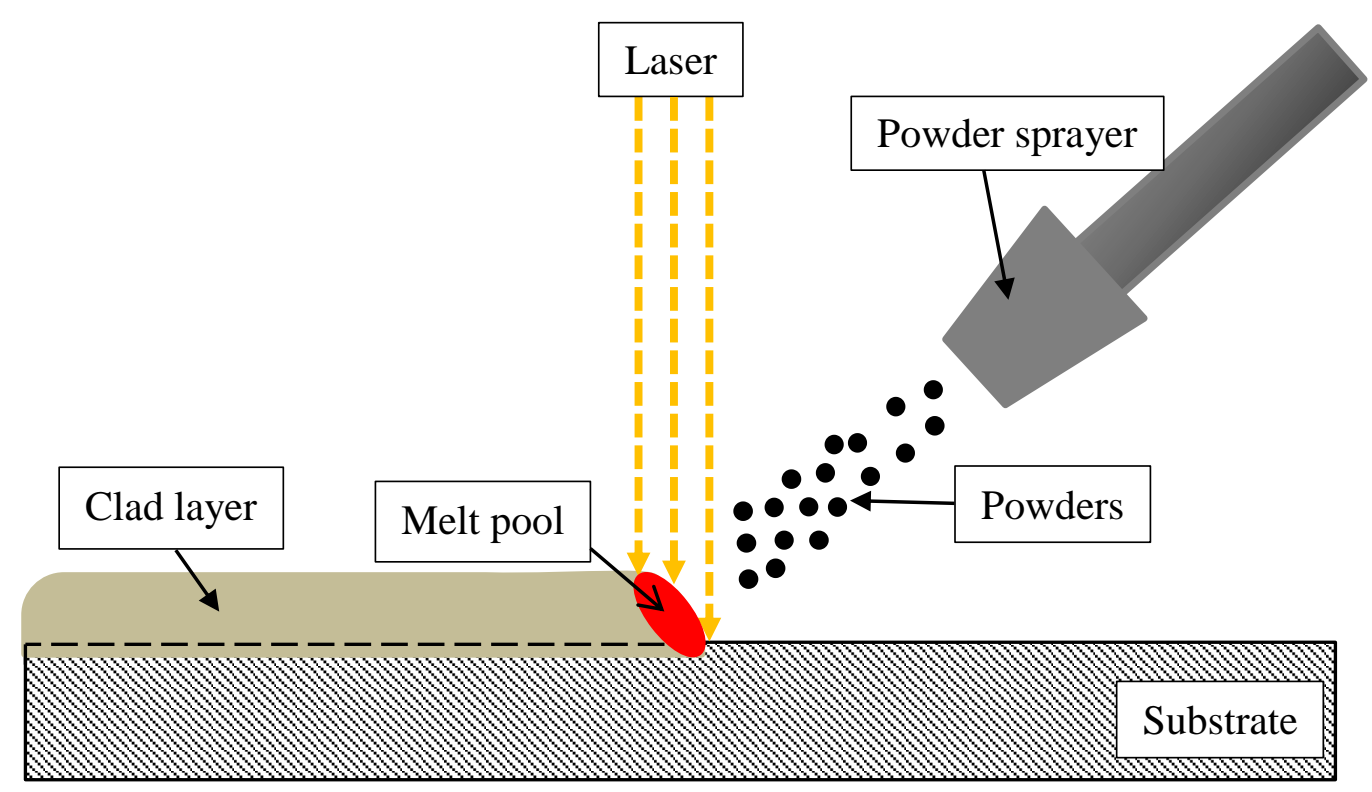

Figure 1.1. Typical laser cladding process

This rapidly developing field has a significant impact in the research areas of transport phenomena due to the fact that a good combination of fluid flow driven by buoyancy force, Marangoni force coupled with the instantaneous nanoparticle tracking has a scarcity in literature. 


\section{Motivation}

Given the range and variety of laser cladding process, it has become increasingly important to optimize and control the process parameters affecting the final product. Numerical modeling of solidification, particle tracking, coupled buoyancy and Marangoni convection has been in the cynosure of research for the last few decades due its importance in understanding the fluid flow and also due to the rapid improvement in computing efficiency. Many researchers have contributed to mathematical modeling of various process involving these phenomena. Generally separate researches are being conducted on coupled Marangoni and buoyancy; Marangoni, buoyancy and solidification or buoyancy and particle tracking. A well-constructed study involving solidification, particle tracking, coupled Marangoni and natural convection has a huge scarcity in literature. The effect of all these parameters are very important during laser cladding induced with nanoparticles. With the advancement in computational fluid dynamics (CFD) software, the effect of above mentioned phenomena can be quantified all together with reasonable accuracy and efficiency.

\section{Background}

The process of solidification during laser cladding has been researched by many researchers due to its effect on materialistic condition of the final product. The combination of many excellent material properties of titanium, especially the unique strength to weight ratio and excellent corrosion resistance makes it widely used in several engineering applications. Silicon carbide ( $\mathrm{SiC}$ ) particles are widely used to circumvent 
the disadvantages of titanium such as high friction and poor wear properties. Several studies have been conducted to visualize the effect of laser cladding based on different parameter. Mridha and Baker (1997) conducted their experiment by preplacing the $\mathrm{SiC}$ powders on a laser melted titanium alloy. This process melt the substrate material by transferring heat through the powder layer, which creates a massive disadvantage of accidental melting of $\mathrm{SiC}$ powder while melting the substrate. It produces unwanted phase in material microstructure depending on the thermophysical properties of substrate and particle. Particles are also being injected along with the laser as discussed by Abboud and West (1991). The heat produced by laser beam primarily interact with the substrate and partially to the particles. A detailed experimental study of the microstructural and compositional study has been conducted by using optical microscope (OM), scanning electron microscopy (SEM) along with energy dispersive X-ray spectroscopy (EDS) and scanning transmission electron microscopy (STEM). Variation of width and thickness of the melt zone dimensions were also quantified based on the intensity of laser and powder flow rate. Ayers et al. (1980), Abboud et al. (1992) and Baker et al. (1994) investigated similar process and it was concluded that parameters such as positioning and amount of powder flow along with particle size, velocity and volume fraction with the molten metal are crucial to achieve specific microstructural characteristics of the final product. Kloosterman et al. (1998) have presented a detailed electron microscope examination of the metal-matrix composition of silicone carbide particles entrapped during solidification of liquid titanium by laser cladding. Mechanical properties of the metal-matrix composites are hugely related with the chemical reactions occurred at the interface and 
existence of high thermal stress in the modified layer. These are very sensitive to the amount of powder used, positioning and interaction time of the particles with laser and powder. Crack initiation and propagation behavior in the interface have been observed and it was found that the cellular reaction layer formed due to laser cladding makes good bond with the silicon carbide particle which is important for the mechanical performance as presented by Mestral and Thevenot (1989). Hashim et al. (2002) discussed about the particle distribution in metal matrix composites. One of the significant problem associated with the production of reinforced composites is the difficulty of achieving a homogenous distribution of the particles which is essential for optimum mechanical properties as explained by Brechet et al. (1991). It was found that particles below 10 micron will almost always be carried by the liquid and the gravitational force acting on them is negligible due to their size. But gravitational force is not negligible for the particle size above 10 micron and they will either sink or float depending on the particle to liquid density ratio. Sahoo et al. (1988) calculated the effect of surface active components on metals by analyzing published data on the interfacial tension of those metals. It was concluded that temperature coefficient of the surface tension is strongly influenced by the different components or the impurities and surface active components which vastly change the coefficient.

Akbar et al. (2009) investigated the particle transportation in a square cavity where only natural convection has been considered. Numerical analysis of nano and micro scale particles has been conducted at different Rayleigh number and particle distribution has been characterized. The quasi-steady state of the particle distribution was 
observed when the particles reaches a near equilibrium re-circulation zone. Ookawara et al. (2007) discussed the effect of particle density on lift force. Particle trajectory calculated by discrete phase model (DPM) experienced a strong centrifugal force acting outward from the center of the geometry where water was the sole fluid. Movement and deposition of aerosol particles with air movement have been studied by Zhao et al. (2003). It was found that the movement of particle was strongly influenced by the airflow pattern. Even with different particle properties and concentration, the deposition and movement were dominated by the velocity of the airflow. Increasing the size of the particles increased particle's rate of deposition. Particle diameter of $10 \mu \mathrm{m}$ or above experienced the lowest rate of mixing in the geometry and highest rate of concentrated deposition of particles. Golkarfard et al. (2013) studied the numerical behavior of particle movement in a three dimensional geometry. The recirculation of particles were observed which follows the streamline of air. Transient particle concentration during different time steps were also observed and quantified. The Lagrangian reference frame was utilized to simulate particle flow in an indoor environment and compared the results with experimental data by Chen et al. (2006). It was found that gravity has a noticeable influence on particles larger than $2 \mu \mathrm{m}$. But for smaller particles, the influence of gravity is very minor if a well-defined flow of fluid with high velocity is present. Mezhericher et al. (2011) studied the numerical modeling of horizontal pneumatic conveying of particles by using two method of particle tracking: discrete element model (DEM) and discrete particle model (DPM). DPM achieved a reasonable accuracy while analyzing the particle movement and distribution in the fluid flow. DPM method provided by ANSYS Fluent 
was further investigated by Feng et al. (2012). Drag forces acting on different shapes (sphere, oblate ellipsoid, prolate ellipsoid) and orientation of nanoparticles were studied along the fluid flow. Particle position, movement and deposition were analyzed and it was concluded that the particle shape and size has a significant effect on movement of particles. Different shapes of particles introduces different hydrodynamic forces which leads to different velocities and paths of particle movement. Results from spherical particles agreed with analytical results found in literature. Particle tracking model provided by ANSYS fluent was further investigated by Robinson et al. (2007), Pirker et al. (2010) and Leduc et al. (2006). The accuracy of discrete phase model were studied and compared with data obtained from different literature. Good accuracy and efficiency were obtained which were discussed by these researchers.

Villers and Platten (1991) have presented detailed work on the convection process of acetone where both buoyancy and Marangoni convection are present. Experimental and numerical studies were conducted for several cases with different Marangoni number and aspect ratio. A strong fluid circulation from the region of low surface tension to high surface tension was observed. Quantitative agreement has been achieved between the experimental and numerical data. Solidification of pure material has been investigated by Liu et al. (1993). A numerical model was verified by comparing with experimental results. Surface tension phenomena were also presented along with the thermocapillary forces during the solidification process. It was found that thermocapillary forces can significantly affect the rate of solidification at low dynamic bond number and Prandtl number. Giangi et al. (2002) investigated the effect of Marangoni convection during 
solidification by using the finite volume method. The liquid-solid interface positions were observed at different Marangoni number. It was found that the free surface responsible for Marangoni convection has a profound impact on the rate of solidification. And with the increase in Marangoni number, the convective flow becomes progressively stronger. Surface tension and buoyancy convection mechanisms were further studied by Shyy et al. (1990) along with the process of phase change. Increase in Marangoni number creates aggressive and strongly curved solidification front. The temperature and velocity gradient along the free surface also increase at high Marangoni number. For a wide variation of Marangoni and Prandtl number, multiple-cell convection patterns exists and the convection is generally dominated by Marangoni number. When Marangoni number is significantly larger than the Rayleigh number, convection of fluid creates a single strong recirculating cell. Different Marangoni number with a wide variety of aspect ratios have been considered and their effects were presented in their study.

Tan (2005) conducted simulations of solidification with surface tension by using Commercial software ANSYS Fluent. Shapes of the solidification front were analyzed and it was found that at high Marangoni number, the curvature solid-liquid interface gets significantly deformed. Experimental and numerical study of Marangoni convection have been conducted by Tan (2005). Particle image velocimetry (PIV) was used to experimentally calculate the flow patterns and velocity vectors. The numerical analysis was conducted on ANSYS Fluent and a good agreement was achieved between the experimental and numerical results. It was observed that Marangoni convection was dominated over natural convection due to large Marangoni number, compared to 
relatively small Rayleigh number. The deformation of free surface under Marangoni convection was studied by Zhou (2014). An increase in free surface deformation was observed with an increase in Marangoni number, especially at high aspect ratio (greater than 10) of the computational domain. At an aspect ratio lower than 5 , the free surface deformation was significantly reduced. Investigators like Fan et al. (2001), Lei et al. (2001), Xu et al. (2007), Kovalev et al. (2011), Ehlen et al. (2003) have conducted numerical investigation on the characteristic of heat transfer while coupling buoyancy and Marangoni convection. Their researches were mainly related with the effect of thermal transport phenomena which directly dictates the shape of the liquid region introduced by laser heat flux.

Although a lot of information is available on the effects of buoyancy and Marangoni convection during solidification, particle concentration and distribution during different convection process; no data could be found which collaborate particle tracking along with the effects of buoyancy and Marangoni convection during solidification. Therefore, extensive studies have been conducted by using different process parameters to visualize the difference in particle distribution. A finite volume method was used to simulate the two dimensional solidification process coupled with discrete phase model particle tracking. The primary modes of heat transfer are conduction and convection. 


\section{CHAPTER 2}

\section{PROBLEM FORMULATION}

\section{$\underline{\text { Concept }}$}

The present study deals with computational fluid dynamics analysis of nanoparticle tracking along with the solidification process during laser cladding. The geometry of the current numerical investigation is shown in Figure 2.1. An aspect ratio of 0.2 was used in the present research where the height and length of the geometry are 5 $\mathrm{mm}$ and $25 \mathrm{~mm}$, respectively. Titanium was chosen as the sole fluid and silicon carbide was chosen as the nanoparticle in this study.

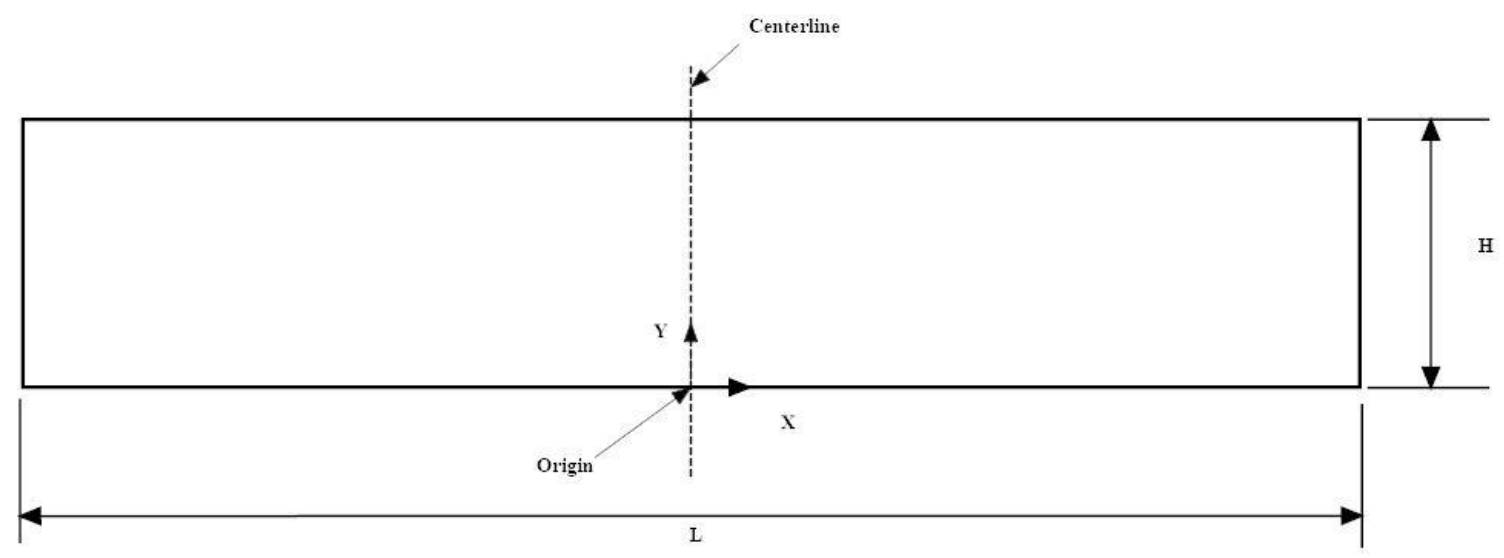

Figure 2.1. Computational domain in terms of dimensional parameters

Titanium was modeled as Newtonian incompressible fluid with Boussinesq approximation. The fluid flow was assumed to be laminar and two-dimensional. Symmetric nature of the overall geometry allowed for modeling right half of the geometry which reduce computing time. In this study, 1900 uniformly distributed silicon 
carbide solid particles with a constant diameter of 40 nanometer were used. The top wall of the domain was exposed to free with an air temperature of $293 \mathrm{~K}$. The right and left walls were at a constant temperature of $1918 \mathrm{~K}$. The bottom wall was subjected to two different boundary conditions, namely, an insulated surface or at a constant temperature with the same value of the side walls. The initial temperature of the fluid was set at 3073 K. Physical properties of the materials are given in Tables 2.1 and 2. 2. The simulations were performed by using Eulerian-Lagrangian approach considering the fact that the concentration of the particles in liquid titanium is very small. The natural and Marangoni convection along with solidification of the domain was modeled using Eulerian frame. The particle tracking was performed in Lagrangian frame.

Table 2.1. Thermophysical properties of pure titanium

\begin{tabular}{|l|l|l|}
\hline Properties & Symbols & Values \\
\hline Density & $\rho$ & $4500 \mathrm{~kg} / \mathrm{m}^{3}$ \\
\hline Specific Heat & $\mathrm{C}_{\mathrm{p}}$ & $528 \mathrm{~J} / \mathrm{kg} \mathrm{K}$ \\
\hline Thermal conductivity & $\mathrm{k}$ & $17 \mathrm{~W} / \mathrm{m} \mathrm{K}$ \\
\hline Dynamic viscosity & $\mu$ & $0.00482 \mathrm{~kg} / \mathrm{m} \mathrm{s}$ \\
\hline Coefficient of thermal expansion & $\beta$ & $8.9 \times 10^{-6} 1 / \mathrm{K}$ \\
\hline Latent heat of fusion & $\mathrm{L}_{\mathrm{H}}$ & $435400 \mathrm{~J} / \mathrm{kg}$ \\
\hline Melting temperature & $\mathrm{T}_{\mathrm{m}}$ & $1923 \mathrm{~K}$ \\
\hline
\end{tabular}


Table 2.2. Thermophysical properties of Silicon carbide

\begin{tabular}{|l|l|l|}
\hline Properties & Symbols & Values \\
\hline Density & $\rho$ & $3210 \mathrm{~kg} / \mathrm{m}^{3}$ \\
\hline Specific heat & $\mathrm{C}_{\mathrm{p}}$ & $670 \mathrm{~J} / \mathrm{kg} \mathrm{K}$ \\
\hline Thermal conductivity & $\mathrm{k}$ & $77.5 \mathrm{~W} / \mathrm{m} \mathrm{K}$ \\
\hline
\end{tabular}

A commercial CFD code ANSYS Fluent, version 14.5 with double precision option was used for the numerical investigation. A user routine was developed to include multiphase flow along with solidification and particle tracking. The user routine was validated with several published results. Dell PowerEdge R620 server was used for all of the numerical simulations.

\section{Governing Equations}

The convection was modelled by using a set of partial differential equations which were solved in terms of the boundary conditions. The partial differential equations were then integrated over each control volume to obtain a discretized linear algebraic equation. The following assumptions were made for the analysis:

1. The fluid was Newtonian and incompressible

2. The fluid flow was laminar.

3. Boussinesq approximation was introduced due to the change in density in the buoyancy terms. 
4. Materials properties were considered constant, homogenous, non-reactive, and isotropic throughout different phases.

5. Viscous heating and dissipation terms were considered negligible.

6. The change in volume during solidification was negligible.

7. The liquid/solid titanium and solid silicon carbide particles were considered as different phases. The liquid and solid titanium were working as continuum in Eulerian system and the particles were discrete entity in a Lagrangian system.

The conservation of mass, momentum and energy equations shown below were solved. These laws are expressed in terms of partial differential equations and discretized with finite volume method.

\section{Conservation of Mass}

The most general form of conservation of mass law illustrates the continuity equation:

$$
\frac{\partial\left(\mathrm{V}_{\mathrm{x}}\right)}{\partial \mathrm{x}}+\frac{\partial\left(\mathrm{V}_{\mathrm{y}}\right)}{\partial \mathrm{x}}=0
$$

\section{Conservation of Momentum}

The momentum equation for a general Newtonian fluid is known as NavierStokes equation which is given by:

Momentum in $\mathrm{x}$ direction:

$$
\frac{\partial\left(\mathrm{V}_{\mathrm{x}}\right)}{\partial \mathrm{t}}+\mathrm{V}_{\mathrm{x}} \frac{\partial\left(\mathrm{V}_{\mathrm{x}}\right)}{\partial \mathrm{x}}+\mathrm{V}_{\mathrm{y}} \frac{\partial\left(\mathrm{V}_{\mathrm{x}}\right)}{\partial \mathrm{y}}=-\frac{1}{\rho} \frac{\partial \mathrm{P}}{\partial \mathrm{x}}+v\left[\frac{\partial^{2} \mathrm{~V}_{\mathrm{x}}}{\partial \mathrm{x}^{2}}+\frac{\partial^{2} \mathrm{~V}_{\mathrm{x}}}{\partial \mathrm{y}^{2}}\right]
$$


Momentum in y direction:

$$
\frac{\partial\left(\mathrm{V}_{\mathrm{y}}\right)}{\partial \mathrm{t}}+\mathrm{V}_{\mathrm{x}} \frac{\partial\left(\mathrm{V}_{\mathrm{y}}\right)}{\partial \mathrm{x}}+\mathrm{V}_{\mathrm{y}} \frac{\partial\left(\mathrm{V}_{\mathrm{y}}\right)}{\partial \mathrm{y}}=-\frac{1}{\rho} \frac{\partial \mathrm{P}}{\partial \mathrm{x}}+v\left[\frac{\partial^{2}\left(\mathrm{~V}_{\mathrm{y}}\right)}{\partial \mathrm{x}^{2}}+\frac{\partial^{2}\left(\mathrm{~V}_{\mathrm{y}}\right)}{\partial \mathrm{y}^{2}}\right]+\mathrm{g}_{\mathrm{y}} \beta\left(\mathrm{T}-\mathrm{T}_{\infty}\right)
$$

Momentum in $\mathrm{z}$ direction has not been considered because the flow is bounded in only $\mathrm{x}$ and $\mathrm{y}$ direction due to the two dimensional geometry.

\section{Energy Equation}

The energy equation is given by:

$$
\frac{\partial \mathrm{T}}{\partial \mathrm{t}}+\mathrm{V}_{\mathrm{x}} \frac{\partial \mathrm{T}}{\partial \mathrm{x}}+\mathrm{V}_{\mathrm{y}} \frac{\partial \mathrm{T}}{\partial \mathrm{y}}=\frac{\mathrm{k}}{\rho \mathrm{C}_{\mathrm{p}}}\left[\frac{\partial^{2} \mathrm{~T}}{\partial \mathrm{x}^{2}}+\frac{\partial^{2} \mathrm{~T}}{\partial \mathrm{y}^{2}}\right]
$$

The continuity and Navier-Stokes equations were first solved to find the unknown parameters, velocity and pressure distribution without considering the temperature. After solving for pressure and velocity field, the energy equation can be solved to find out the temperature distribution. However for buoyancy driven flow the density of the fluid changes with the change in temperature. Hence the Boussinesq approximation was introduced in the body force in conservation of momentum equation. This couples the momentum equation with energy equation. In liquid phase, the velocity terms are distributed by the resulting velocity vector. But in the solid phase, the $\mathrm{x}$ and $\mathrm{y}$ components of velocity vectors are set to be zero (White, 1991). 


\section{$\underline{\text { Natural Convection and Marangoni Convection }}$}

Natural convection occurs due to the change in density gradient in conjunction with a gravitational field. The density gradient occurs due to the change in temperature in the fluid field, hence the change in temperature gradient. When the temperature changes in flow, the density of the fluid also changes at the same point. The fluid with relatively lower density tends to move downward and the fluid with relatively higher density tends to move upward due to the force of gravitation acting on the density variation. If the density gradient is sufficiently large, it will create a convection, which is defined as the natural convection (Mills, 1999). For present study, the gravitational force is considered to be acting in the direction of $-\mathrm{y}$. The Rayleigh number can be calculated as follows:

$$
\text { Rayleigh Number, } \mathrm{Ra}=\frac{\mathrm{g} \beta \Delta \mathrm{TH}^{3}}{v \alpha}
$$

Change in temperature at the free surface of the domain changes the surface tension of the fluid; which creates a gradient based on surface tension forces. At liquidair interface, this tension under imbalance forces creates a convection directing from lower surface tension to higher surface tension. This is called Marangoni convection which is defined as:

$$
\text { Marangoni number, } \mathrm{Ma}=\frac{\partial \sigma}{\partial \mathrm{T}} \frac{\Delta \mathrm{TH}}{\mu \alpha}
$$




\section{Enthalpy-Porosity Technique}

Enthalpy-porosity technique has been employed to model the solidification process. In this method, instead of tracking the melt interface explicitly, liquid fraction is calculated at each iteration by satisfying the enthalpy balance. Liquid fraction can be defined as the fraction of cell volume that is in the liquid state. Phase change phenomenon varies depending on the material. For pure metal, the phase change happens with almost negligible temperature variation. However for the materials that are not pure (e.g. an alloy), the phase change occurs over a wide range of temperature band. It is really difficult to deal with this problem computationally due to the fact that for observing moving liquid-solid interface, deformed grid is necessary with explicit conditions on the heat flow at the liquid-solid interface is needed, as studied by Ramachandra et al. (1982) and Gadgil et al. (1984). The alternative approach is to use the enthalpy formation which works with a fixed grid size. Enthalpy-porosity method represents the solid-liquid phase change interface as a pseudo porous media, where the porosity of the mushy state decreases as the latent heat being exerted from the liquid, in other word, when the solidification happens. When full solidification occurs, the porosity becomes zero in a cell which makes the velocity in that cell goes to zero. To account for this change in porosity, a source term is added to the momentum equation. The momentum equation can be written as:

$$
\frac{\partial}{\partial \mathrm{x}}(\rho \mathrm{H})+\nabla \cdot(\rho \overrightarrow{\mathrm{v}} \mathrm{H})=\nabla \cdot(\mathrm{k} \nabla \mathrm{T})+\mathrm{S}
$$


The source term in the momentum equation can be defined as:

$$
S=\frac{\left(1-\beta_{\mathrm{L}}\right)^{2}}{\left(\beta_{\mathrm{L}}^{3}+\varepsilon\right)} A_{\text {mushy }} \overrightarrow{\mathrm{u}}
$$

Where, $\beta_{\mathrm{L}}$ is the liquid fraction, $\varepsilon$ is a small computational constant $(0.001)$ to avoid division by zero and $A_{\text {mushy }}$ is the Mushy zone constant. The term $\frac{\left(1-\beta_{\mathrm{L}}\right)^{2}}{\left(\beta_{\mathrm{L}}^{3}+\varepsilon\right)}$ is also known as the porosity function defined by Brent et al. (1987). Mushy zone constant is a large number which is generally in between $10^{4}$ to $10^{8}$. The sensitivity of the results with $10^{5}$ to $10^{7}$ has been checked by Brent et al. (1987) and Pal and Joshi (2001). The differences in the results were not significant. That is why $10^{7}$ was used in the present study. Enthalpy of the material can be computed as the sum of sensible enthalpy $\left(\mathrm{h}_{\mathrm{s}}\right)$ and latent heat content $(\Delta \mathrm{H})$, and can be expressed as:

$$
\begin{gathered}
\mathrm{H}_{\mathrm{E}}=\mathrm{h}_{\mathrm{s}}+\Delta \mathrm{H} \\
\mathrm{h}_{\mathrm{s}}=\mathrm{h}_{\mathrm{s}, \mathrm{ref}}+\int_{\mathrm{T}_{\mathrm{ref}}}^{\mathrm{T}} \mathrm{c}_{\mathrm{p}} \mathrm{dT}
\end{gathered}
$$

Where $h_{s, r e f}$ and $T_{\text {ref }}$ are the reference enthalpy and temperature. $C_{p}$ represents the specific heat at constant pressure. The latent heat content can also be written in terms of liquid fraction and latent heat of fusion of a specific material. Latent heat $(\Delta \mathrm{H})$ is zero for solid since liquid fraction $\left(\beta_{\mathrm{L}}\right)$ becomes zero, and it varies for liquid depending on specific latent heat of fusion $\left(\mathrm{L}_{\mathrm{H}}\right)$ of individual material. 


$$
\Delta \mathrm{H}=\beta_{\mathrm{L}} \mathrm{L}_{\mathrm{H}}
$$

The relationship between liquid fraction, solidus and liquidus temperature was defined by Swaminathan and Voller (1992) and expressed as:

$$
\begin{array}{cc}
\beta_{L}=0 & \text { if } T<T_{S} \\
\beta_{L}=1 & \text { if } T>T_{L} \\
\beta_{L}=\frac{T-T_{S}}{T_{L}-T_{S}} & \text { if } T_{S}<T<T_{L}
\end{array}
$$

Where $T_{S}$ and $T_{L}$ are the solidus and liquids temperature of the material.

\section{Euler-Lagrangian Approach}

The particle tracking was performed by using Euler-Lagrangian method with one way coupling. The concentration of the particles in the liquid metal is assumed to be very low. That is why the natural convection was modelled by using the Eulerian approach by neglecting the effect of particle suspension in the domain. Eulerian approach works at a certain fixed coordinates in the flow field and evaluates the change in fluid properties such as pressure, temperature, velocity as a function of space and time. With the calculated velocity distribution obtained by the Eulerian approach, particle tracking was performed in Lagrangian frame, where tracking the movement of individual particles were done. 


\section{$\underline{\text { Particle Motion Equations }}$}

\section{$\underline{\text { Equation of Force Balance }}$}

Particle force balance equation utilizes the concept of Newton's $2^{\text {nd }}$ law of motion for particle, which can be stated as: the summation of all the forces acting on a particle is proportional to the acceleration of particle. The motion of particle was calculated in Lagrangian frame by using the particle force balance equation. The acceleration of particles in the flow field is a sum of drag force, gravitational force, and several additional forces acting per unit mass of the particle. This equation was integrated to predict the path of particle movement and can be expressed as:

$$
\frac{d u_{p}}{d t}=F_{D}\left(\vec{u}-\overrightarrow{u_{p}}\right)+\frac{\vec{g}\left(\rho_{p}-\rho\right)}{\rho_{p}}+\overrightarrow{F_{v}}+\overrightarrow{F_{P}}+\overrightarrow{F_{B}}+\overrightarrow{F_{S}}
$$

Where,

$$
\begin{aligned}
& \mathrm{F}_{\mathrm{D}}\left(\overrightarrow{\mathrm{u}}-\overrightarrow{\mathrm{u}_{\mathrm{p}}}\right)=\text { Drag force } \\
& \overrightarrow{\mathrm{F}_{\mathrm{V}}}=\text { Virtual mass force } \\
& \overrightarrow{\mathrm{F}_{\mathrm{P}}}=\text { Pressure gradient force } \\
& \overrightarrow{\mathrm{F}_{\mathrm{B}}}=\text { Brownian force } \\
& \overrightarrow{\mathrm{F}_{\mathrm{S}}}=\text { Saffman's lift force }
\end{aligned}
$$

Equation implies gravitational force acting on the particle. Additional forces are implied in the calculation based on their appropriate function with respect to particle mass and size, lift force. These forces are described below. 


\section{Drag Force}

For submicron particles, inertia forces are negligibly small compared to viscous forces acting on them. Thus Stokes' drag law, as discussed by Ounis et al. (1991), was incorporated as the drag law in present study. One assumption made by Stokes was that the relative velocity of the fluid acting on the surface of individual spherical particle was zero. This assumption does not hold true for submicron particles as the size of particles get close to the mean free path of the fluid $(\lambda)$. The mean free path can be explained as the average distance travelled by fluid molecules between collision. Cunningham slip correction, as described by Hinds (1998), accounts for that slip on the surface of the particles. The drag force on a spherical particle can be written as:

$$
\mathrm{F}_{\mathrm{D}}=\frac{18 \mu}{\mathrm{d}_{\mathrm{p}}^{2} \rho_{\mathrm{p}} \mathrm{C}_{\mathrm{C}}}
$$

Where, $\mathrm{C}_{\mathrm{C}}$ is the Cunningham correction factor and is given by:

$$
\mathrm{C}_{\mathrm{c}}=1+\frac{2 \lambda}{\mathrm{d}_{\mathrm{p}}}\left(1.257+0.4 \mathrm{e}^{-1\left(\frac{1.1 \mathrm{~d}_{\mathrm{p}}}{2 \lambda}\right)}\right)
$$

\section{Virtual Mass and Pressure Gradient Force}

Virtual mass effect describes the movement of fluid surrounding a particle when the particle moves through it. This creates additional mass around particles. Force required to accelerate this mass of fluid surrounding the particle is called virtual mass force. Virtual mass force is negligible when the density of particle is much larger than the density of the fluid $\left(\rho>>\rho_{p}\right)$. However when $\rho>\rho_{p}$, the virtual mass flow becomes 
significant and needs to be included in the particle force balance equation. Virtual mass force can be written as:

$$
\overrightarrow{\mathrm{F}_{\mathrm{V}}}=\frac{1}{2} \frac{\rho}{\rho_{p}} \frac{d}{d t}\left(\overrightarrow{\mathrm{u}}-\overrightarrow{\mathrm{u}_{\mathrm{p}}}\right)
$$

Change in pressure gradient surrounding the particle creates an additional force which is defined as the pressure gradient force and can be written as:

$$
\overrightarrow{F_{P}}=\frac{\rho}{\rho_{p}} \overrightarrow{u_{p}} \frac{\partial \vec{u}}{\partial x}
$$

\section{$\underline{\text { Saffman's Lift Force }}$}

Particles experience a lift force due to the shear field between particles and fluid flow. This lift force is generally perpendicular to the direction of flow and defined as Saffman's lift force. The generalized expression is provided by Saffman (1965) \& Li et

al. (1992) where $\mathrm{d}_{\mathrm{ij}}, \mathrm{d}_{\mathrm{jk}}, \mathrm{d}_{\mathrm{kl}}$ are the deformation tensor and $\mathrm{K}$ is a constant with a value of 2.594 .

$$
\overrightarrow{F_{S}}=\frac{2 K v^{\frac{1}{2}} \rho d_{i j}}{\rho_{p} d_{p}\left(d_{i j} d_{k l}\right)^{\frac{1}{4}}}\left(\vec{v}-\overrightarrow{v_{p}}\right)
$$

\section{Brownian Motion}

Brownian motion is an important force acting on the particle submerged in a fluid (liquid or gas). This motion can be defines as the random force acting on the particle due to the result of collision with the quickly moving atoms or molecules of the fluid. It is to 
be noted that Brownian motion is completely random due to the fact that classical mechanics cannot confirm the distance travelled per unit time because of the gigantic amount of collision a single particle will undergo in a given second. The value of collision is roughly estimated as $10^{21}$ by Chandrasekhar (1943). Brownian force acting on particle can be defined as:

$$
\overrightarrow{\mathrm{F}_{B_{1}}}=G_{i} \sqrt{\frac{\pi S_{o}}{\Delta t}}
$$

Where, $\mathrm{G}_{\mathrm{i}}$ are independent Gaussian random number with zero means and unit variance. $\Delta \mathrm{t}$ is the size of time step in seconds, and $\mathrm{S}_{\mathrm{o}}$ can be defined as

$$
S_{o}=\frac{216 v k_{B} T}{\pi^{2} \rho d_{p}^{5}\left(\frac{\rho_{p}}{\rho}\right)^{2} C_{c}}
$$

Where,

$$
\begin{aligned}
& v=\text { Kinematic viscosity } \\
& \mathrm{k}_{\mathrm{B}}=\text { Boltzmann constant }=1.3806488 \times 10^{-23} \mathrm{~m}^{2} \mathrm{~kg} \mathrm{~s}^{-2} \mathrm{~K}^{-1} \\
& \mathrm{~T}=\text { Absolute temperature of the fluid } \\
& \mathrm{C}_{\mathrm{C}}=\text { Cunningham correction }
\end{aligned}
$$




\section{CHAPTER 3}

\section{NUMERICAL METHOD}

\section{$\underline{\text { Introduction }}$}

Finite volume method utilizes the concept of conservation law in control volume, where the flux entering the control volume is identical to the flux leaving the neighboring volume. This method divides the computational domain into different grids and each nodes are surrounded by small volume defined as control volume. Finite volume method discretizes the partial differential equation into algebraic equation by using the divergence theorem. The volume integral present in the partial differential equation containing divergence term is converted into surface integral, yielding a discrete equation that expresses the conservation law on the control volume. The surface integral terms are then evaluated as flux at each control volume.

The conservation of mass, momentum and energy equations can be rewritten in a generalized form:

$$
\frac{\partial}{\partial \mathrm{t}}(\rho \phi)+\nabla \cdot(\rho \phi \overrightarrow{\mathrm{v}})=\nabla \cdot\left(\Gamma_{\phi} \nabla \phi\right)+\mathrm{S}_{\phi}
$$

Where $\phi$ is a general variable for scalar quantity, $\Gamma_{\phi}$ is coefficient of diffusion and $S_{\phi}$ is the source term for scalar quantity $\phi$. The integral form of Equation 3.1 based on control volume (V) can be written based on unsteady, advection, diffusion and source term; and can be expressed as: 


$$
\underbrace{\int_{\mathrm{V}} \frac{\partial \rho \phi}{\partial \mathrm{t}} \mathrm{dV}}_{\text {Transient }}+\underbrace{\oint \rho \phi \overrightarrow{\mathrm{V}} \cdot \mathrm{d} \overrightarrow{\mathrm{A}}}_{\text {Advection }}=\underbrace{\oint \Gamma_{\phi} \nabla \phi \cdot \mathrm{d} \overrightarrow{\mathrm{A}}}_{\text {Diffusion }}+\underbrace{\int_{\mathrm{V}} \mathrm{S}_{\phi} \mathrm{dV}}_{\text {Source }}
$$

Where, Diffusion and advection terms are expressed as an integral of surface area vector, $\vec{A}$ and vector of velocity, $\vec{v}=u \hat{\imath}+$ vj in two dimensions and gradient of scalar quantity as $\phi=\left(\frac{\partial \phi}{\partial x}\right) \hat{\imath}+\left(\frac{\partial \phi}{\partial y}\right) \hat{\jmath}$.

Figure 3.1 illustrates two dimensional control volumes. $\mathrm{C}_{\mathrm{o}}$ and $\mathrm{C}_{1}$ are two cell centers. The term $\mathrm{f}$ indicates the face centroid where face is defined as the interface between two adjacent cells. A vector directed from cell centroid to face centroid is defined as $\overrightarrow{\mathrm{r}}$.

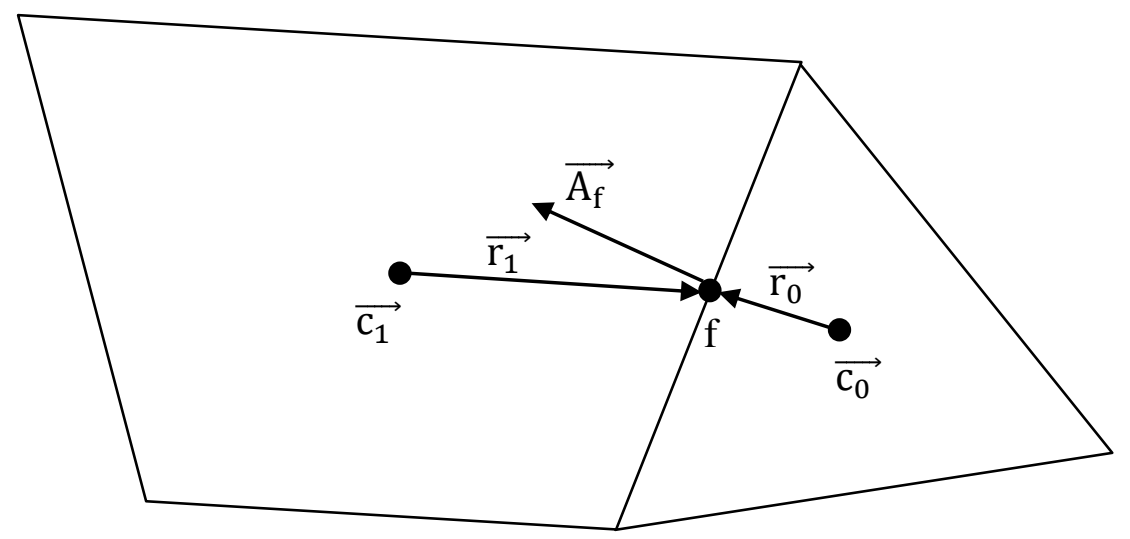

Figure 3.1. Illustration of control volume discretizing

The Equation 3.2 is applicable for each single control volume or cell in the computational domain. The discretization of this equation on a given cell can be expressed as follows: 


$$
\frac{\partial \rho \phi}{\partial t} V+\sum_{\mathrm{f}}^{N_{\text {faces }}} \rho_{\mathrm{f}} \overrightarrow{\mathrm{v}_{\mathrm{f}}} \phi_{\mathrm{f}} \overrightarrow{\mathrm{A}_{\mathrm{f}}}=\sum_{\mathrm{f}}^{\mathrm{N}_{\text {faces }}} \Gamma_{\phi} \nabla \phi_{\mathrm{f}} \overrightarrow{\mathrm{A}_{\mathrm{f}}}+\mathrm{S}_{\phi} \mathrm{V}
$$

The discretized scalar transport equation consists of unknown scalar variable $\phi$ at the center of the cell as well as the surrounding neighbor cells. So a linearized form of the discretized scalar transport equation needs to be used. This equation utilizes the linearized coefficient of $\phi$ as $a_{p}$ and $a_{n b}$ where $p$ is the present cell and $n b$ is the neighboring cell. This equation can be written as:

$$
a_{p} \phi=\sum_{n b} a_{n b} \phi_{n b}+b
$$

\section{$\underline{\text { Discretization }}$}

\section{$\underline{\text { Discretization of Transient Terms }}$}

A backward difference scheme was used to discretize and evaluate the transient derivative of scalar variable $\phi$. The equations for first and second order transient discretization can be written as:

$$
\begin{gathered}
\frac{\partial \phi}{\partial \mathrm{x}}=\frac{\phi^{\mathrm{n}+1}-\phi^{\mathrm{n}}}{\Delta \mathrm{t}} \\
\frac{\partial \phi}{\partial \mathrm{x}}=\frac{3 \phi^{\mathrm{n}+1}-4 \phi^{\mathrm{n}}+\phi^{\mathrm{n}-1}}{2 \Delta \mathrm{t}}
\end{gathered}
$$

Since the governing equations were discretized in terms of time and space, discretization done in Equations 3.5 and 3.6 are based on a time step $\Delta \mathrm{t}$. For transient 
simulation, finite volume method discretized the governing equation in terms of space and time. Temporal discretization integrates all the terms of the differential equations over a time step $\Delta \mathrm{t}$. The current, previous and next time steps are defined as $\mathrm{n}, \mathrm{n}-1$ and $\mathrm{n}+1$ time steps, respectively.

\section{Discretization of Advection and Diffusion Terms}

The power law discretization scheme uses the solution of a one dimensional advection-diffusion equation and interpolates the face value of $\phi$, where $\Gamma, \rho$ and $u$ are constant around the interval of $\partial \mathrm{x}$.

$$
\frac{\partial}{\partial x}(\rho u \phi)=\frac{\partial}{\partial x} \Gamma \frac{\partial \phi}{\partial x}
$$

Advection and diffusion terms provided in Equation 3.2 utilizes the face value of scalar quantity $\phi$, known as $\phi_{\text {f. }}$. The face value of the scalar quantity was interpolated by using the cell center values. Discretized values of $\phi$ at cell center are stored initially and used to interpolate for finding out the face values of $\phi$. Power law upwind approach was used for this interpolation where the face value of $\phi$ is collected from the quantities in the cell upstream relative to the direction of the normal velocity $\mathrm{v}_{\mathrm{n}}$. For convection dominated flow, face values of desired variables are equal to cell upstream values.

The integrated form of Equation 3.7 based on variation of $\phi$ as a function of $x$ can be written as:

$$
\frac{\phi(\mathrm{x})-\phi_{0}}{\phi_{\mathrm{L}}-\phi_{0}}=\frac{\exp \left(\mathrm{Pe} \frac{\mathrm{X}}{\mathrm{L}}\right)-1}{\exp (\mathrm{Pe})-1}
$$


Where,

$$
\begin{aligned}
& \phi_{0}=\left.\phi\right|_{\mathrm{x}=0} \\
& \phi_{\mathrm{L}}=\left.\phi\right|_{\mathrm{x}=\mathrm{L}}
\end{aligned}
$$

\section{Discretization of Continuity and Momentum Equations}

Continuity and momentum equations were discretized based on the linear form of the discretized scalar transport equation. Integrated form of continuity and momentum equation at steady state are shown below by considering force vector $(\vec{F})$, Stress tensor $(\overline{\bar{\tau}})$ and identity matrix (I).

Continuity equation:

$$
\oint \rho \overrightarrow{\mathrm{V}} \cdot \mathrm{d} \overrightarrow{\mathrm{A}}=0
$$

Momentum equation: $\quad \oint \rho \vec{v} \vec{V} \cdot d \vec{A}=-\oint p I \cdot d \vec{A}+\int_{V} \vec{F} d V+\oint \overline{\bar{\tau}} \cdot d \vec{A}$

Pressure $\left(\mathrm{p}_{\mathrm{c}_{0}}, \mathrm{p}_{\mathrm{c}_{1}}\right)$ and normal velocities $\left(\mathrm{v}_{\mathrm{n}, \mathrm{c}_{0}}, \mathrm{v}_{\mathrm{n}, \mathrm{c}_{1}}\right)$ between two adjacent cells $c_{o}$ and $c_{1}$ can be incorporated to produce a simplified form of mass flux through the face $f$ between two adjacent cells $\mathrm{c}_{\mathrm{o}}$ and $\mathrm{c}_{1}$, which can be defined as:

$$
\mathrm{J}_{\mathrm{f}}=\widehat{\mathrm{J}_{\mathrm{f}}}+\mathrm{d}_{\mathrm{f}}\left(\mathrm{p}_{\mathrm{c}_{0}}-\mathrm{p}_{\mathrm{c}_{1}}\right)
$$

Where, $\mathrm{J}_{\mathrm{f}}$ is also a product of density and value of velocity of the face in between two cells. $\mathrm{J}_{\mathrm{f}}$ can be written as a linearized form of the scalar transport equation. 


$$
\mathrm{J}_{\mathrm{f}}=\rho_{\mathrm{f}} \frac{\mathrm{a}_{\mathrm{p}, \mathrm{c}_{0}} \mathrm{v}_{\mathrm{n}, \mathrm{c}_{0}}+\mathrm{a}_{\mathrm{p}, \mathrm{c}_{1}} \mathrm{v}_{\mathrm{n}, \mathrm{c}_{1}}}{\mathrm{a}_{\mathrm{p}, \mathrm{c}_{0}}+\mathrm{a}_{\mathrm{p}, \mathrm{c}_{1}}}+\mathrm{d}_{\mathrm{f}}\left(\left(\mathrm{p}_{\mathrm{c}_{0}}+(\nabla \mathrm{p})_{\mathrm{c}_{0}} \cdot \overrightarrow{\mathrm{r}_{0}}\right)-\left(\mathrm{p}_{\mathrm{c}_{1}}+(\nabla \mathrm{p})_{\mathrm{c}_{1}} \cdot \overrightarrow{\mathrm{r}_{1}}\right)\right)
$$

Momentum weighted average (Rhie and Chow, 1983) method was used to associate the face and cell center values of velocity $\overrightarrow{V_{n}}$. This method is particularly helpful to avoid resultant unphysical values of pressure caused by linear interpolation.

Integrating the continuity equation with respect to the control volume yields the following simplified discretized equation.

$$
\sum_{\mathrm{f}}^{\mathrm{N}_{\text {faces }}} \mathrm{J}_{\mathrm{f}} \mathrm{A}_{\mathrm{f}}=0
$$

However, the linearized form of continuity equation does not actually calculate the pressure explicitly. Navier-Stokes equation can be discretized for solving velocities in $\mathrm{x}$ and $\mathrm{y}$ directions, only if the pressure field is known. Momentum equation cannot be solved without knowing the pressure distribution. Pressure correction schemes are generally used to conduct an iterative procedure that adjusts the pressure field at each iteration to make sure that the velocity field satisfies the continuity equation. Thus mass flux through face $\mathrm{f}$, defined as $\mathrm{J}_{\mathrm{f}}$ needs to be rewritten as:

$$
\mathrm{J}_{\mathrm{f}}=\widehat{\mathrm{J}_{\mathrm{f}}^{*}}+\mathrm{d}_{\mathrm{f}}\left(\mathrm{p}_{\mathrm{c}_{0}}^{*}-\mathrm{p}_{\mathrm{c}_{1}}^{*}\right)+\mathrm{d}_{\mathrm{f}}\left(\mathrm{p}_{\mathrm{c}_{0}}^{\prime}-\mathrm{p}_{\mathrm{c}_{1}}^{\prime}\right)
$$

Or, in a simplified form:

$$
\mathrm{J}_{\mathrm{f}}=\mathrm{J}_{\mathrm{f}}^{*}+\mathrm{J}_{\mathrm{f}}^{\prime}
$$


$J_{\mathrm{f}}^{*}$ is mass heat flux $\left(\mathrm{J}_{\mathrm{f}}\right)$ through face $\mathrm{f}$ corresponding to assumed pressure field $\left(\mathrm{p}^{*}\right) . \mathrm{J}_{\mathrm{f}}^{\prime}$ is added as a mass heat flux correction scheme related with the cell pressure correction values $\left(\mathrm{p}_{\mathrm{c}_{0}}^{\prime}\right.$ and $\left.\mathrm{p}_{\mathrm{c}_{1}}^{\prime}\right)$.

This pressure correction scheme yields a discretized equation for the pressure correlation $\mathrm{p}^{\prime}$ which is:

$$
\mathrm{a}_{\mathrm{p}} \mathrm{p}^{\prime}=\sum_{\mathrm{nb}} \mathrm{a}_{\mathrm{nb}} \mathrm{p}_{\mathrm{nb}}^{\prime}+\mathrm{b}
$$

Where the source term $b$ is the net flow rate into the cell and can be expressed as:

$$
b=\sum_{f}^{N_{\text {faces }}} J_{f}^{*} A_{f}
$$

Discretization of the momentum equation was done by replacing the scalar quantity $\phi$ with the vector of velocity along with some modification related with momentum equation, in the discretized scheme. Velocity field can be obtained by solving this equation. A standard scheme was incorporated to calculate the pressure values at different faces by interpolation, using the momentum equation coefficient from Rhie and Chow (1983), since the pressure between each cell center experience a smooth variation.

$\mathrm{x}$ momentum equation:

$$
a_{p} u=\sum_{n b} a_{n b} u_{n b}+\sum p_{f} A \cdot \hat{\imath}+S
$$

Where, 


$$
\mathrm{P}_{\mathrm{f}}=\frac{\frac{\mathrm{P}_{\mathrm{c}_{0}}}{\mathrm{a}_{\mathrm{p}, \mathrm{c}_{0}}}+\frac{\mathrm{P}_{\mathrm{c}_{1}}}{\mathrm{a}_{\mathrm{p}, \mathrm{c}_{1}}}}{\frac{1}{\mathrm{a}_{\mathrm{p}, \mathrm{c}_{0}}}+\frac{1}{\mathrm{a}_{\mathrm{p}, \mathrm{c}_{1}}}}
$$

\section{$\underline{\text { Pressure based Segregated Algorithm }}$}

Pressure based segregated algorithm solves all the governing equations in terms of solution variables. It implements the projection method from Chorin (1968). For pressure based coupled algorithm, the coefficient of discretized continuity and momentum equations were solved simultaneously and once a set of solution is done, the process was repeated until the convergence happens. Segregated algorithm solves each individual variables separately and update each value after convergence. Coupled algorithm increases the time of solution with minor improvement in accuracy. Segregated algorithm provides less time required for computation along with good accuracy. Thus pressure based segregated algorithm was incorporated in the present study. The fluid properties were updated at each time step based on the current solution. Initially the nodes were identified as fluid based on initial condition. Later, the nodes were identified as either solid or liquid by comparing their temperature with solidification temperature of the fluid. The momentum equations were solved in the liquid zone based on the updated values of pressure and face mass flux. Then the pressure correction equation was solved by using the updated values of velocity field and mass flux. After that the face mass fluxes, pressure and velocity field values were updated based on the outputs obtained after solving the pressure correction equation. Finally the energy and source terms were solved and convergence of the whole solution was calculated. For solid region, velocity 
in $\mathrm{x}$ and $\mathrm{y}$ directions were are set to zero. If solution converges then it stopped the analysis. Or else it continued to update the properties of solution variable again and then did the whole steps again until the convergence criteria are meet. The solution convergence was relatively slow due to continuous iteration of the coupled non-linear governing equations till the convergence of solution. The normalized rate of convergence was checked at each iteration. Convergence monitor was set to $10^{-10}$. The solution was considered converged if the normalized rate of change of all the process variables were less than or equal to the value of convergence monitor. The normalized convergence monitor for any scalar quantity $\phi$ can be written as:

$$
\text { Convergence Monitor }=\sum_{\mathrm{i}=1}^{\mathrm{n}} \frac{\left|\phi_{\mathrm{i}}^{\mathrm{k}}-\phi_{\mathrm{i}}^{\mathrm{k}-1}\right|}{\left|\phi_{\mathrm{i}}^{\mathrm{k}}\right|}
$$

Convergence monitor considers the sum of results calculated between current $(\mathrm{k})$ iteration and previous iteration ( $\mathrm{k}-1)$, divided by the sum of current iteration $(\mathrm{k})$. This calculation of absolute values was performed for all nodes (n). 


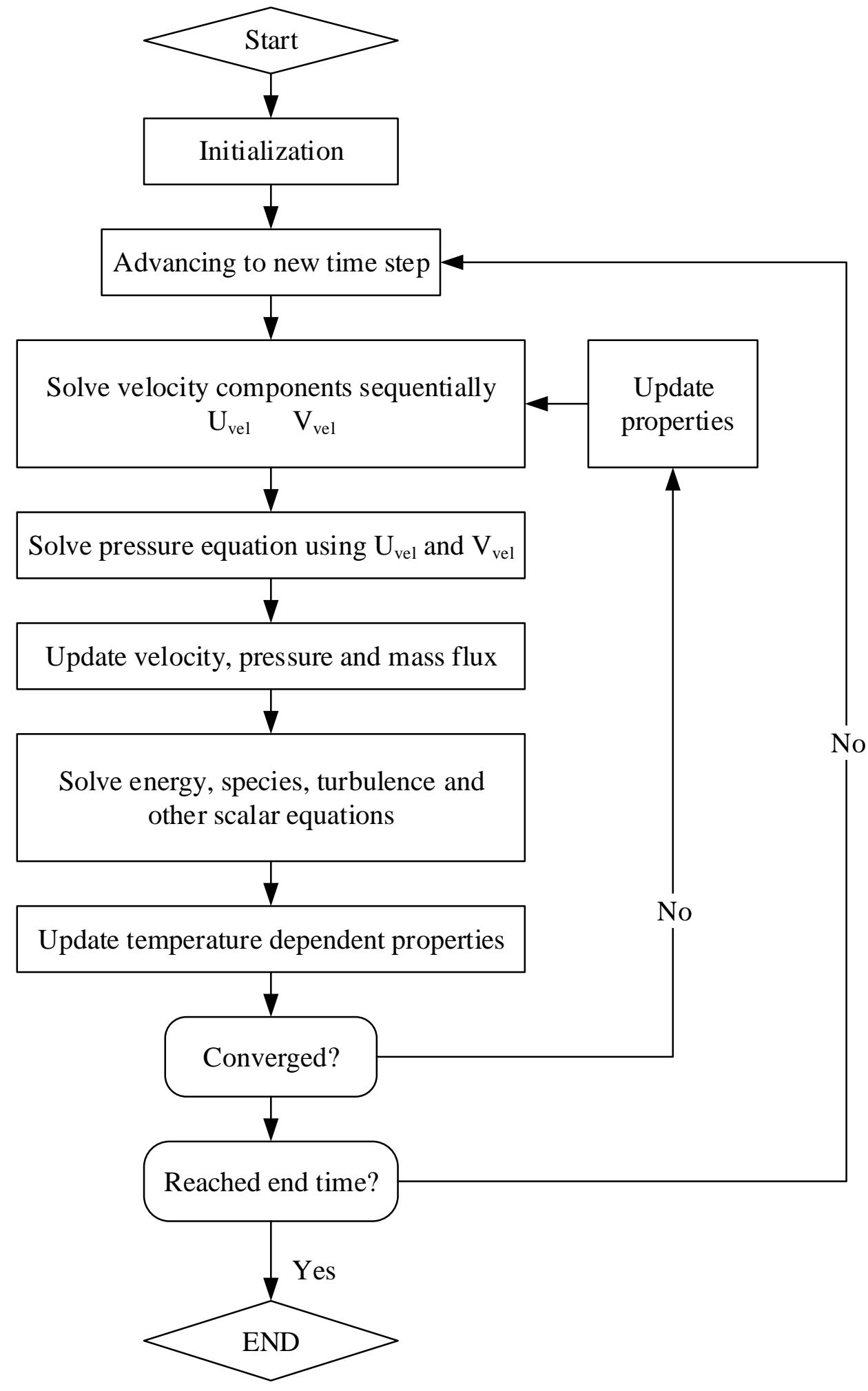

Figure 3.2. Overview of the pressure based segregated algorithm 


\section{$\underline{\text { Code Validation }}$}

The present code along with the user algorithm was validated by comparing with experimental and numerical results. The solidification process was validated with the experimental data from Wolff and Viskanta (1988) and the particle tracking process was validated with Akbar at el. (2009).

\section{Validation of Solidification Process}

The problem presented by Wolff and Viskanta (1988) consisted of a rectangular enclosure with molten tin. Left and right vertical walls were held at a constant temperature of $233^{\circ} \mathrm{C}$ and $229^{\circ} \mathrm{C}$ respectively. Top and bottom walls were insulated. The molten tin was subjected to solidification. Details of the experimental set up and results can be obtained from Wolff and Viskanta (1988). In the solid region, pure conduction was responsible for heat transfer. For the liquid region, natural convection was solely responsible for the convection. Molten tin gradually solidified as time progressed. The solidification front positions, obtained numerically from present code, were compared with the experimental results obtained from Wolff and Viskanta (1988). Three cases at 0.077, 0.165 and 0.529 hours were considered and compared in Figure 3.3. The results obtained by present method are in good agreement with the published results. 


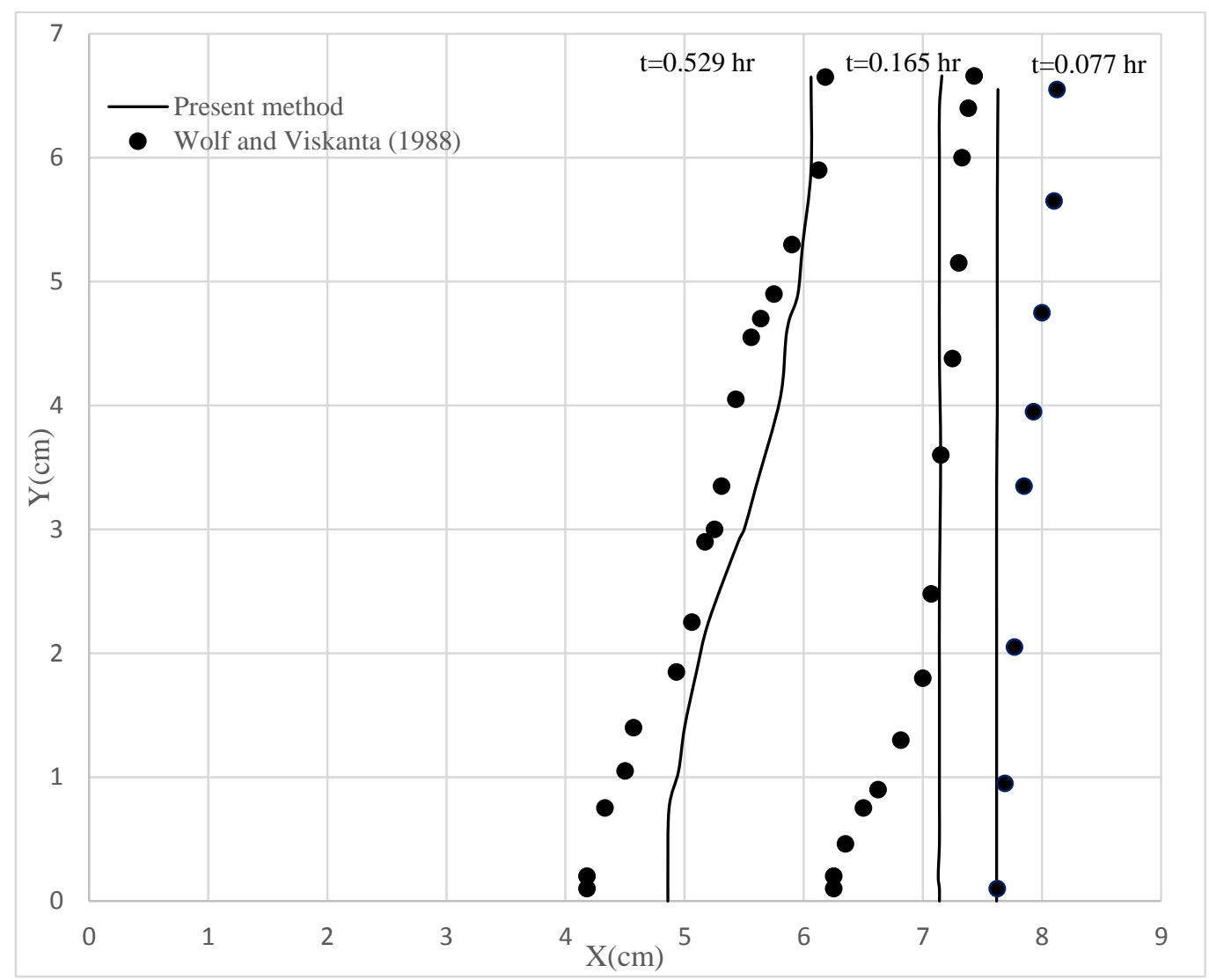

Figure 3.3. Comparison of numerically obtained solidification front positions with experimental data by Wolff and Viskanta (1988)

\section{$\underline{\text { Validation of Particle Tracking Process }}$}

The present work was validated by comparing results of particle tracking from Akbar at el. (2009). Natural convection of air in a rectangular enclosure was modeled with silicon dioxide nanoparticles. A 0.5334 centimeter enclosure with a temperature difference between left and right wall of $100 \mathrm{~K}$ was considered. The left and right walls were at $373 \mathrm{~K}$ and $273 \mathrm{~K}$. The horizontal walls were insulated. At a constant Rayleigh number of $10^{3}$, the distribution of particles at different times were analyzed and compared in Figure 3.4. 


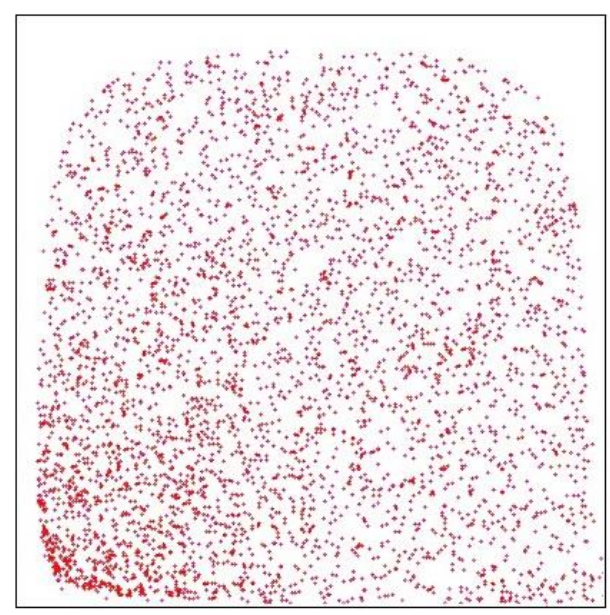

(a1)

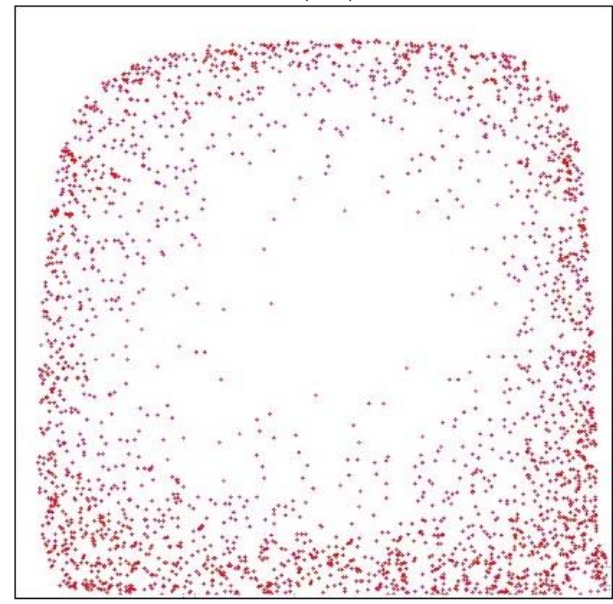

(b1)

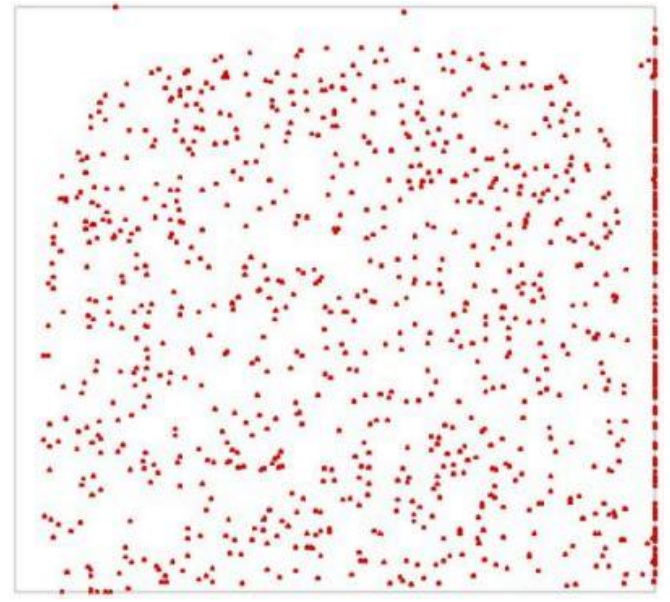

(a2)

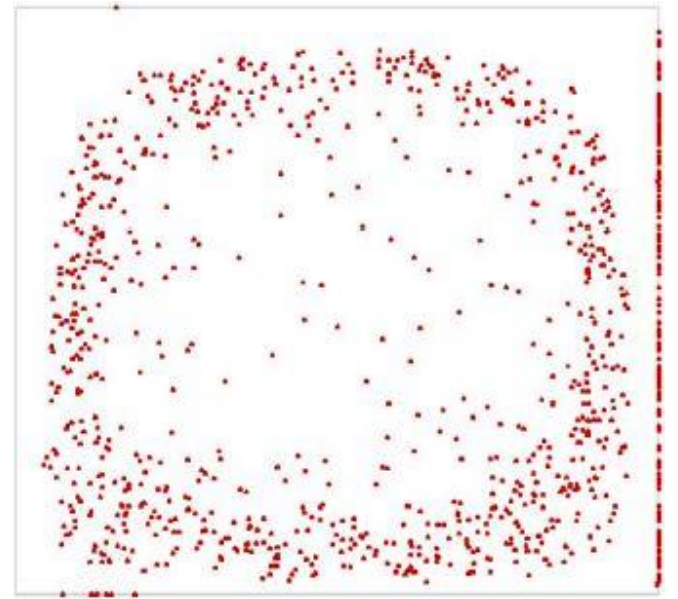

(b2)

Figure 3.4. Comparison of numerically obtained particle distribution with numerical results from Akbar et al. (2009).

The results obtained from present work shows a good agreement with the published results. Cases (a1) and (b1) correspond to present work at $\mathrm{t}=2.5$ and 25 seconds. Cases (a2) and (b2) correspond to the numerical results of Akbar et al. (2009). In their study, particles were removed from the flow field once it impacts on a wall, assuming particles went outside of the enclosure. Thus the total number of particle reduces as the time goes by. This reduction is characterized as remaining particle fraction where a value of 1 means $100 \%$ of the particles are in the enclosure and a value of 0 
means all the particles were removed from the flow field due to their impact on the enclosure walls. Figure 3.5 compares the remaining particle fraction obtained by present code with numerical results from Akbar et al. (2009), which shows a good agreement in this regard.

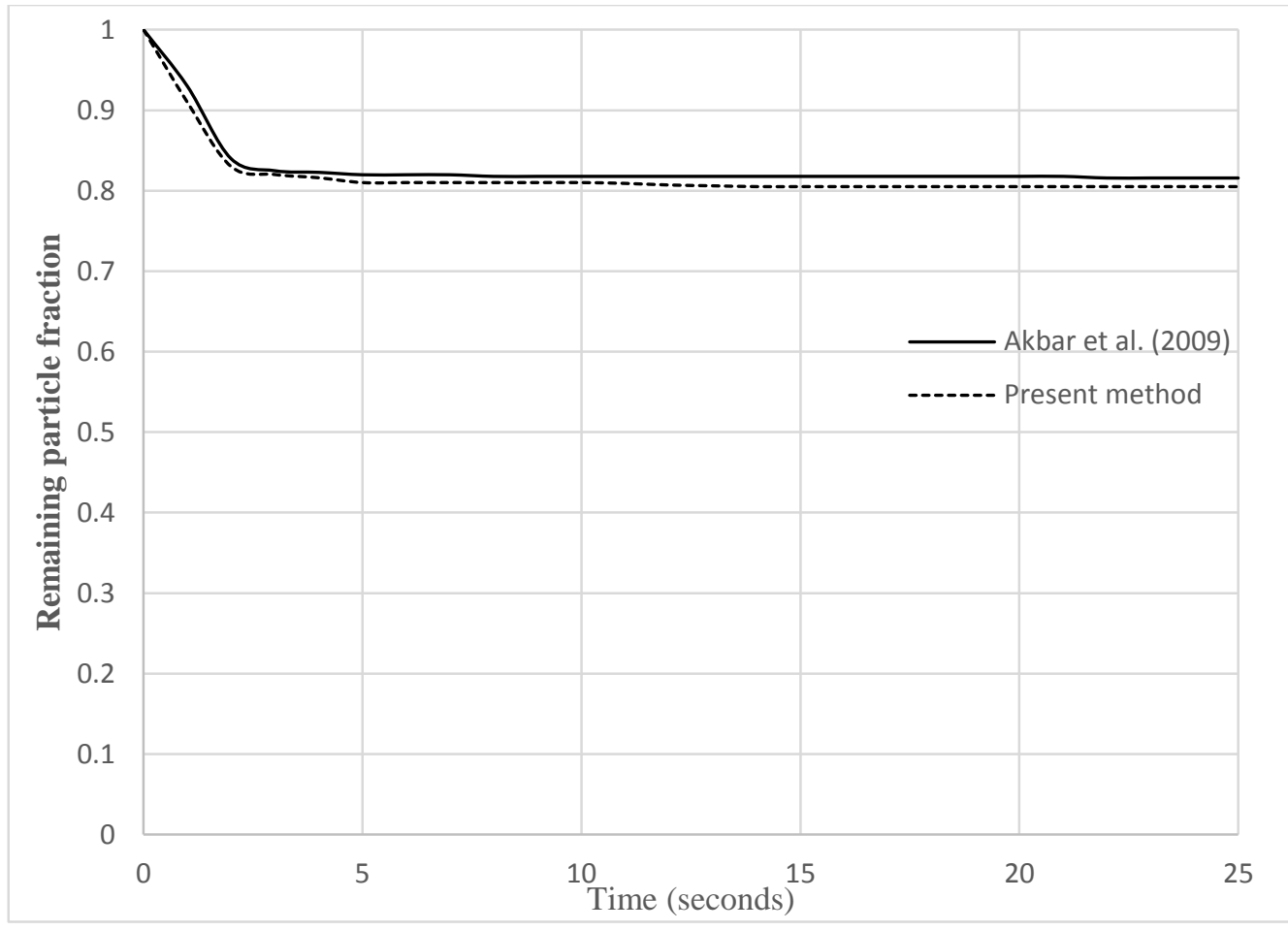

Figure 3.5. Quantitative comparison of numerically obtained particle fraction remained in the domain with numerical results from Akbar et al. (2009) 


\title{
CHAPTER 4
}

\section{MODELING OF PROCESS PARAMETERS}

\author{
$\underline{\text { Introduction }}$
}

Marangoni and natural convection, along with rate of solidification plays an important role in the diffusion of particles after solidification. High Marangoni number produces higher velocity of flow which is directly responsible for higher movement of particle. However, higher rate of solidification restricts that movement by trapping the particles in solidified region. Thus, even with high Marangoni number, particles may not get sufficient time to move along the flow of fluid. Present work correlates the relationship between Marangoni and Rayleigh number, rate of solidification and initial distribution of particles to visualize and quantify the final distribution of nanoparticles.

\section{$\underline{\text { Grid Independence Test }}$}

Grid independency tests were carried out to identify a grid size which produces accurate results along with optimum computational time. Grid independent means calculated results change such a small amount along with a denser grid that the error can be ignored to decrease the computational time. Generally, computational time increases if the number of elements are increased. Two different grids of 5200 and 11000 were examined with parameters of $\mathrm{Ma}=4.3 \times 10^{4}$, convective heat transfer coefficient, $\mathrm{h}=146$ $\mathrm{W} / \mathrm{m}^{2} \mathrm{~K}$ and insulated bottom wall boundary condition. The top wall and symmetry wall 
temperatures were compared at $t=1$ second of the simulation. The temperature distribution is shown in Figure.

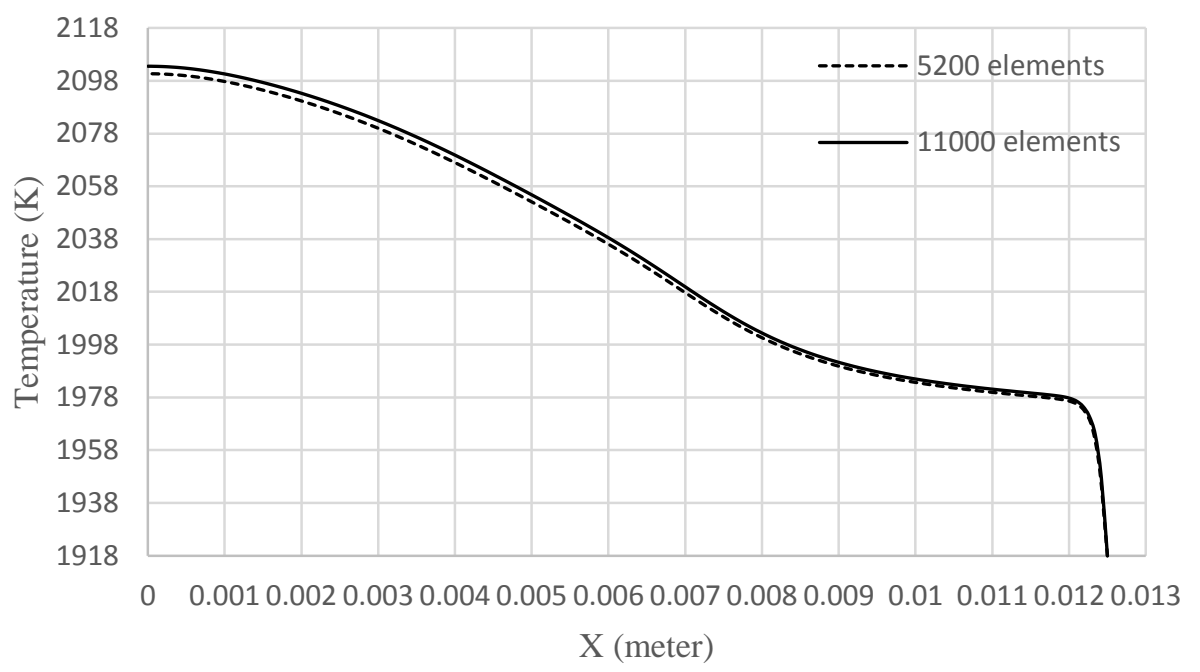

(a) Top wall temperature

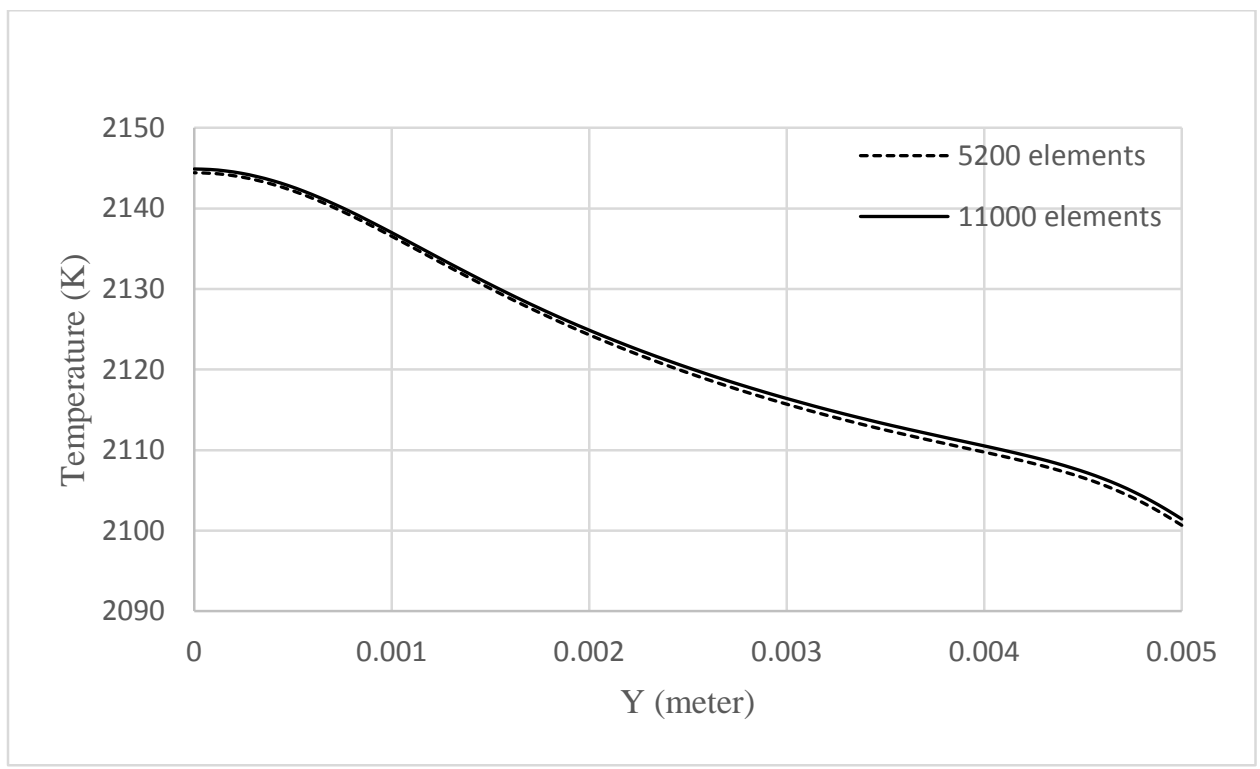

(b) Symmetry wall temperature

Figure 4.1. Comparison of temperature profile for grid independence 
A grid with 5200 elements were chosen based on the grid independency test. For computing power and time efficiency, only right half of the problem domain shown in Figure 2.1 was solved during analysis. The computational mesh of that right half is shown in Figure 4.2.

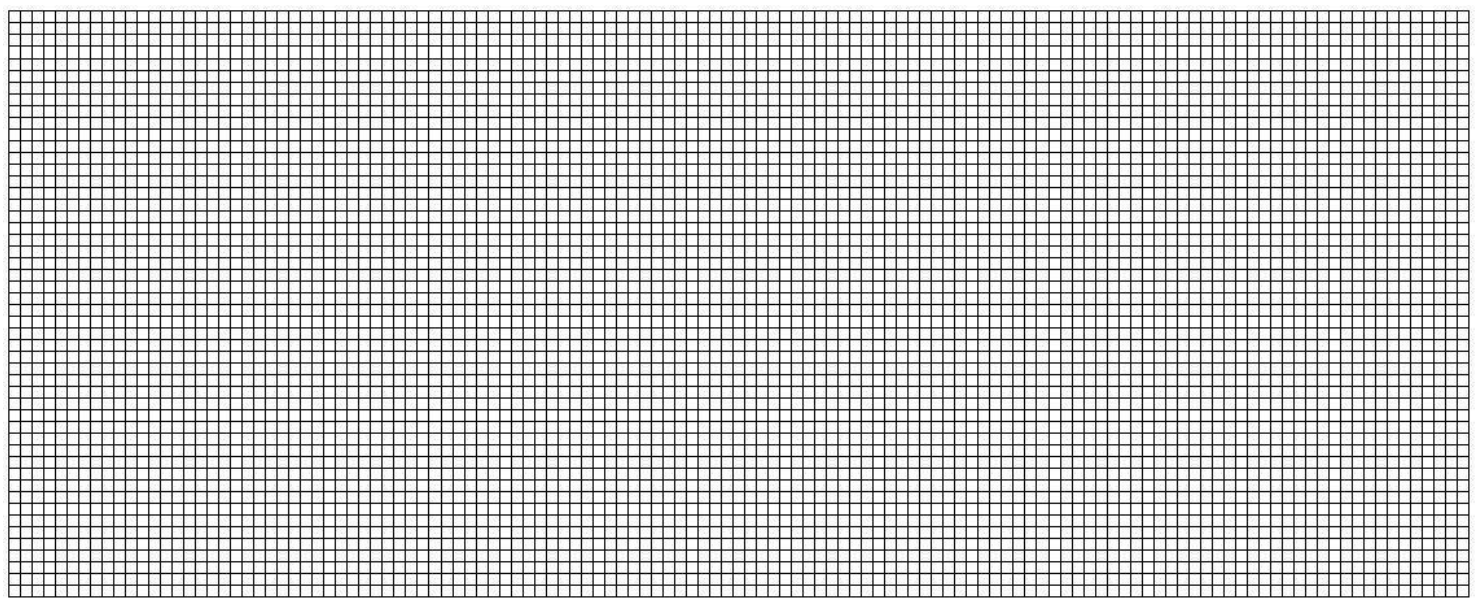

Figure 4.2. Computational mesh

Movement of particle was also compared between two grids. Three nanoparticles were initially located at the horizontal centerline of the geometry. Their initial position and final position after complete solidification of the geometry is shown in Figure 4.3. Three individual nanoparticles were marked as A, B and C at initial position. After solidification, those nanoparticles are marked as $\mathrm{A}_{\text {final position, }} \mathrm{B}_{\text {final position }}$ and $\mathrm{C}_{\text {final position }}$. 


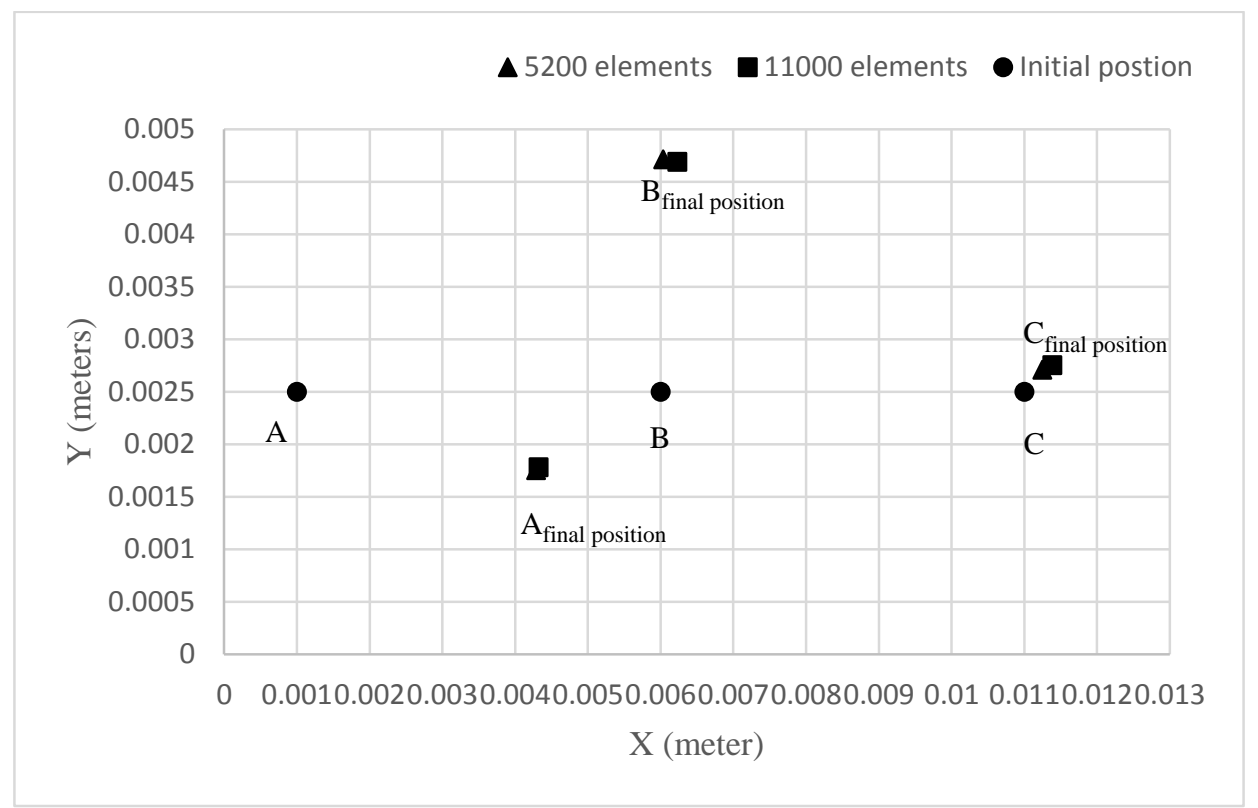

Figure 4.3. Comparison of nanoparticle distribution

Numerical study was performed based on the following process parameters:

- Marangoni number (Ma).

- Convective heat transfer coefficient (h).

- Bottom wall thermal boundary condition (insulated or constant temperature).

- Different initial particle distribution.

Only one parameter was allowed to vary one time to study the effect of that specific parameter on analysis. The effect of each parameter on the final distribution of particles after solidification, time required for solidification of top and entire geometry and heat flux variation was studied. The top wall of the domain was exposed to free with an air temperature of $293 \mathrm{~K}$. The right and left walls were at a constant temperature of 1918 K. The bottom wall was subjected to two different boundary conditions, namely, an 
insulated surface or at a constant temperature with the same value of the side walls. The initial temperature of the fluid was set at $3073 \mathrm{~K}$. For computing power and time efficiency, only right half of the problem domain was solved during the analysis. It was possible due to the symmetric nature of the overall geometry and control parameters. A total of 1900 silicon carbide (SiC) nanoparticles were tracked.

\section{Computational Matrix}

The ranges of parameters used in the present study were

- $\mathrm{Ma}=4.3 \times 10^{3}$ to $4.3 \times 10^{5}$.

- $\mathrm{h}=5$ to $600 \mathrm{~W} / \mathrm{m}^{2} \mathrm{~K}$.

- Insulated or constant temperature bottom boundary for all the cases.

- Different initial distribution of particles.

A total of 186 cases were simulated in the current study. A uniform initial distribution of particles was considered for the first 42 cases. The distribution is shown in Figure 4.4

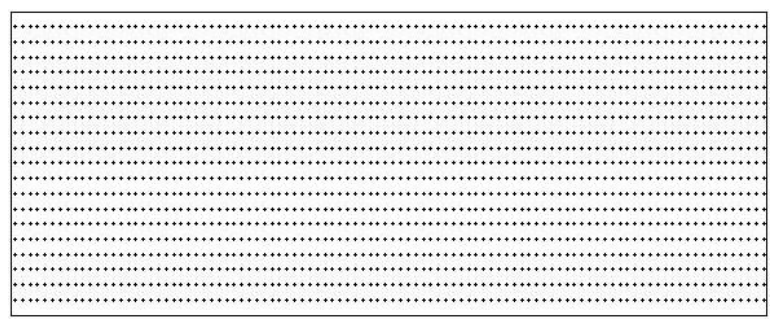

Figure 4.4. Initial uniform distribution of particles 
The computational matrix for 21 cases are shown in Table 4.1. Each of those cases were run for both insulated and constant temperature bottom wall boundary conditions, separately, resulting in 42 cases.

Table 4.1. Computational matrix for the study with initially uniform particle distribution

\begin{tabular}{|c|c|}
\hline Marangoni number (Ma) & Convective heat transfer coefficient (h) \\
\hline $4.3 \times 10^{3}$ & 5 \\
\hline $4.3 \times 10^{3}$ & 25 \\
\hline $4.3 \times 10^{3}$ & 50 \\
\hline $4.3 \times 10^{3}$ & 146 \\
\hline $4.3 \times 10^{3}$ & 300 \\
\hline $4.3 \times 10^{3}$ & 400 \\
\hline $4.3 \times 10^{3}$ & 600 \\
\hline $4.3 \times 10^{4}$ & 5 \\
\hline $4.3 \times 10^{4}$ & 25 \\
\hline $4.3 \times 10^{4}$ & 50 \\
\hline $4.3 \times 10^{4}$ & 146 \\
\hline $4.3 \times 10^{4}$ & 300 \\
\hline $4.3 \times 10^{4}$ & 400 \\
\hline $4.3 \times 10^{4}$ & 600 \\
\hline $4.3 \times 10^{5}$ & 5 \\
\hline $4.3 \times 10^{5}$ & 25 \\
\hline
\end{tabular}


Table 4.1 continued

\begin{tabular}{|c|c|}
\hline $4.3 \times 10^{5}$ & 50 \\
\hline $4.3 \times 10^{5}$ & 146 \\
\hline $4.3 \times 10^{5}$ & 300 \\
\hline $4.3 \times 10^{5}$ & 400 \\
\hline $4.3 \times 10^{5}$ & 600 \\
\hline
\end{tabular}

In addition to the cases shown above, a total of 144 cases were conducted with different initial distribution of particles. Table 4.2 shows 9 cases.

Table 4.2. Computational matrix for cases with initially non uniform particle distribution

\begin{tabular}{|c|c|}
\hline Marangoni number (Ma) & Convective heat transfer coefficient (h) \\
\hline $4.3 \times 10^{3}$ & 5 \\
\hline $4.3 \times 10^{3}$ & 146 \\
\hline $4.3 \times 10^{3}$ & 600 \\
\hline $4.3 \times 10^{4}$ & 5 \\
\hline $4.3 \times 10^{4}$ & 146 \\
\hline $4.3 \times 10^{4}$ & 600 \\
\hline $4.3 \times 10^{5}$ & 5 \\
\hline $4.3 \times 10^{5}$ & 146 \\
\hline $4.3 \times 10^{5}$ & 600 \\
\hline
\end{tabular}


Each of these cases were run for both insulated and constant temperature bottom wall boundary conditions, separately, resulting in 18 cases. Eight different initial distributions, as shown in Figure 4.5, were considered for these 18 cases in the current study, making a total of 144 cases.

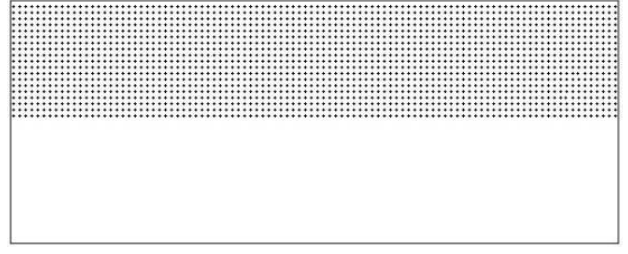

Case 1(Top thick)

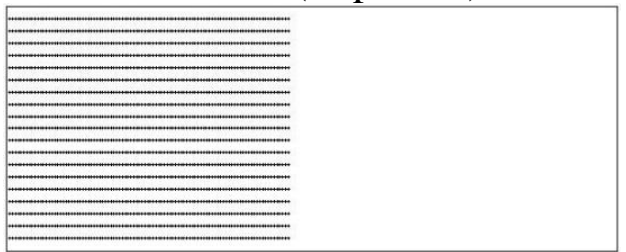

Case 3(Left thick)

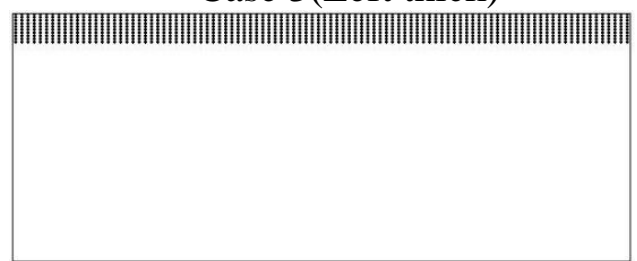

Case 5(Top thin)

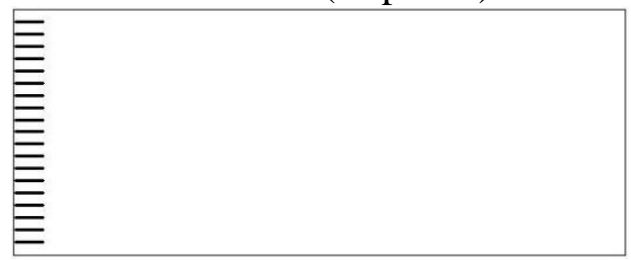

Case 7(Left thin)

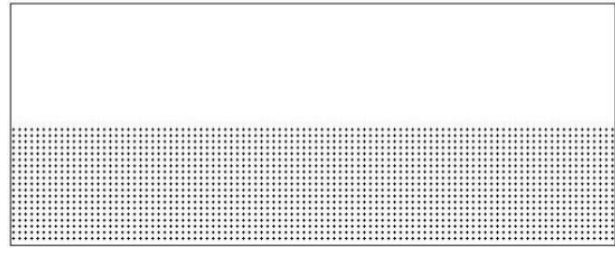

Case 2(Bottom thick)

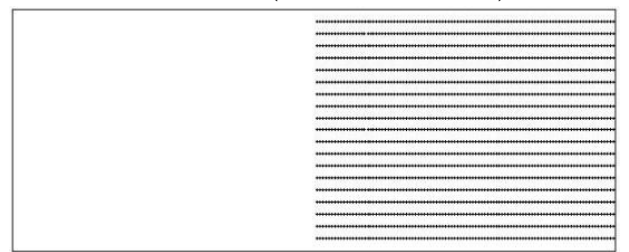

Case 4(Right thick)

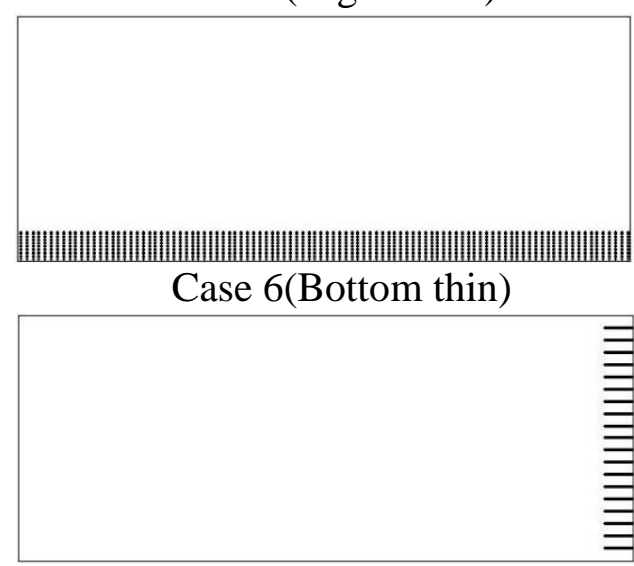

Case 8( Right thin)

Figure 4.5. Initial particle distribution for different cases 


\section{CHAPTER 5}

\section{RESULTS AND DISCUSSIONS}

The results of the numerical analysis were interpreted and deduced to substantial conclusions. The solidification and particle tracking process were conducted as a transient one and results were obtained once the entire geometry was solidified.

\section{Fluid Hydrodynamics and Particle Diffusion Characteristics}

Fluid hydrodynamics is controlled by Marangoni and buoyancy convection. The Rayleigh number for each of the cases were kept constant at $10^{4}$. The movement of particles were dictated by strong Marangoni convection and natural convection due to sub-micron diameter of the nanoparticles. Marangoni convection is directly related with the temperature coefficient of surface tension on the free surface which follows the general rule that increase in temperature decreases surface tension and vice versa. As a result, a strong clockwise recirculating flow was established in the domain with a unique shape of velocity vector known for Marangoni convection. Figure 5.1 shows the velocity vector and particle distribution in a transient manner at different times. The case with $\mathrm{Ma}$ $=4.3 \times 10^{4}, \mathrm{~h}=146 \mathrm{~W} / \mathrm{m}^{2} \mathrm{~K}$, insulated bottom wall and an initial uniform distribution of

particles was considered for illustration. Left column shows the velocity profile and right column shows particle distribution. At $\mathrm{t}=0.1$ to 1 seconds, the initial development of velocity can be observed. During this time, the particles move along the velocity vector. At $\mathrm{t}=5$ seconds, the solidified region in the geometry is visible near the right hand wall, 
where no velocity vector exists. Particle tends to follow the recirculating velocity vector of the fluid and creates a well-defined quasi-equilibrium state, which can be defined as a state where the system deviates from an equilibrium state by an infinitesimally small amount. Centrifugal force is the key factor creating a void in the geometry with no particles and highly concentrated particles in the quasi-equilibrium region. The solidification process can be observed just by interpreting the velocity vector from Figure 5.1. The right wall gets solidified first, then the top wall and gradually the rest of the geometry. After solidification of the top wall, buoyancy convection takes over because Marangoni convection goes away due to absence of surface tension on free surface. Thus the velocity decreases significantly and particles don't get enough force to move. The entire geometry solidified at 53 seconds. Due to negligible movement in particles, velocity vector and particle distribution were not shown till the end of solidification process.
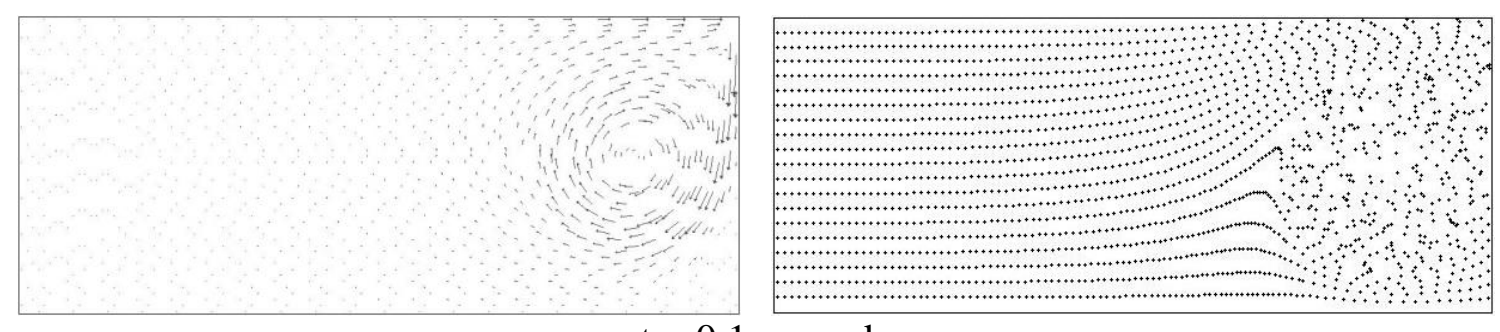

$\mathrm{t}=0.1$ second

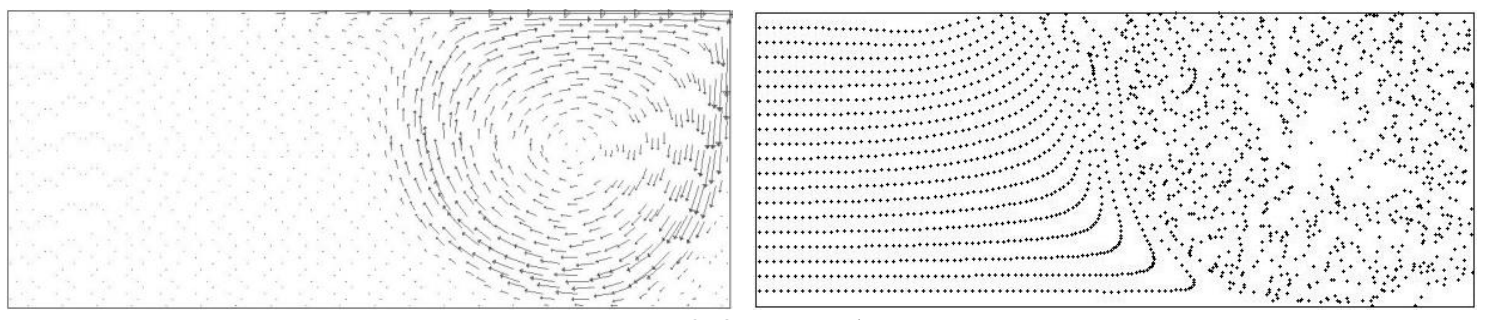

$\mathrm{t}=0.3$ second

Figure 5.1. Velocity profile and particle distribution at specific time steps 
Figure 5.1 continued
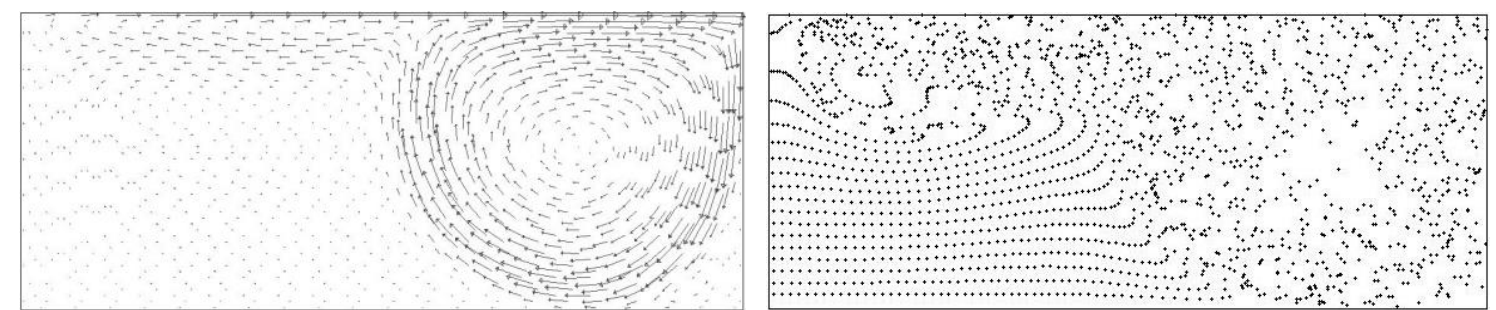

\section{$\mathrm{t}=0.5$ second}
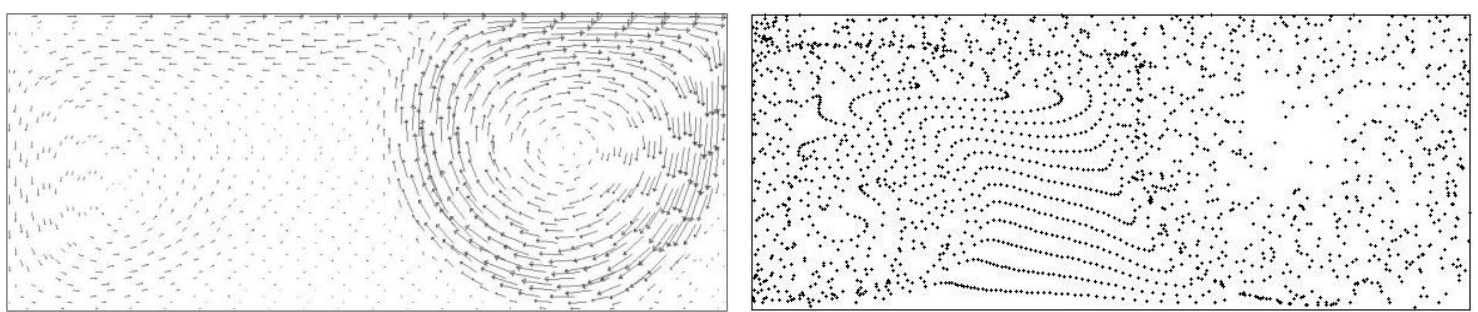

$\mathrm{t}=0.7$ second
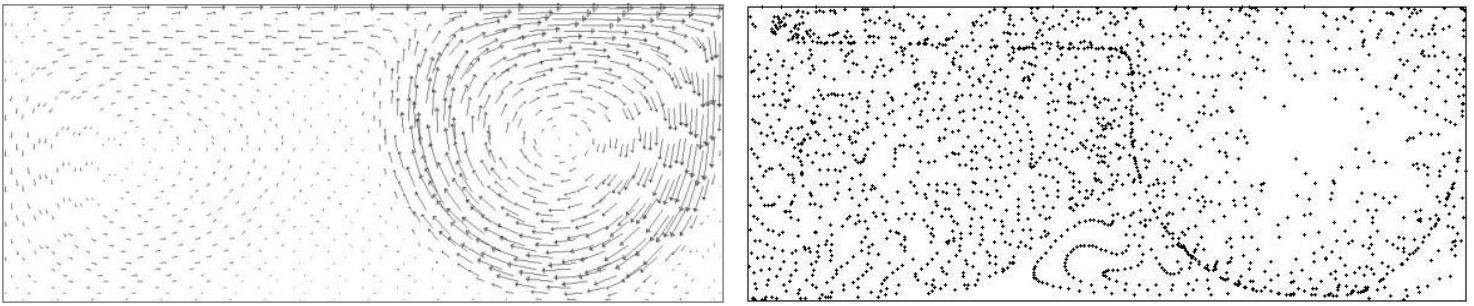

\section{$\mathrm{t}=1$ second}
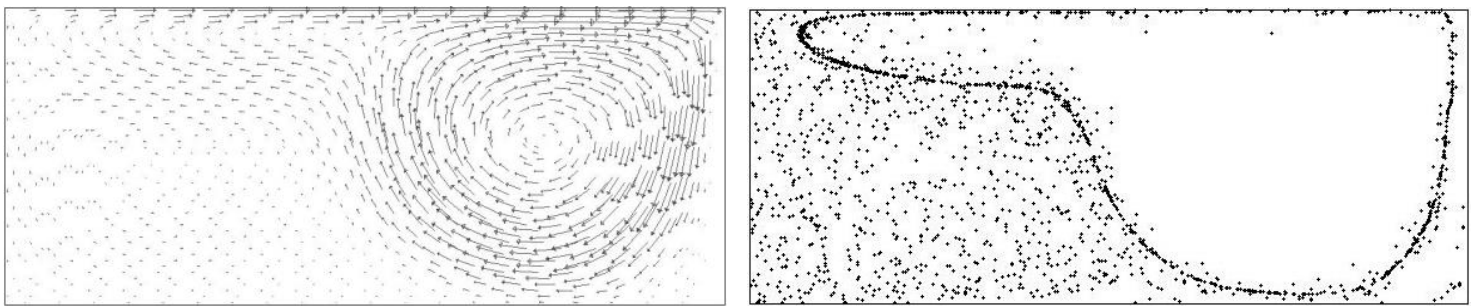

$\mathrm{t}=5$ second
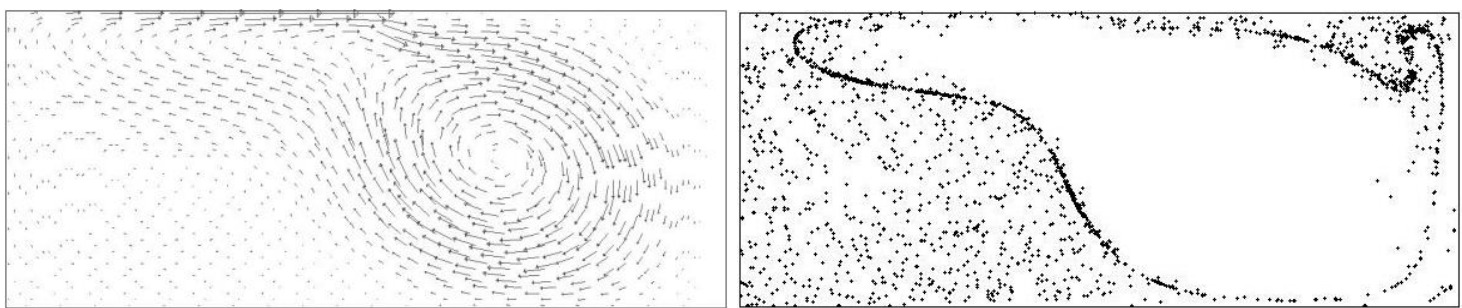

$\mathrm{t}=6$ second 
Figure 5.1 Continued

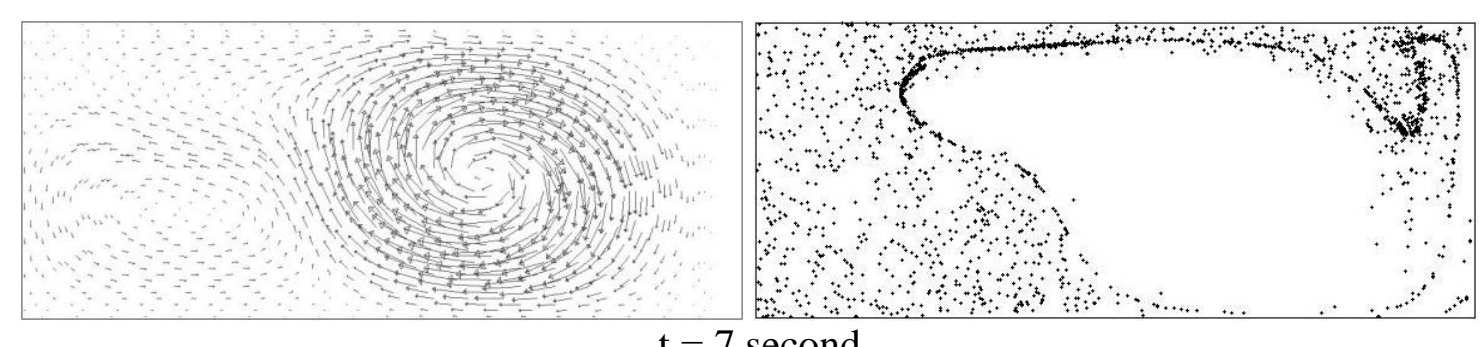

\section{$\mathrm{t}=7$ second}
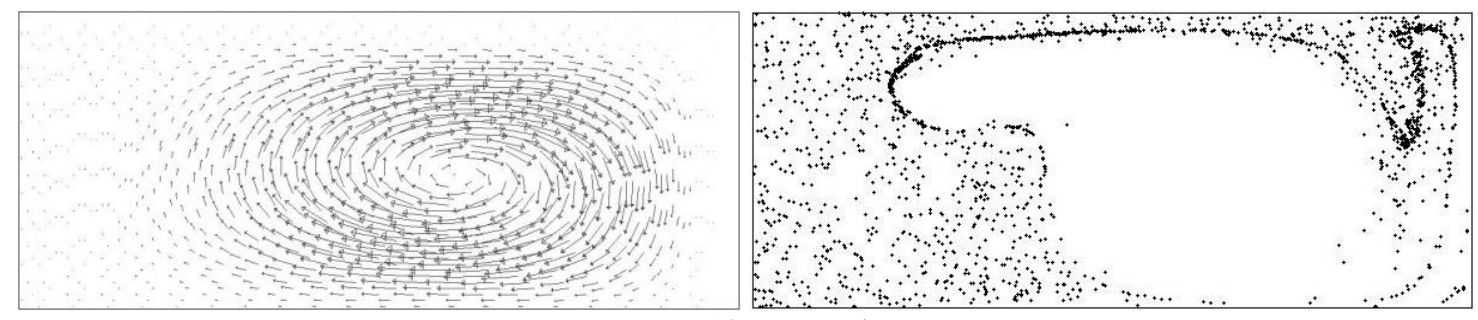

$\mathrm{t}=10$ second

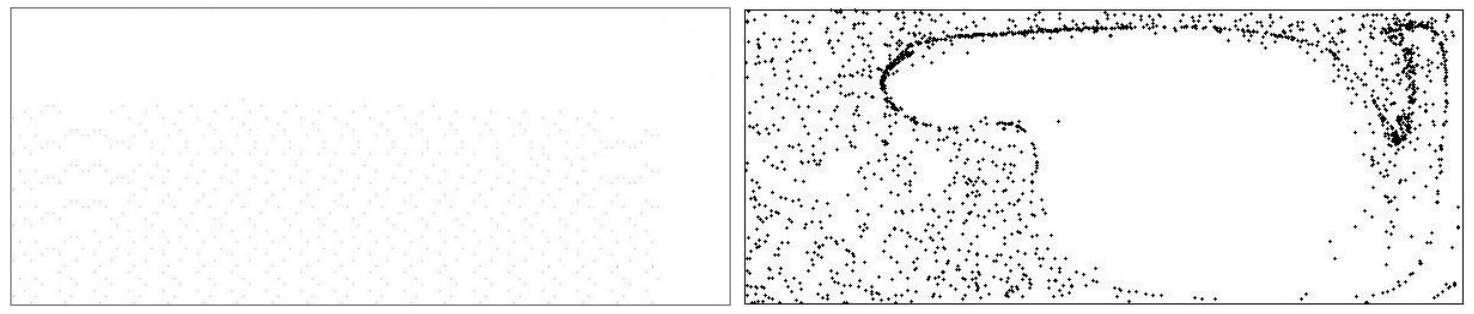

$\mathrm{t}=20$ second

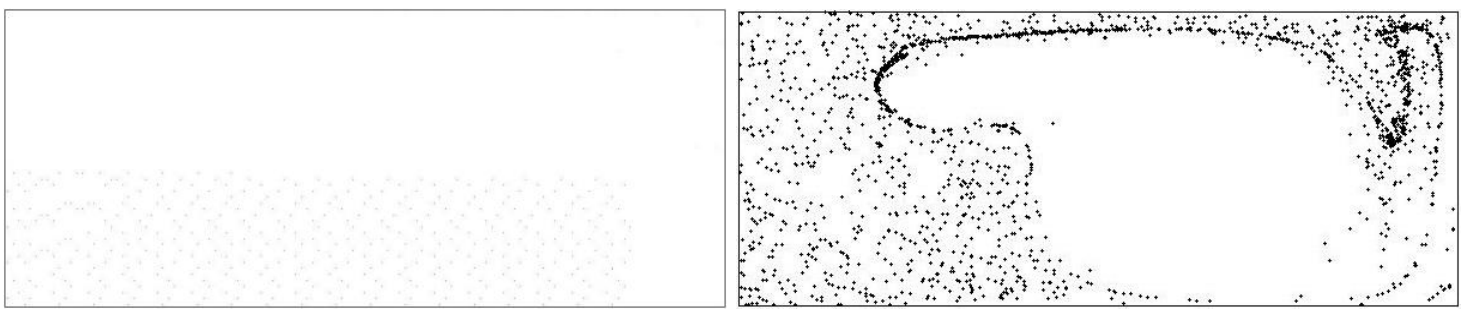

$\mathrm{t}=30$ second 
$\underline{\text { Initial Distribution of Particles: Uniform }}$

Uniform distribution of particles as an initial condition makes it easier to identify the effects Marangoni number, convective heat transfer coefficient and bottom wall thermal conditions. Figure 5.2 shows the effects of Marangoni number (Ma) and bottom wall thermal conditions (insulated or constant temperature) on the distribution of particles. The corresponding results have a convective heat transfer coefficient (h) value of $5 \mathrm{~W} / \mathrm{m}^{2} \mathrm{~K}$. Cases (a1), (b1) and (c1) have an insulated bottom and Cases (a2), (b2) and (c2) have a constant temperature bottom wall boundary condition.

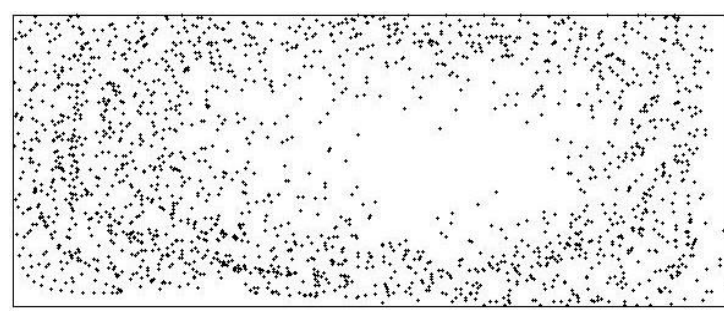

(a1)

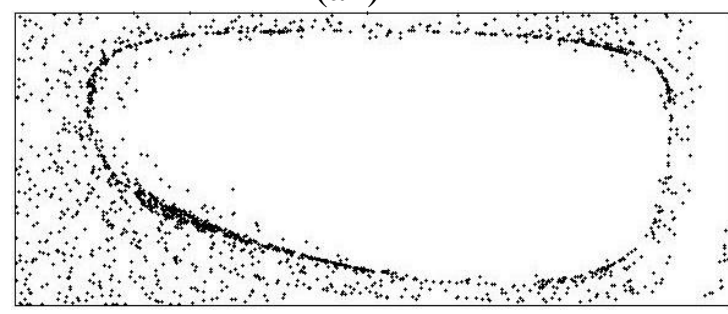

(b1)

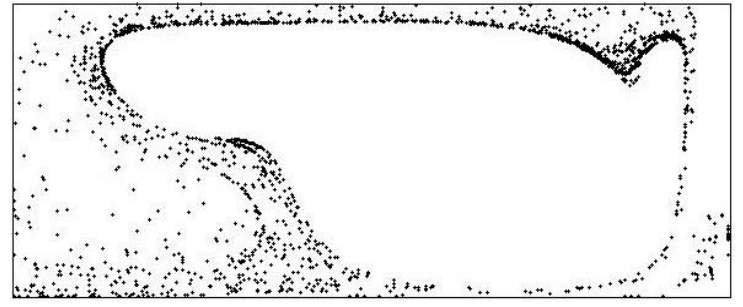

(c1)

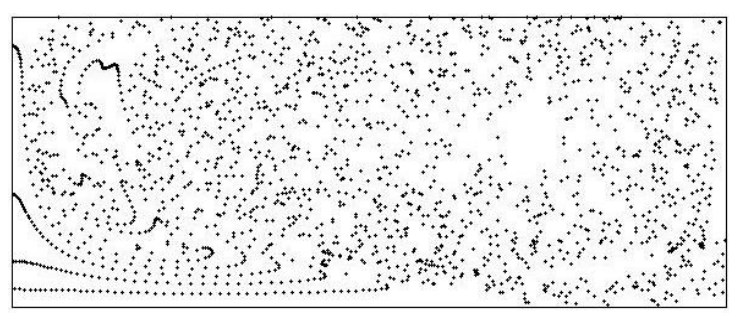

(a2)

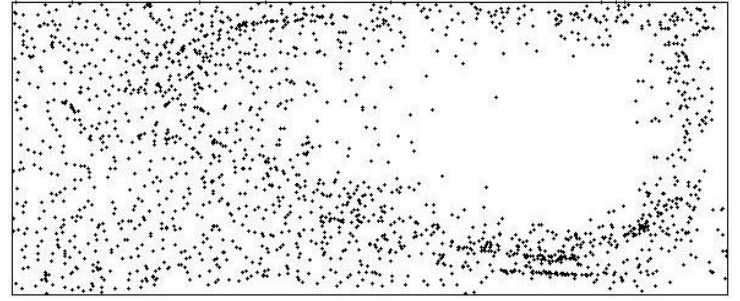

(b2)

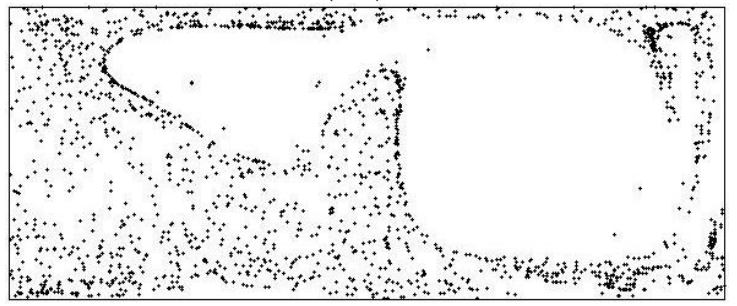

(c2)

Figure 5.2. Final particle distribution at $\mathrm{h}=5 \mathrm{~W} / \mathrm{m}^{2} \mathrm{~K}$ :

(a) $\mathrm{Ma}=4.3 \times 10^{3}$, (b) $\mathrm{Ma}=4.3 \times 10^{4}$ (c) $\mathrm{Ma}=4.3 \times 10^{5}$ 
The solidification times for Cases (a1), (b1) and (c1) are higher than Cases (a2), (b2) and (c2) mainly because of the insulated bottom boundary condition for the first set of cases. Due to the effect of insulated boundary, the distribution of the particles were dominated by the Marangoni number and the temperature at the right wall. For the cases where there was a constant temperature bottom wall, this wall temperature also accelerated the solidification process. Since the size of the particles were $40 \mathrm{~nm}$, the movement of the particles were directly related with the fluid velocity, as it was described by Brechet et al. (1991). The temperature coefficient of surface tension acts on the free surface of the domain, which is the top boundary. Surface tension force is nonexistent when the top boundary solidifies, in other words, when there is no free surface. Thus the flow becomes dominated by only buoyancy convection once the top wall completely solidifies.

Comparing Figure 5.2, Cases (a1) and (a2), the dynamic of the particles are quite interesting. The inertia and thermophoresis forces tend to push the particles outward to the fluid flow where the velocity of the flow is maximum. These resultant forces create a vortex which is defined as quasi-equilibrium zone as stated by Akber et al. (2009). At the same time period, the top wall was gradually solidifying at different rates due to the difference in bottom wall boundary condition. Constant temperature at bottom wall accelerated the solidification process, compared to insulated bottom wall. Marangoni number of $4.3 \times 10^{3}$ produced relatively lower fluid velocity. Thus a very well defined quasi-equilibrium region did not occur. Figure 5.2, Cases (b1) and (b2) are a very close resemblance of Cases (a1) and (a2), only the Marangoni number is higher. It can be 
observed that increasing the Marangoni number significantly impacted the particle distribution. Due to the increase in Marangoni number, the fluid velocity increases thus the quasi-equilibrium region gets more dominant. The solidification time decreased very slightly. Increase in fluid velocity dictated the movement of the particles in such a way that the particles followed the velocity stream line of the fluid. However, once the top wall solidified, the velocity suddenly decreased due to the omission of surface tension force. Since the buoyancy number was constant for all the cases, once the top solidified, remaining particles in the fluid region were only influenced by buoyancy. And it did not provide sufficient velocity to move the particles very much due to low Rayleigh number.

For $\mathrm{Ma}=4.3 \times 10^{5}$, the recirculation became progressively stronger when the top boundary was not solidified. However, due to increase in heat transfer resulted by higher velocity of larger Marangoni number, the top boundary eventually solidified earlier compared to previously mentioned lower Marangoni number cases. Due to higher recirculating velocity, the particles created a well-defined quasi-equilibrium state of distribution for both the insulated and constant temperature bottom boundary condition cases and can be seen from Figure 5.2, Cases (c1) and (c2).

Figure 5.3, Cases (a1-c2) follows the same case study of Figure 5.2, Cases (a1c2); except the convective heat transfer coefficient was $25 \mathrm{~W} / \mathrm{m}^{2} \mathrm{~K}$ for all the cases in Figure 5.3. It can be observed that increasing the value of convective heat transfer coefficient (h) restricted the movement of the particles very slightly. Cases (a1) and (a2) in Figures 5.2 and 5.3 have a very similar final distribution of particles because at lower Marangoni number, two relatively similar low convective heat transfer coefficient will 
not produce significantly different results, mainly because of the lower velocities produced by low Marangoni numbers. For both of the cases, particles got sufficient time to evenly distribute until solidification.

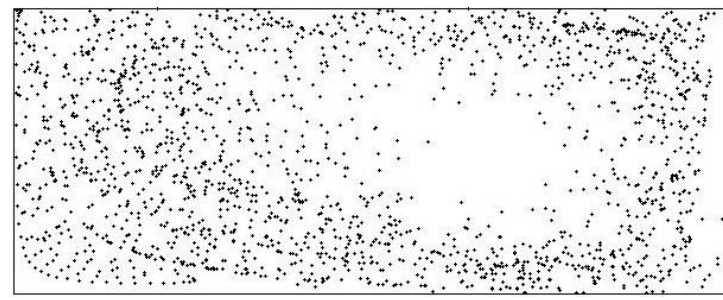

(a1)

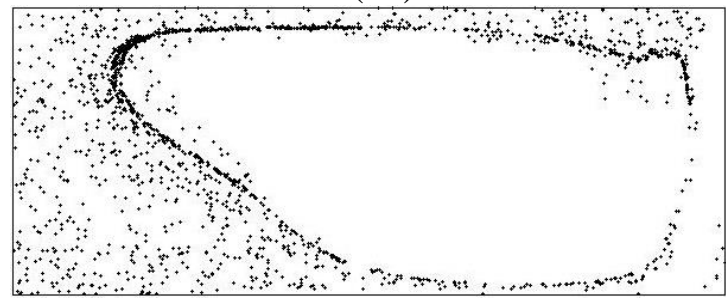

(b1)

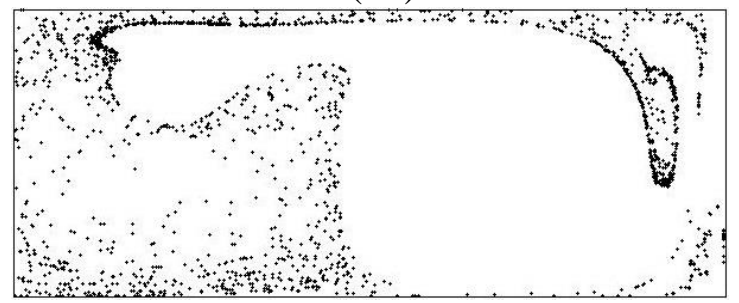

(c1)

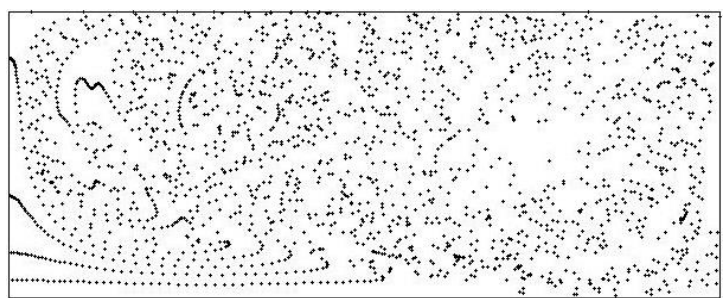

(a2)

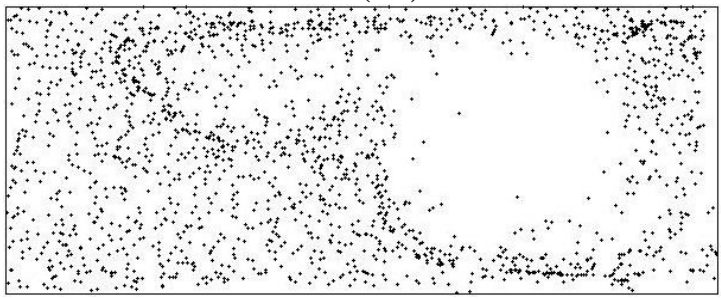

(b2)

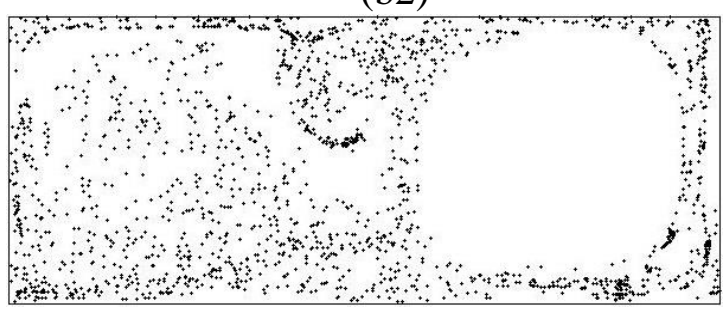

(c2)

Figure 5.3. Final particle distribution at $\mathrm{h}=25 \mathrm{~W} / \mathrm{m}^{2} \mathrm{~K}$ :

(a) $\mathrm{Ma}=4.3 \times 10^{3}$, (b) $\mathrm{Ma}=4.3 \times 10^{4}$ (c) $\mathrm{Ma}=4.3 \times 10^{5}$

Comparing Figures 5.2 and 5.3, Case (b1), it can be observed that due to relatively high convective heat transfer coefficient, Figure 5.3, Case (b1) has a slightly different shape of concentrated particles in the geometry. Higher rate of solidification was responsible this change in shape of the concentrated particles, which restricts the movement of particles very slightly by solidifying the top wall a bit early. Between Figure 5.2 and 5.3, Case (c2), an interesting phenomena can be observed. Due to higher 
convective heat transfer coefficient (h), top wall of the Figure 5.3, Case (c2) solidified slightly earlier than a Figure 5.2, Case (c2). Thus the movement of the particles became slightly restricted and the unique shape of concentrated particles observed throughout the geometry in Figure 5.2, Case (c2) is only visible in the right side of the geometry in Figure 5.3, Case (c2).

Figure 5.4, Cases (a1-c2) have a very similar phenomena as Figures 5.2-5.3, Cases (a1-c2) except the convective heat transfer coefficient was $50 \mathrm{~W} / \mathrm{m}^{2} \mathrm{~K}$ in all the cases of Figure 5.4.

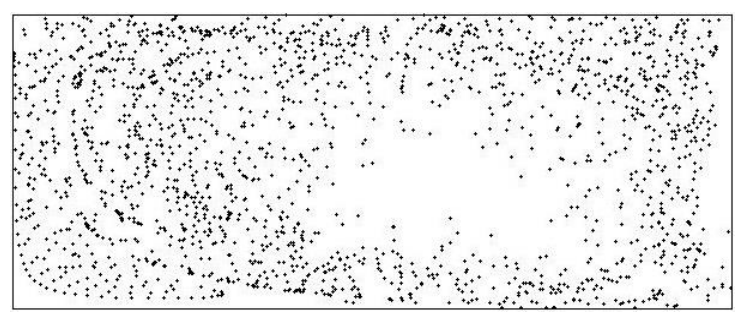

(a1)

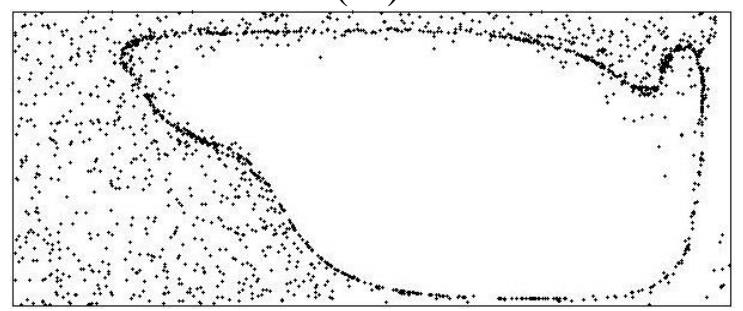

(b1)

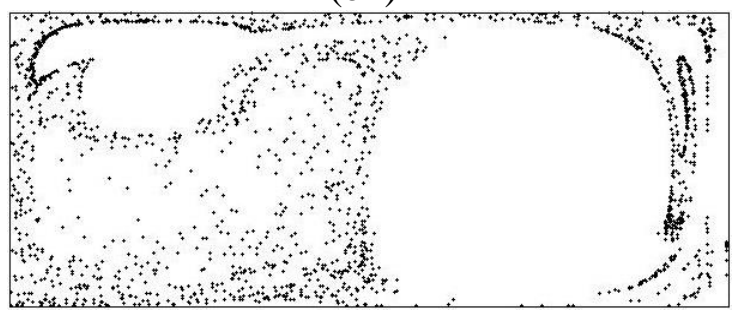

(c1)

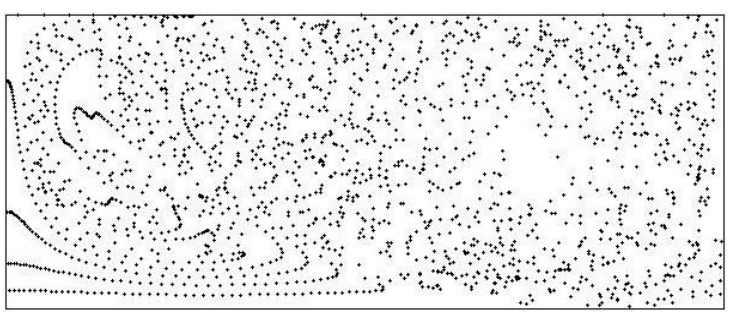

(a2)

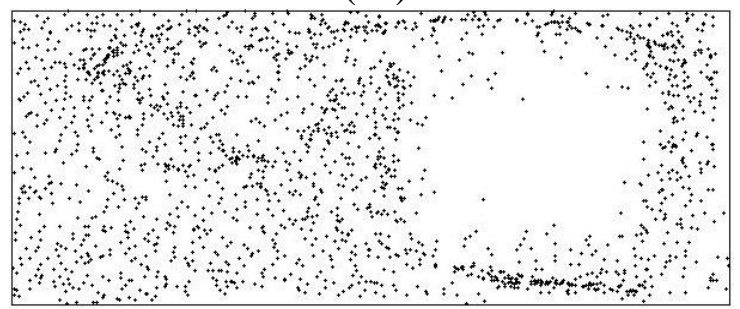

(b2)

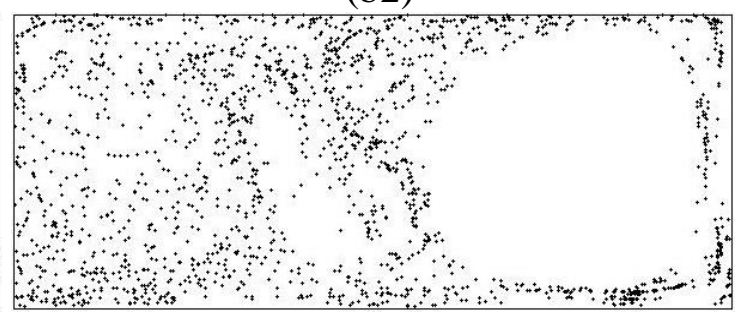

(c2)

Figure 5.4. Final particle distribution at $\mathrm{h}=50 \mathrm{~W} / \mathrm{m}^{2} \mathrm{~K}$ :

(a) $\mathrm{Ma}=4.3 \times 10^{3}$, (b) $\mathrm{Ma}=4.3 \times 10^{4}$ (c) $\mathrm{Ma}=4.3 \times 10^{5}$ 
The distribution of particles are very similar between Figures 5.3 and 5.4. The slight difference, which can be observed by comparing them side by side, are mainly due to a little higher rate of solidification in Figure 5.4.

Figure 5.5, Cases (a1-c2) shows the effect of convective heat transfer coefficient of $146 \mathrm{~W} / \mathrm{m}^{2} \mathrm{~K}$ on different Marangoni numbers and bottom wall conditions. Cases in Figure 5.5 exhibited higher rate of solidification compared to previous cases in Figures

\section{2-5.4.}

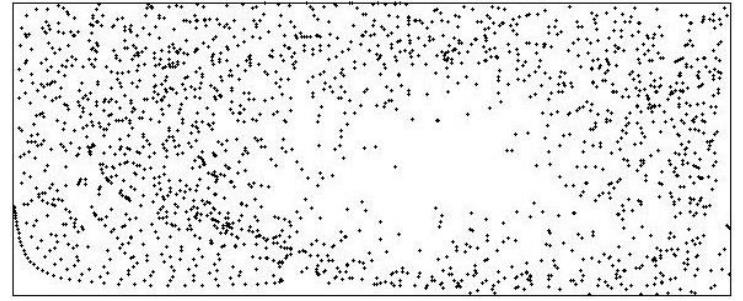

(a1)

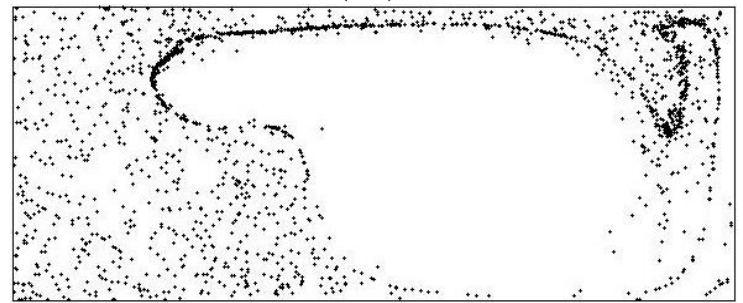

(b1)

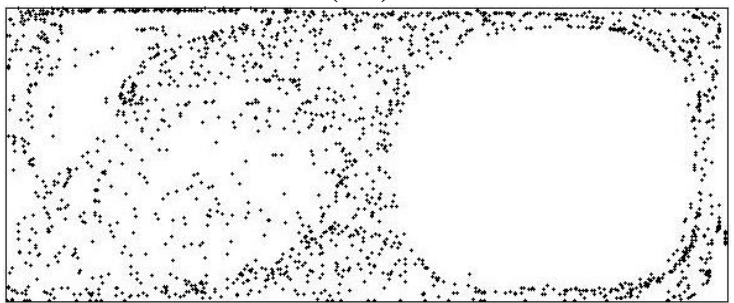

(c1)

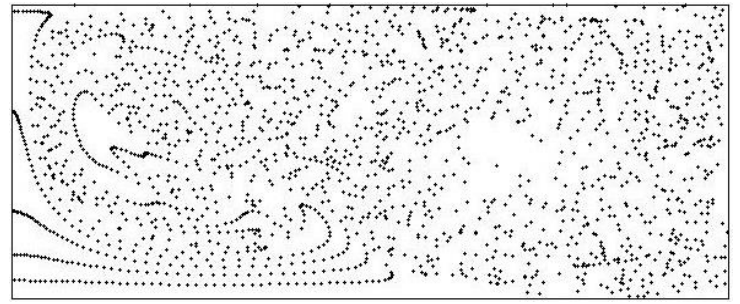

(a2)

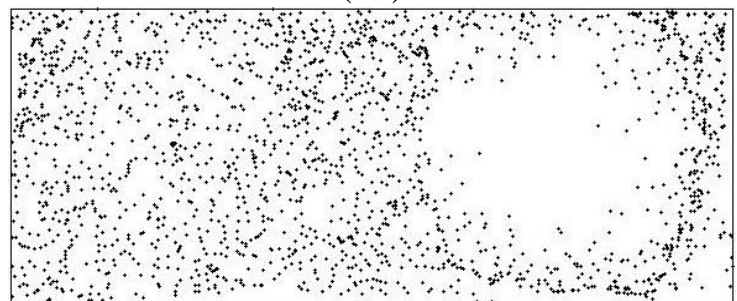

(b2)

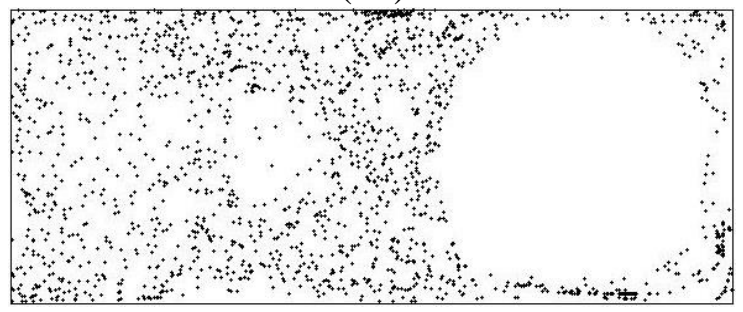

(c2)

Figure 5.5. Final particle distribution at $\mathrm{h}=146 \mathrm{~W} / \mathrm{m}^{2} \mathrm{~K}$ :

(a) $\mathrm{Ma}=4.3 \times 10^{3}$, (b) $\mathrm{Ma}=4.3 \times 10^{4}$ (c) $\mathrm{Ma}=4.3 \times 10^{5}$

At $\mathrm{Ma}=4.3 \times 10^{3}$ in Figure 5.5, Cases (a1) and (a2), the final distribution of particles are very similar as Cases (a1) and (a2) having $\mathrm{Ma}=4.3 \times 10^{3}$ in Figures 5.2-5.4. 
It indicates that at a lower Marangoni number, the rate of solidification does not have a lot of effects on movement of particles. Due to lower velocity produced by lower Marangoni number, the particles did not form a well-defined quasi-steady state region. This phenomena can be observed in all the cases with $\mathrm{Ma}=4.3 \times 10^{3}$, which includes Cases (a1) and (a2) in Figures 5.2-5.8.

In Figure 5.5, Cases (b1) and (b2), Marangoni number of $4.3 \times 10^{4}$ produced slightly different shape than what have been observed at a lower convective heat transfer coefficient values in Figures 5.2-5.4 for same Marangoni number. Higher rate of solidification of top wall and entire geometry is solely responsible for this small change in shape. Figure 5.5, Case (c1) shows a relatively different concentrated particle distribution. In Figures 5.2-5.4, Case (c1), a well-defined shape with concentrated particles and void in the middle can be seen on the left hand side of the geometry. That shape on the left hand side of the geometry is almost gone in Figure 5.5, Case (c1). It is related to the higher Marangoni number of $4.3 \times 10^{5}$. At any convective heat transfer coefficient value, higher or lower, $\mathrm{Ma}=4.3 \times 10^{5}$ has a significant impact on the particle movement due to higher velocity produced. If the convective heat transfer coefficient is lower, that means lower rate of solidification on top wall; particle will be distributed in a very highly concentrated form following the quasi-steady equilibrium region. However, when the value of convective heat transfer coefficient (h) increases, the top wall gets solidified relatively quickly. This quicker rate of solidification restricted the movement of the particles when they were trying to create the well-defined shape with concentrated particles with void in the middle of them, on left hand side of the geometry. Similar 
phenomena can be observed while comparing Case (c2) between Figure 5.2 and Figures

\section{3-5.5.}

The effect of higher rate of solidification can also be observed in most of the cases of Figures 5.6 and 5.7. The only major difference is the Case (b1), where the welldefined shape with concentrated particles and void in the middle shown in Figures 5.2-

\section{5 becomes less visible in Figures 5.6-5.7.}

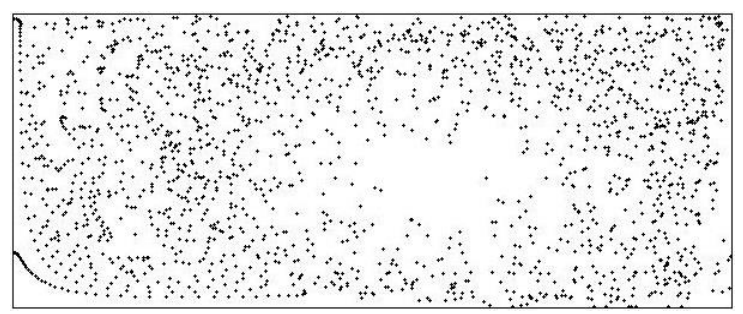

(a1)

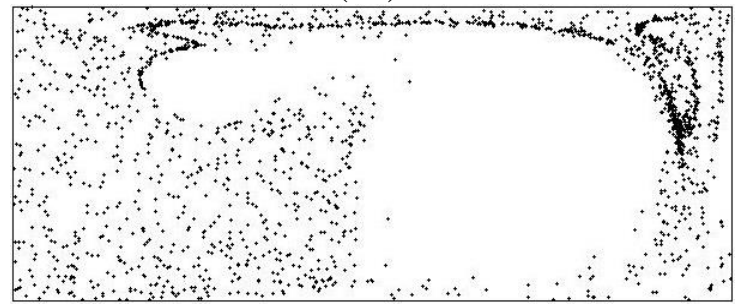

(b1)

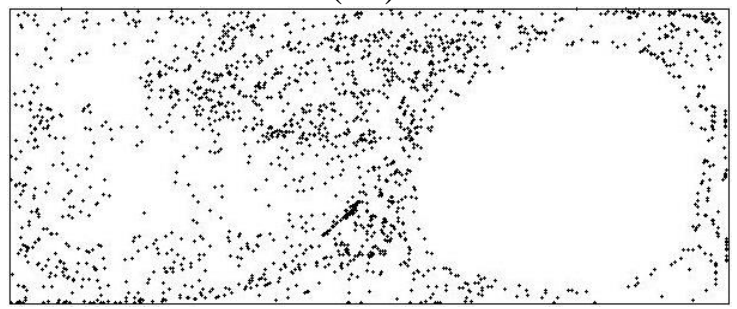

(c1)

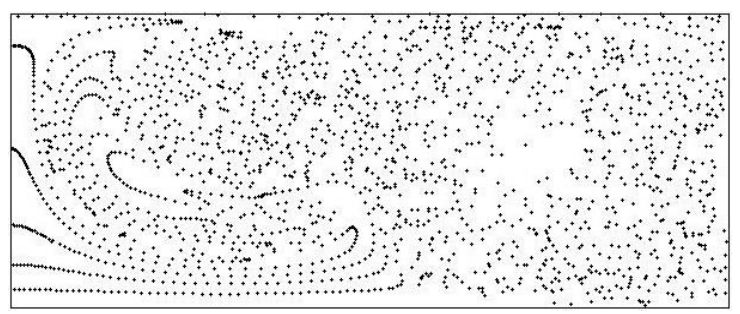

(a2)

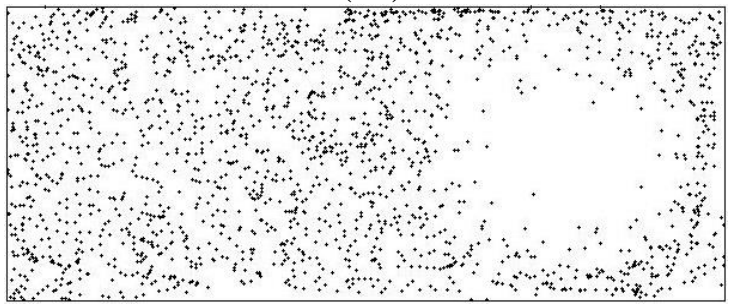

(b2)

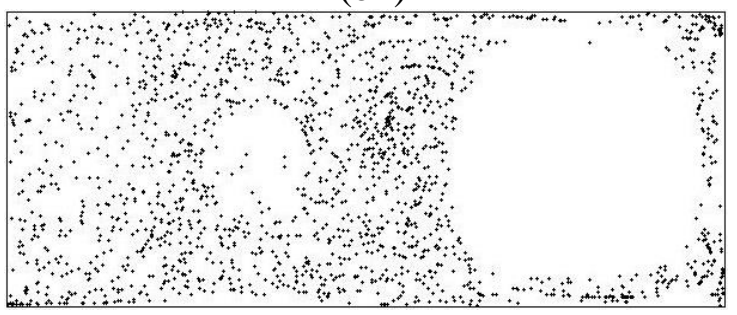

(c2)

Figure 5.6. Final particle distribution at $\mathrm{h}=300 \mathrm{~W} / \mathrm{m}^{2} \mathrm{~K}$ :

(a) $\mathrm{Ma}=4.3 \times 10^{3}$, (b) $\mathrm{Ma}=4.3 \times 10^{4}$ (c) $\mathrm{Ma}=4.3 \times 10^{5}$

Figure 5.8 exhibits the cases with convective heat transfer coefficient value of 600 $\mathrm{W} / \mathrm{m}^{2} \mathrm{~K}$, which produced the highest rate of solidification at different Marangoni number in this present study. 


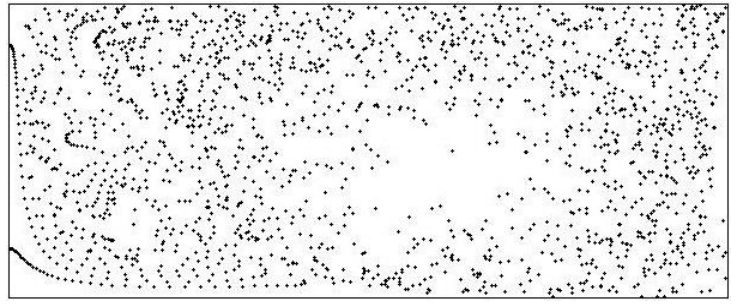

(a1)

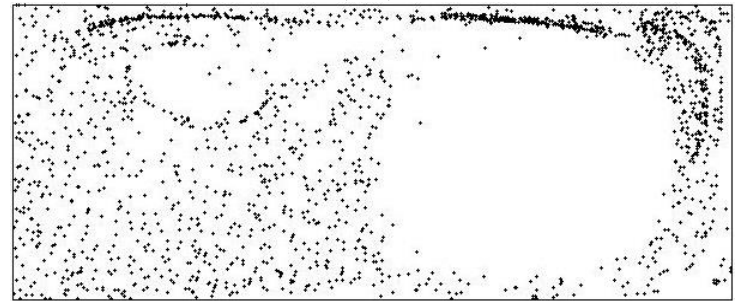

(b1)

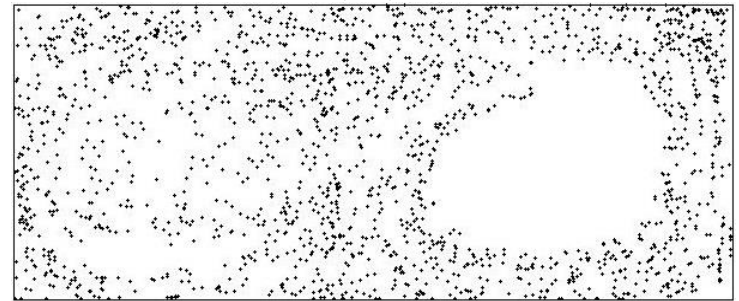

(c1)

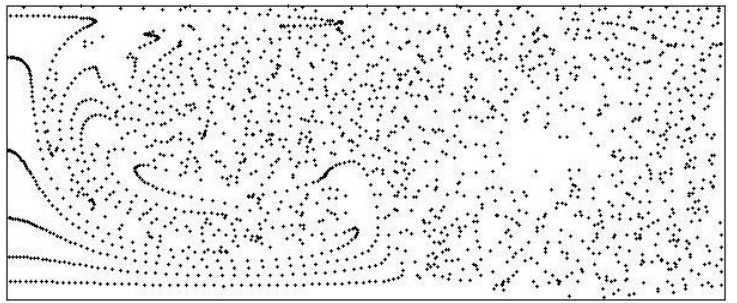

(a2)

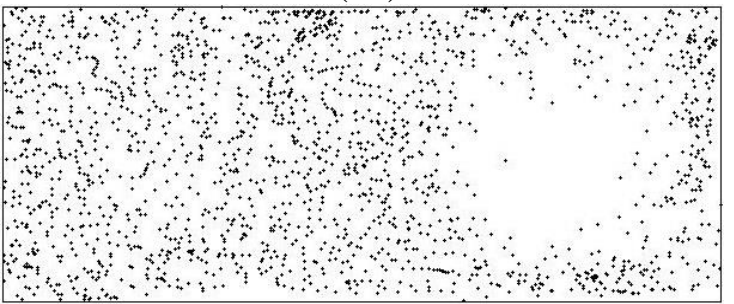

(b2)

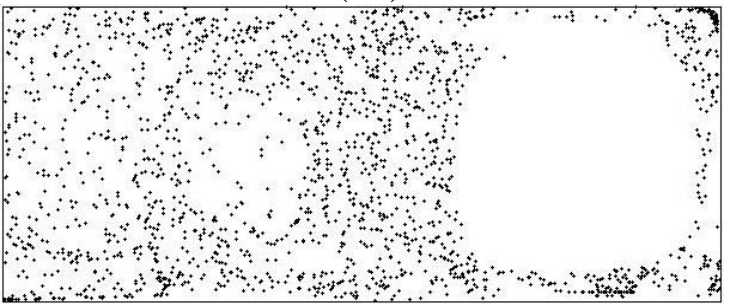

(c2)

Figure 5.7. Final particle distribution at $\mathrm{h}=400 \mathrm{~W} / \mathrm{m}^{2} \mathrm{~K}$ :

(a) $\mathrm{Ma}=4.3 \times 10^{3}$, (b) $\mathrm{Ma}=4.3 \times 10^{4}$ (c) $\mathrm{Ma}=4.3 \times 10^{5}$

The overall movement of the particles in Figure 5.8 decreased significantly compared to cases with low convective heat transfer coefficient (h), due to quick solidification of the top boundary. The interesting fact is that, even a small amount of time before solidification of the top wall is sufficient at high Marangoni number, which accelerates the movement of the particles toward the quasi equilibrium zone and creates a very well defined quasi-equilibrium state. This can be seen by comparing Figure 5.8, Cases (c1) and (c2), where both exhibits $\mathrm{Ma}=4.3 \times 10^{5}$. 


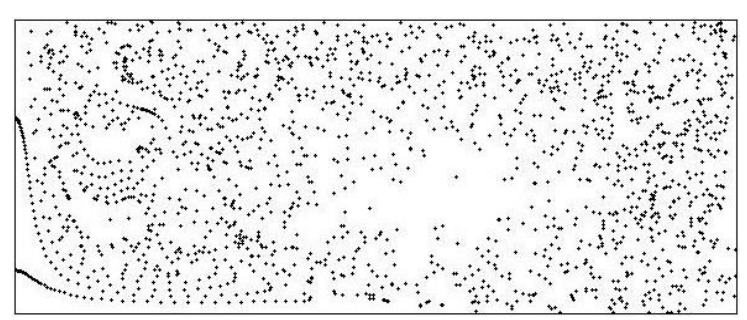

(a1)

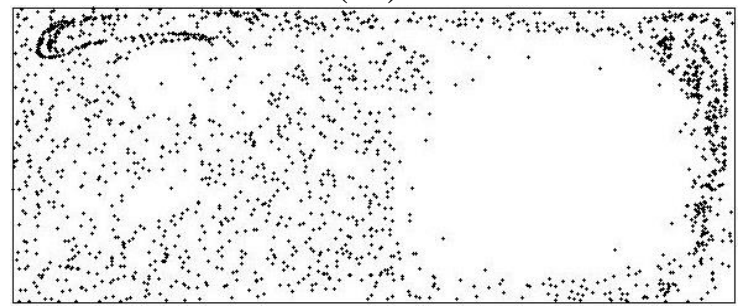

(b1)

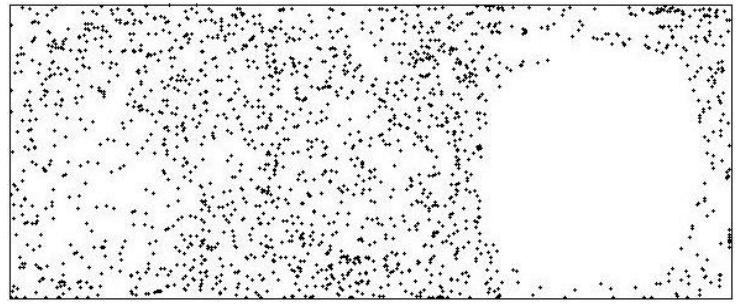

(c1)

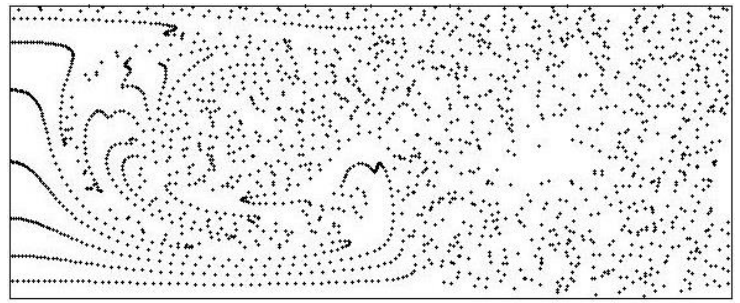

(a2)

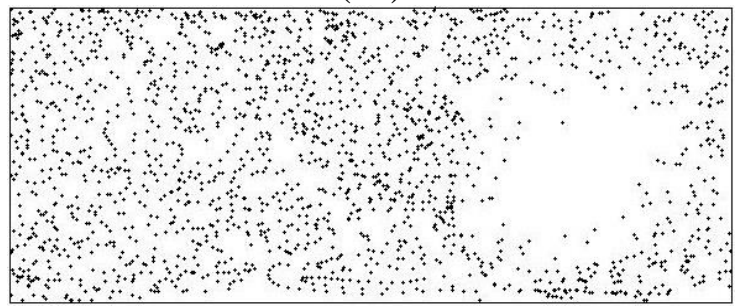

(b2)

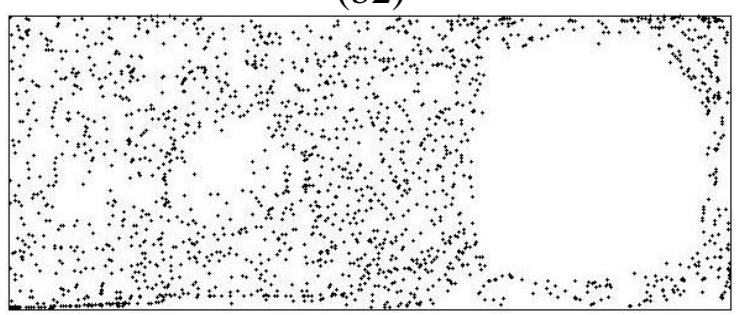

(c2)

Figure 5.8. Final particle distribution at $\mathrm{h}=600 \mathrm{~W} / \mathrm{m}^{2} \mathrm{~K}$ :

(a) $\mathrm{Ma}=4.3 \times 10^{3}$, (b) $\mathrm{Ma}=4.3 \times 10^{4}$ (c) $\mathrm{Ma}=4.3 \times 10^{5}$

\section{$\underline{\text { Initial Distribution of Particles: Non-uniform }}$}

Different initial distribution of particles were considered to see their effects on the final distribution of particles after solidification. The values of Marangoni number (Ma) and convective heat transfer coefficient (h) used for numerical analysis were:

- $\mathrm{Ma}=4.3 \times 10^{3}, 4.3 \times 10^{4}$ and $4.3 \times 10^{5}$

- $\mathrm{h}=5,146$ and $600 \mathrm{~W} / \mathrm{m}^{2} \mathrm{~K}$

For all the cases, constant temperature and insulated bottom boundary walls were used. The non-uniform initial distribution of particles were previously shown in Figure 4.5 along with the computational matrix in Table 4.2. 
Figures 5.9 and 5.10 show the effects of different initial distribution of particles when $\mathrm{h}=5 \mathrm{~W} / \mathrm{m}^{2} \mathrm{~K}$ and $\mathrm{Ma}=4.3 \times 10^{3}$. Figure 5.9 has insulated bottom wall and Figure 5.10 has constant temperature bottom wall boundary conditions. All of these cases exhibited the slowest rate of solidification, due to the lowest values of convective heat transfer coefficient (h) and Marangoni number (Ma). As explained earlier, particles move along the contour with higher fluid velocity. Thus, due to centrifugal force, it creates a vortex consisting of large number of particles. In Figure 5.9, Case 1 (Top thick), since the particles were initially situated at the top region of the geometry, they experienced the maximum possible velocity contour of $\mathrm{Ma}=4.3 \times 10^{3}$, as maximum velocity was situated towards the top of the geometry due to free surface. Thus it produced similar final distribution of particles after solidification for the similar case (Figure 5.2, Case (a1) with $\mathrm{h}=5 \mathrm{~W} / \mathrm{m}^{2} \mathrm{~K}$ and $\mathrm{Ma}=4.3 \times 10^{3}$ ) with uniform distribution of particles. The distribution of velocity was explained in Figure 5.1. For Figure 5.9, Case 2 (Bottom thick), particles were concentrated at the bottom half of the geometry. The contours with higher velocities are located at the free surface, so particles tend to move towards that contour during their diffusion, due to centrifugal force. Since they were moved from the bottom of the geometry by the high velocity vectors located on the top and right sides, they remains slightly more concentrated than Figure 5.9, Case 1 (Top thick). That is why the void with no particles in it, is slightly prominent in Figure 5.9, Case 2 (Bottom thick), compared to Figure 5.9, Case 1 (Top thick). Similar phenomena happened when the initial distribution of particles were concentrated in the left half of the geometry, as seen in Figure 5.9, Case 3 (Left thick). From Figure 5.1, it was clearly visible that high velocity region of the fluid 
flow is situated on the top and right side of the geometry. Thus particles got trapped in a high velocity contour in a concentrated form similar to their initial distribution and kept following those contours till the solidification of the fluid. For Figure 5.9, Case 4 (Right thick), particles were initially placed where the contours with higher fluid velocity existed. Thus they got more evenly distributed compared to Figure 5.9, Case 3(Left thick), due to experiencing the maximum possible velocity contours at the lowest Marangoni number. Figure 5.9, Cases 5-8 follows similar trend as Figure 5.9, Cases 1-4. Particles were initially very concentrated for Cases 5-8. Thus the amount of void region with no particles in it is significantly higher because they got trapped in higher velocity contours and could not leave the quasi equilibrium region. Case 7 (Left thin) is of high interest because particles remained very concentrated during the whole solidification process.

Figure 5.10 has similar parameters of cases except the bottom wall was at a constant temperature boundary condition. This constant temperature bottom wall increased the rate of solidification which made the movement of particles more limited, which resulted in less amount of time for movement. The trend of final distribution of particles between similar cases in Figures 5.9 and 5.10 are comparable. In Figure 5.10, particles followed all the phenomena experienced in Figure 5.9. 


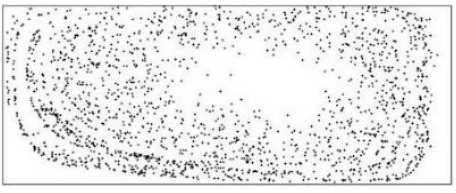

Case 1(Top thick)

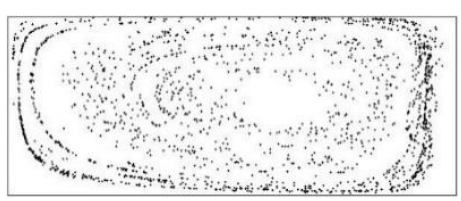

Case 5(Top thin)

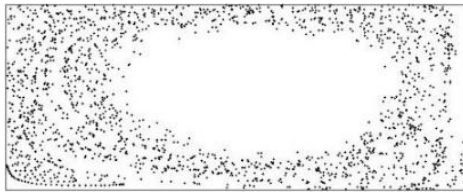

Case 2(Bottom thick)

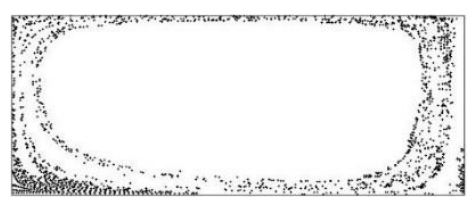

Case 6(Bottom thin)

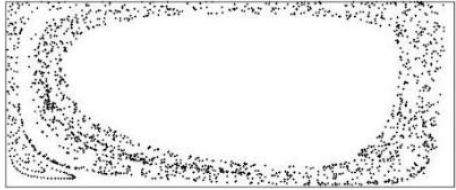

Case 3(Left thick)

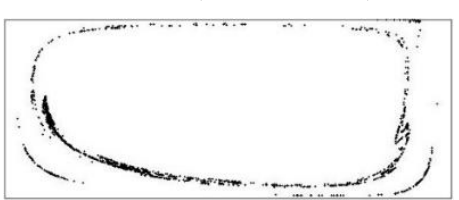

Case 7(Left thin)

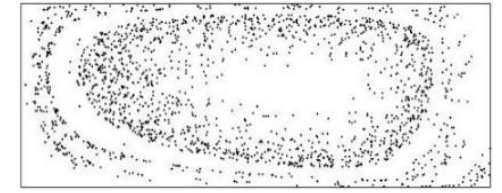

Case 4(Right thick)

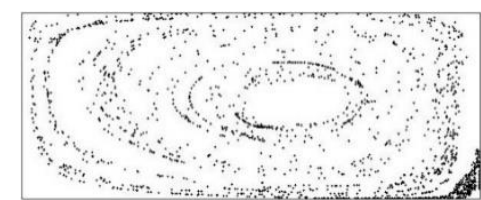

Case 8(Right thin)

Figure 5.9. Final particle distribution at $\mathrm{h}=5 \mathrm{~W} / \mathrm{m}^{2} \mathrm{~K}, \mathrm{Ma}=4.3 \times 10^{3}$ and insulated bottom wall

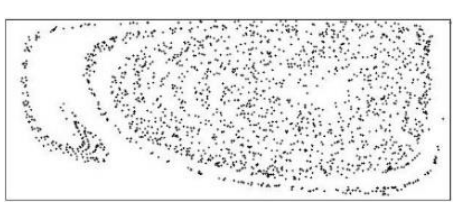

Case 1(Top thick)

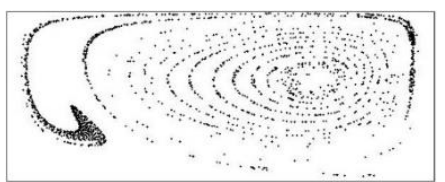

Case 5(Top thin)

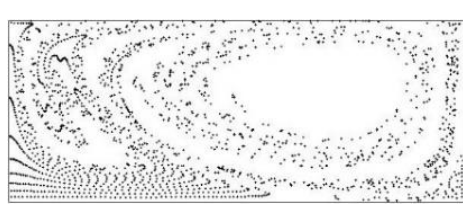

Case 2(Bottom thick)

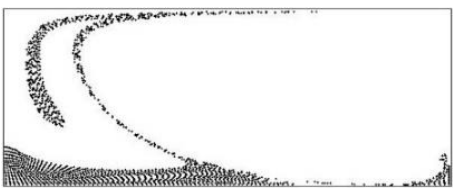

Case 6(Bottom thin)

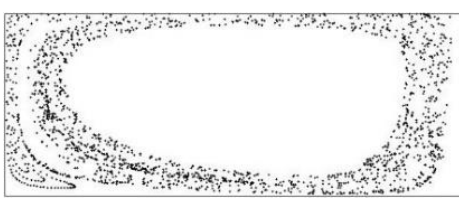

Case 3(Left thick)

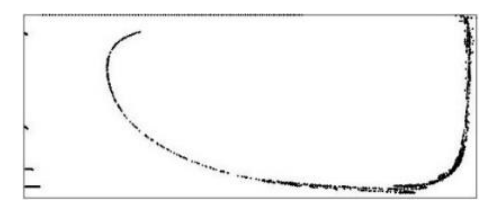

Case 7(Left thin)

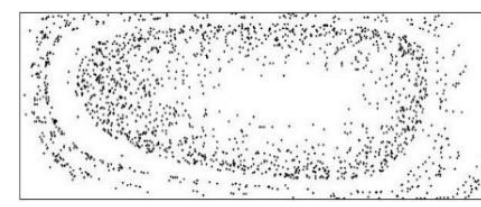

Case 4(Right thick)

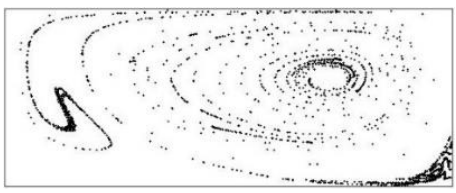

Case 8(Right thin)

Figure 5.10. Final particle distribution at $\mathrm{h}=5 \mathrm{~W} / \mathrm{m}^{2} \mathrm{~K}, \mathrm{Ma}=4.3 \times 10^{3}$ and constant temperature bottom wall 
For some of these cases in Figure 5.10, they got trapped in the solidified region as highly concentrated entity due to higher rate of solidification experienced in Figure 5.10, Cases 5-8. Thus particles in Figure 5.10, Cases 5-8 were even more concentrated than Figure 5.9, Cases 5-8. It is clearly visible by comparing above mentioned cases between Figures 5.9 and 5.10.

Figures 5.11 and 5.12 share similar process parameters as Figures 5.9 and 5.10, except the convective heat transfer coefficient was set to $146 \mathrm{~W} / \mathrm{m}^{2} \mathrm{~K}$. An increase in convective heat transfer coefficient accelerates the rate of solidification. Thus particles get even less time of movement before getting trapped in the solidified region. The movement characteristics of different cases in Figures 5.9 and 5.10 holds somewhat true for similar cases in Figures 5.11 and 5.12. The similar diffusion characteristics or phenomena between these figures are as follows: similar structures of final distribution of particles, similar shapes of empty spaces in the geometry with no particles in it, concentrated final distribution of particles in the different region of the geometry, less movement of particles when the bottom wall was at constant temperature etc. Due to redundancy, all the minor differences are not mentioned here. Those can be easily identified by comparing Figure 5.9-5.12 side by side. Figure 5.12 Cases 6-7 revealed a very interesting finding. Comparing these with Figure 5.10, Cases 6-7, it can be observed that reduction in solidification time of the geometry in Figure 5.12, Cases 6-7 was so significant that particles did not have sufficient movement from initial distribution to final distribution. 


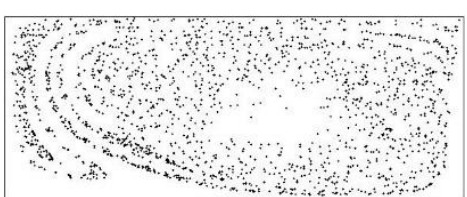

Case 1(Top thick)

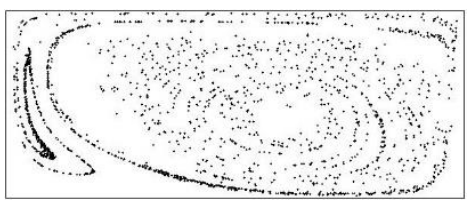

Case 5(Top thin)

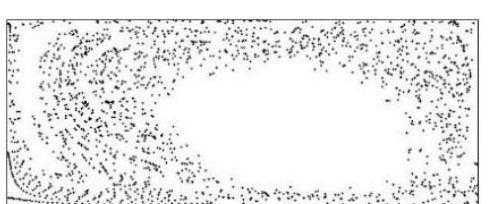

Case 2(Bottom thick)

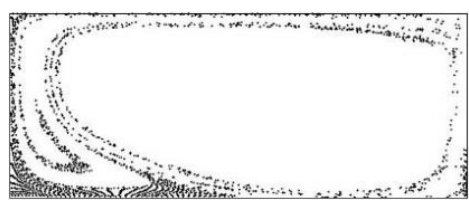

Case 6(Bottom thin)

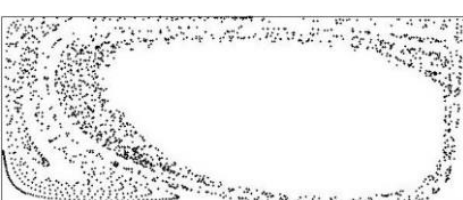

Case 3(Left thick)

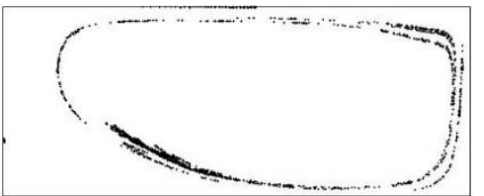

Case 7(Left thin)

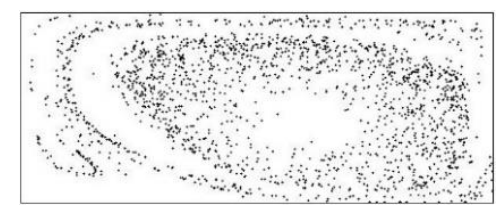

Case 4(Right thick)

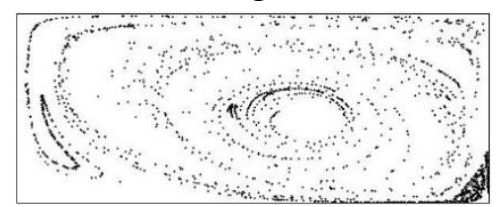

Case 8(Right thin)

Figure 5.11. Final particle distribution at $\mathrm{h}=146 \mathrm{~W} / \mathrm{m}^{2} \mathrm{~K}, \mathrm{Ma}=4.3 \times 10^{3}$ and insulated bottom wall

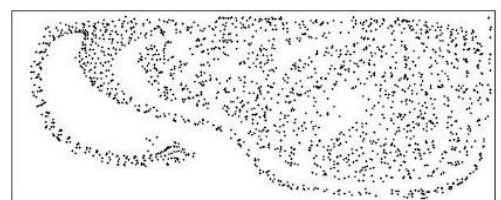

Case 1(Top thick)

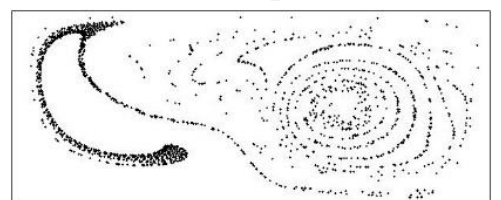

Case 5(Top thin)

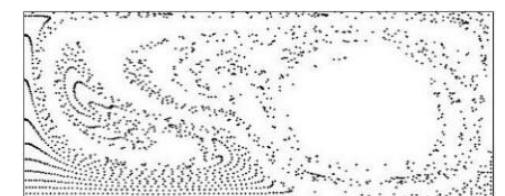

Case 2(Bottom thick)

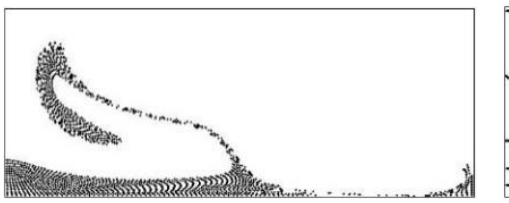

Case 6(Bottom thin)

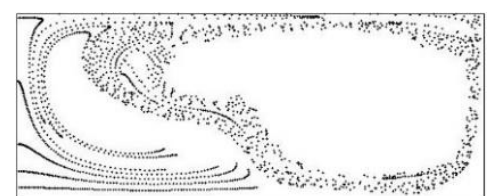

Case 3(Left thick)

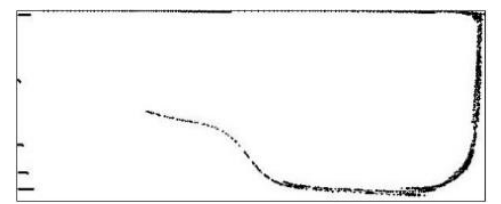

Case 7(Left thin)

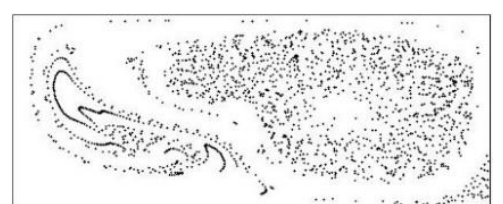

Case 4(Right thick)

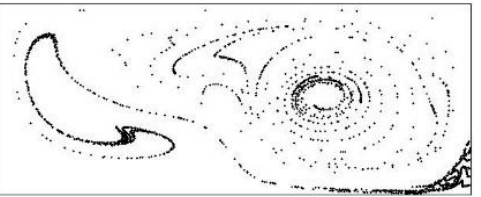

Case 8(Right thin)

Figure 5.12. Final particle distribution at $\mathrm{h}=146 \mathrm{~W} / \mathrm{m}^{2} \mathrm{~K}, \mathrm{Ma}=4.3 \times 10^{3}$ and constant temperature bottom wall 
In Figure 5.12, Case 6 (Bottom thin), particles were trying to go upward toward the contour with higher velocity in a clockwise rotation, but failed to reach to the top due to higher rate of solidification of the geometry. Similar phenomena can also be observed in Figure 5.12, Case 7 (Left thin), where particles tried to move in the similar shape as seen in Figure 5.10, Case 7 (Left thin), but got interrupted due to solidification of the geometry.

Particle distribution after solidification shown in Figure 5.13 has a very close resemblance with the cases in Figure 5.11, with minor differences. Convective heat transfer coefficient (h) was the only difference in terms of boundary conditions, which was set at $600 \mathrm{~W} / \mathrm{m}^{2} \mathrm{~K}$ for all the cases in Figure 5.13. A constant Marangoni number (Ma) of $4.3 \times 10^{3}$ was used. Higher value of convective heat transfer coefficient increases the rate of solidification. Thus particles get even less time to travel. All the cases in Figure 5.13 resemble this phenomena compared to cases in Figure 5.11. Due to higher rate of solidification, particles get less time for their movement and get trapped quickly in the solidified region of the geometry. It can be clearly observed by comparing each individual cases between Figures 5.11 and 5.13. For example, Comparing Case 6 (Bottom thin) between Figures 5.11 and 5.13, it can be seen that particles were trying to move from the bottom of the geometry towards top in clockwise manner following the flow of the fluid. However, due to higher rate of solidification in Figure 5.13, Case 6 (Bottom thin); particles started moving towards the top but got trapped in the solidified titanium before even hitting the right wall near the top boundary. 


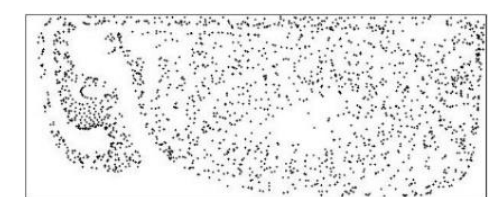

Case 1(Top thick)

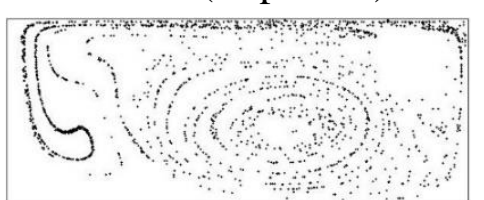

Case 5(Top thin)

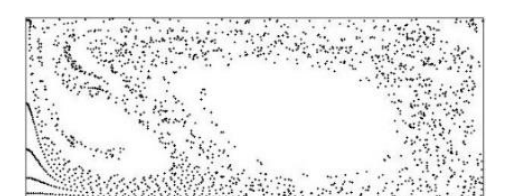

Case 2(Bottom thick)

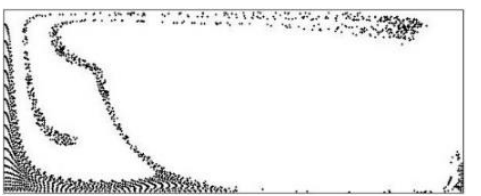

Case 6(Bottom thin)

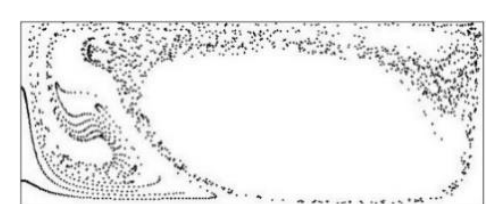

Case 3(Left thick)

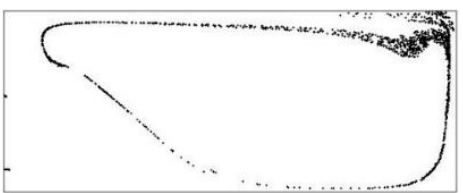

Case 7(Left thin)

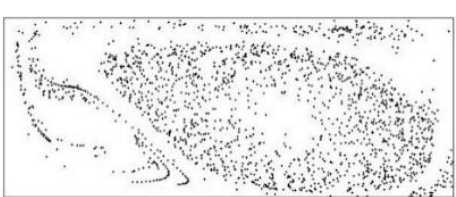

Case 4(Right thick)

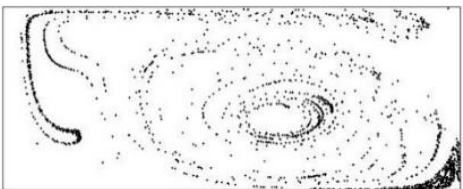

Case 8(Right thin)

Figure 5.13. Final particle distribution at $\mathrm{h}=600 \mathrm{~W} / \mathrm{m}^{2} \mathrm{~K}, \mathrm{Ma}=4.3 \times 10^{3}$ and insulated bottom wall

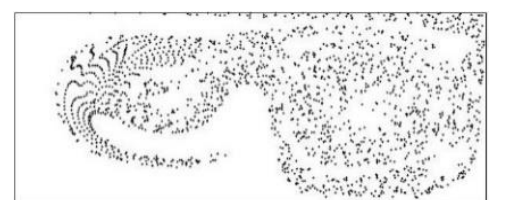

Case 1(Top thick)

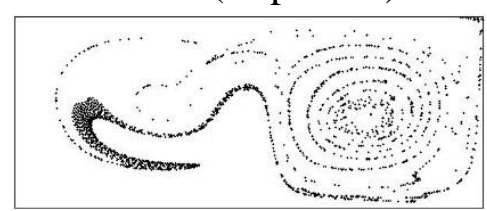

Case 5(Top thin)

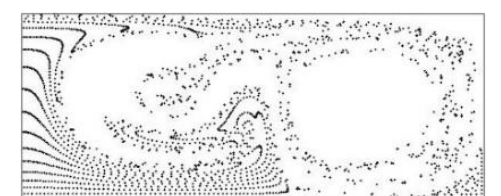

Case 2(Bottom thick)

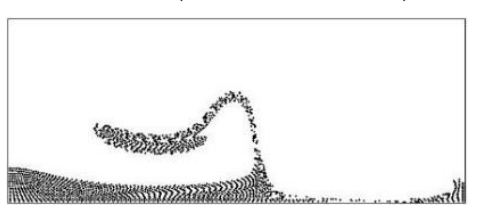

Case 6(Bottom thin)

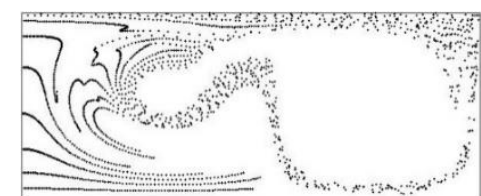

Case 3(Left thick)

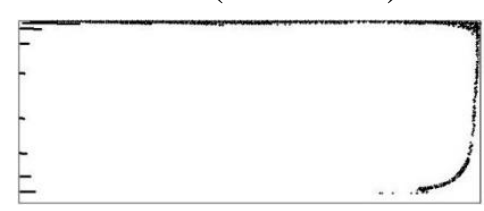

Case 7(Left thin)

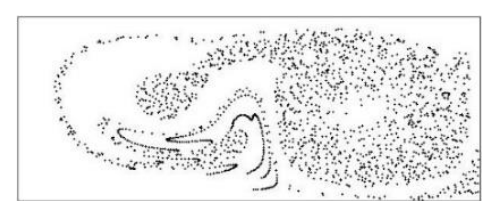

Case 4(Right thick)

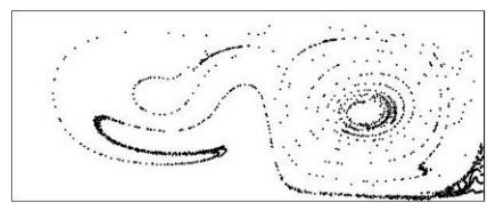

Case 8(Right thin)

Figure 5.14. Final particle distribution at $\mathrm{h}=600 \mathrm{~W} / \mathrm{m}^{2} \mathrm{~K}, \mathrm{Ma}=4.3 \times 10^{3}$ and constant temperature bottom wall 
Whereas in Figure 5.11, Case 6(Bottom thin), particles were easily able to that and went even further in a clockwise flow, in terms of movement. The differences in the shape of final concentrated particle distribution between Figures 5.11 and 5.13, Case 7 (left thin) is also associated with the higher rate of solidification in Figure 5.13 due to higher convective heat transfer coefficient value (h) for the cases in Figure 5.13.

Similar phenomena can be observed between Figures 5.12 and 5.14. Due to constant temperature bottom wall boundary condition, the movement of the particles gets even more restricted due to higher rate of solidification in Figure 5.14. Difference in final particle distribution between all the cases in Figures 5.12 and 5.14 are very visible. Higher rate of solidification in Figure 5.14, compared to Figure 5.12, was solely responsible for the differences.

Figure 5.15 have cases with same initial distribution of particles as before, but the Marangoni number was set at $4.3 \times 10^{4}$. Higher Marangoni number produced higher velocity of fluid, which made it easier for particles to move from a concentrated initial distribution and eventually fall in to the quasi equilibrium region. The characteristics of this quasi equilibrium region were explained earlier in this study. All the cases in figure 5.15 have lowest convective heat transfer coefficient value of $5 \mathrm{~W} / \mathrm{m}^{2} \mathrm{~K}$. Thus the rate of solidification was lower. High velocity of fluid flow (provided by higher Marangoni number) and lower rate of solidification (provided by lower convective heat transfer coefficient) gave the particles sufficient time and velocity to move towards the contour of high velocity, get concentrated in the quasi equilibrium region and create empty spaces in the geometry where there are no particles available. This phenomena can be clearly 
observed for all the cases in Figure 5.15. The minor differences can still be seen due to different initial distribution of particle and their initial positioning with respect to maximum velocity contour. Same phenomena does not hold true for cases in Figure 5.16. The main difference between Figures 5.15 and 5.16 was the constant temperature wall boundary condition for all the cases in Figure 5.16. This constant temperature wall increased the rate of solidification significantly. Thus, even with a higher Marangoni number (Ma) of $4.3 \times 10^{4}$, particles did not get sufficient time for their movement. That is why the final particle distribution after solidification is vastly different between all the cases in Figures 5.15 and 5.16. Cases where particles were initially situated at the top (Cases 1 and 5) or near the right wall (Cases 4 and 8) in Figure 5.16, the particles were distributed in a quasi-equilibrium region after solidification. They are not as concentrated as the similar cases in Figure 5.15. That is due to their higher rate of solidification which slightly restricted further movement of particles toward the quasi equilibrium region due to having less time for travel. Cases 6 and 7 in Figure 5.16 experienced slightly different concentration of final distribution of particles than the rest of the cases in Figure 5.16. Since the contours with higher velocity are located at the free surface, particle tend to move towards to that contour during their diffusion, due to centrifugal force. Since they were moved from the bottom of the geometry and the major velocity vectors were located on the top and right hand side, they remains slightly more concentrated than rest of the cases in Figure 5.16. 


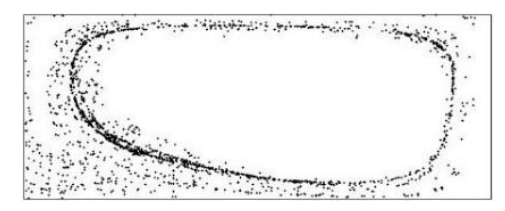

Case 1(Top thick)

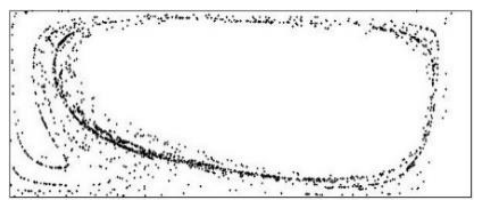

Case 5(Top thin)

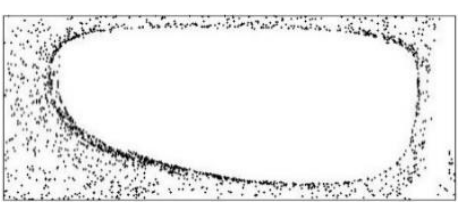

Case 2(Bottom thick)

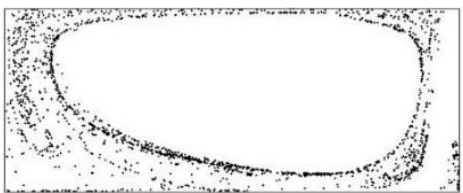

Case 6(Bottom thin)

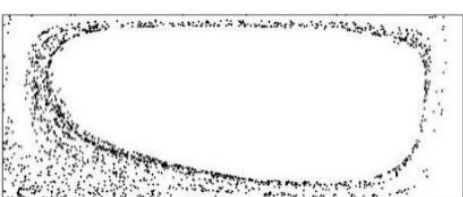

Case 3(Left thick)

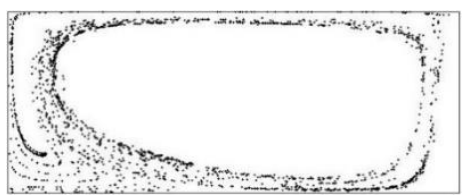

Case 7(Left thin)

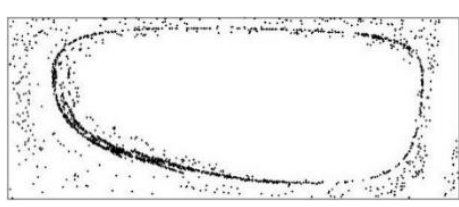

Case 4(Right thick)

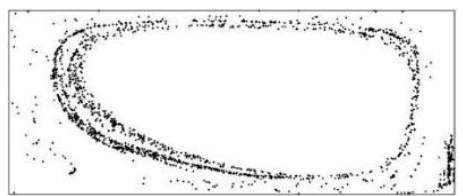

Case 8(Right thin)

Figure 5.15. Final particle distribution at $\mathrm{h}=5 \mathrm{~W} / \mathrm{m}^{2} \mathrm{~K}, \mathrm{Ma}=4.3 \times 10^{4}$ and insulated bottom wall

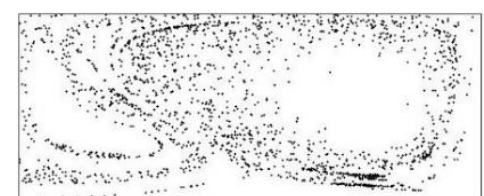

Case 1(Top thick)

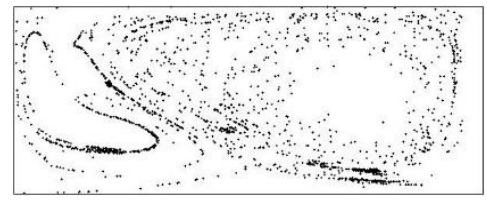

Case 5(Top thin)

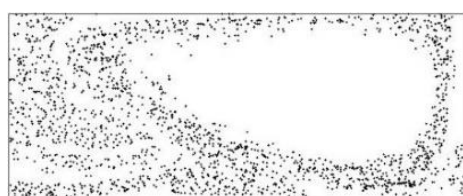

Case 2(Bottom thick)

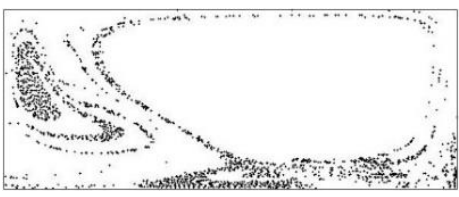

Case 6(Bottom thin)

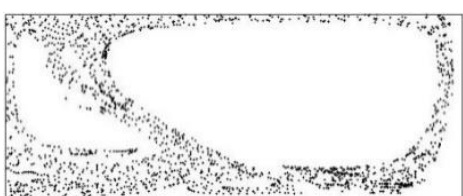

Case 3(Left thick)

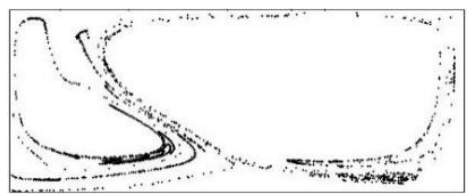

Case 7(Left thin)

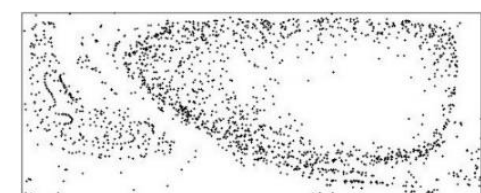

Case 4(Right thick)

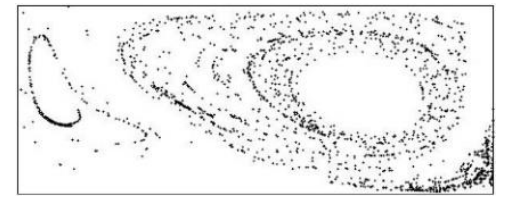

Case 8(Right thin)

Figure 5.16. Final particle distribution at $\mathrm{h}=5 \mathrm{~W} / \mathrm{m}^{2} \mathrm{~K}, \mathrm{Ma}=4.3 \times 10^{4}$ and constant temperature bottom wall 
Figures 5.17 and 5.18 have the similar concept as Figures 5.15 and 5.16, except the convective heat transfer coefficient (h) was set at a higher value of $146 \mathrm{~W} / \mathrm{m}^{2} \mathrm{~K}$ for all the cases in Figures 5.17 and 5.18. Comparing Figures 5.15 and 5.17, it can be clearly seen that, for all the cases, particles got concentrated in the quasi equilibrium region and created empty spaces in the geometry where there are no particles available. The minor differences in the final distribution of particles were solely because of the higher rate of solidification at higher convective heat transfer coefficient (h) in Figure 5.17.

Comparing all the cases between Figures 5.16 and 5.18, a common characteristic of flow of particles can be observed. The difference between each of the cases with same initial distribution of particles in Figures 5.16 and 5.18 are solely based on the rate of solidification, since cases in Figure 5.18 solidified earlier than cases in Figure 5.16. The major empty space in the geometry of different cases in Figure 5.16 with no particles was situated at the heart of convective flow which is on the right hand side of the geometry. As it was seen from Figure 5.1, due to circular motion of the fluid flow, the empty spaces seen in Figure 5.18 are somewhat circular. Previous cases in earlier figures did not have this circular structure because the rate of top wall solidification was lower than cases in Figure 5.18. As seen from the velocity vector in Figure 5.1, the shape of the major Marangoni convection velocity vector changes during the solidification process of the top wall, so does the trapped particle concentration in solidified geometry. 

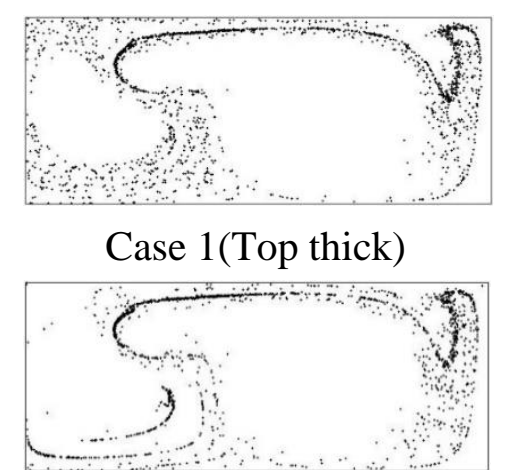

Case 5(Top thin)

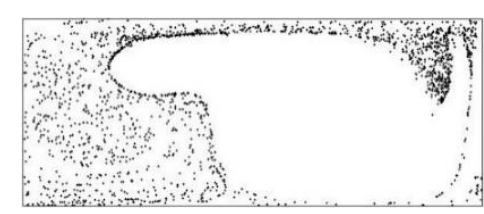

Case 2(Bottom thick)

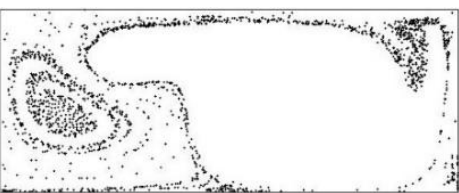

Case 6(Bottom thin)

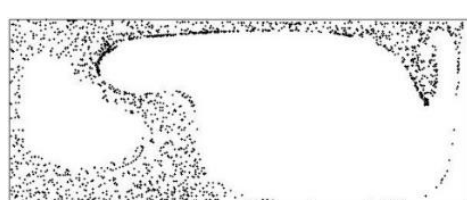

Case 3(Left thick)

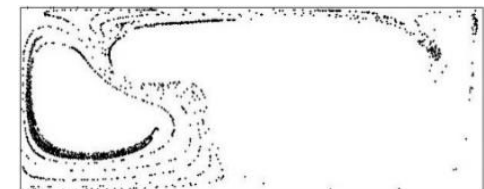

Case 7(Left thin)

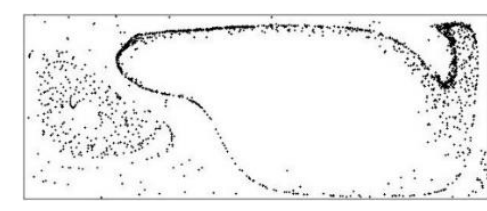

Case 4(Right thick)

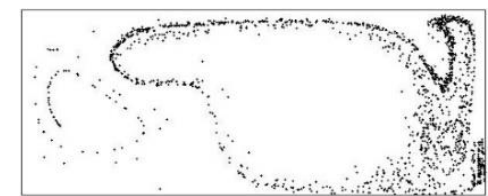

Case 8(Right thin)

Figure 5.17. Final particle distribution at $\mathrm{h}=146 \mathrm{~W} / \mathrm{m}^{2} \mathrm{~K}, \mathrm{Ma}=4.3 \times 10^{4}$ and insulated bottom wall

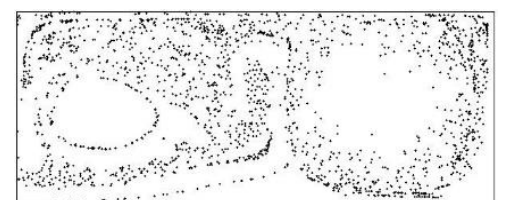

Case 1(Top thick)

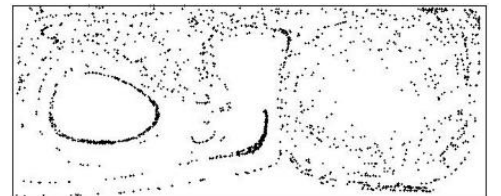

Case 5(Top thin)

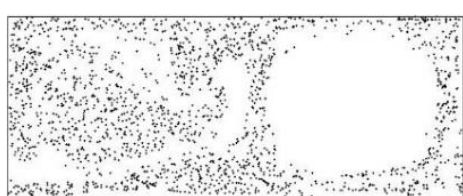

Case 2(Bottom thick)

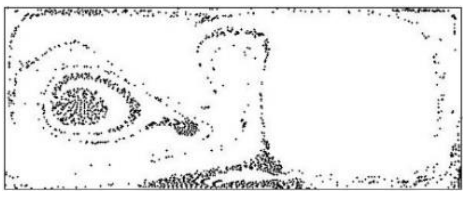

Case 6(Bottom thin)

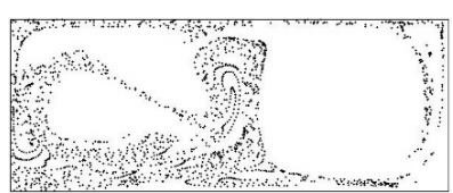

Case 3(Left thick)

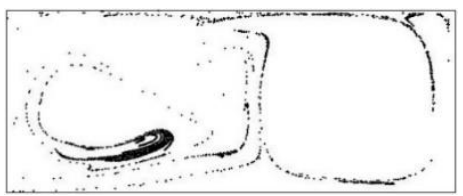

Case 7(Left thin)

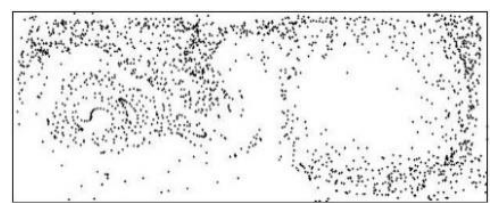

Case 4(Right thick)

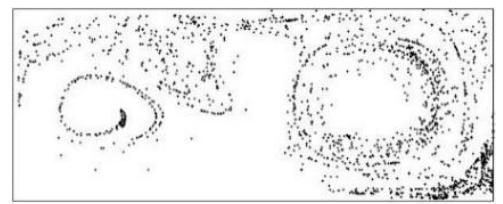

Case 8(Right thin)

Figure 5.18. Final particle distribution at $\mathrm{h}=146 \mathrm{~W} / \mathrm{m}^{2} \mathrm{~K}, \mathrm{Ma}=4.3 \times 10^{4}$ and constant temperature bottom wall 
At convective heat transfer coefficient (h) of $146 \mathrm{~W} / \mathrm{m}^{2} \mathrm{~K}$ with constant temperature bottom wall, the solidification of top wall was so fast that particles did not get sufficient time to move along to a changed velocity vector shown in Figure 5.1. Thus they remained in the initial circular motion of fluid flow. This phenomena is solely responsible for those specific shapes in Figure 5.18. Figure 5.19 does not resemblance the well-defined structure of particle distribution after solidification observed in Figures 5.15 and 5.17. For all the cases in Figure 5.19, particles did not get highly concentrated in the quasi equilibrium region as it was seen in Figures 5.15 and 5.17. Figure 5.19 has a convective heat transfer coefficient (h) of $600 \mathrm{~W} / \mathrm{m}^{2} \mathrm{~K}$, which accelerated the rate of solidification of the top wall as well as the entire geometry. Thus, even at a high Marangoni number of $4.3 \times 10^{4}$, particles do not get sufficient time to form a very well defined quasi equilibrium region. Similar trend of final particle distribution based on initial distribution can be seen between Figures 5.18 and 5.20. Increase in convective heat transfer coefficient decreased the time required for solidification. As a result particle movement was more restricted. It is interesting to point out that particle distribution is more concentrated in Figure 5.18, Case 7 (Left thin) than Figure 5.20, Case 7 (Left thin). Particles in Figure 5.18, Case 7 (Left thin) got more time to move and follow the velocity vortex on the right hand side of the geometry, due to lower rate of solidification. Thus they eventually fall into the quasi-equilibrium state whereas particle in Figure 5.19, Case 7 (Left thin) could not, due to higher cooling rate. The extra time the particles received, made them follow the vortex which can look like a thin circular line of particles and can be seen in Figure 5.18, Case 7 (Left thin). 


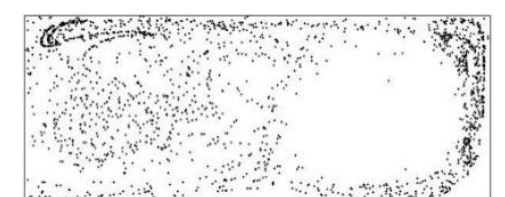

Case 1(Top thick)

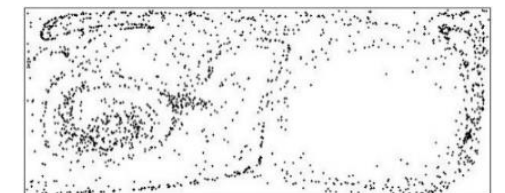

Case 5(Top thin)

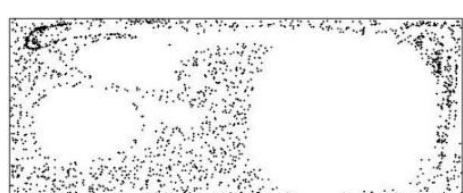

Case 2(Bottom thick)

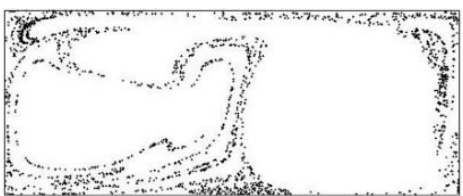

Case 6(Bottom thin)

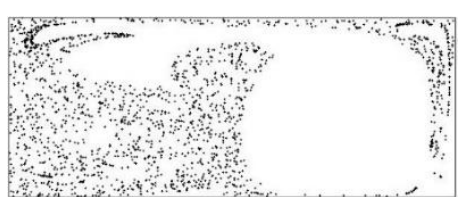

Case 3(Left thick)

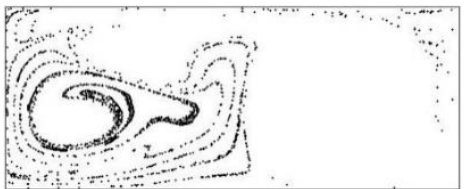

Case 7(Left thin)

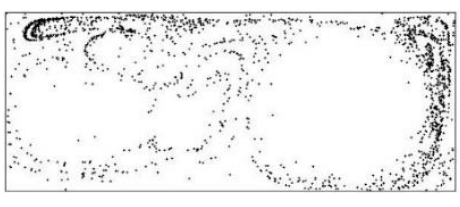

Case 4(Right thick)

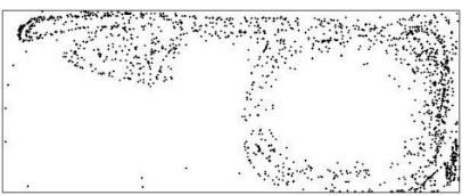

Case 8(Right thin)

Figure 5.19. Final particle distribution at $\mathrm{h}=600 \mathrm{~W} / \mathrm{m}^{2} \mathrm{~K}, \mathrm{Ma}=4.3 \times 10^{4}$ and insulated bottom wall

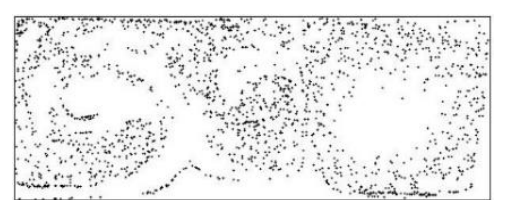

Case 1(Top thick)

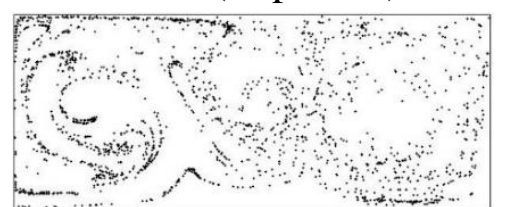

Case 5(Top thin)

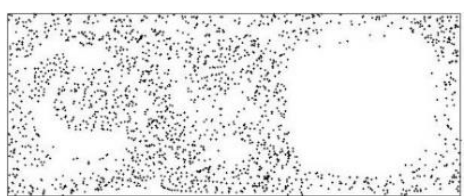

Case 2(Bottom thick)

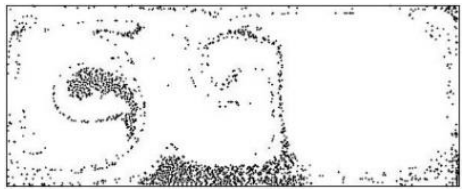

Case 6(Bottom thin)

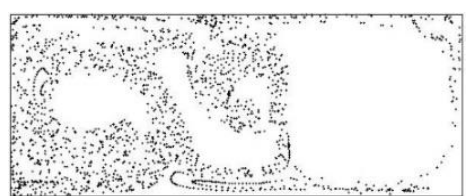

Case 3(Left thick)

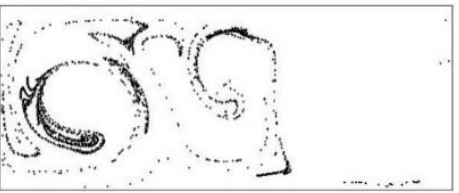

Case 7(Left thin)

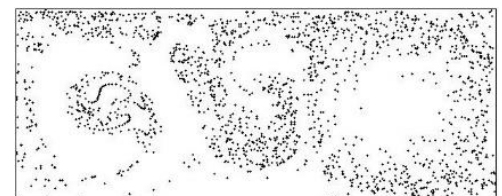

Case 4(Right thick)

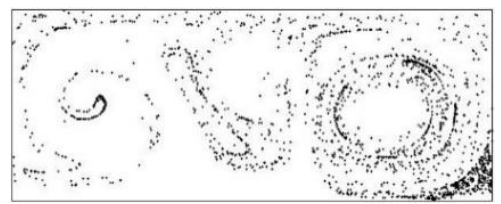

Case 8(Right thin)

Figure 5.20. Final particle distribution at $\mathrm{h}=600 \mathrm{~W} / \mathrm{m}^{2} \mathrm{~K}, \mathrm{Ma}=4.3 \times 10^{4}$ and constant temperature bottom wall 
Figures 5.21-5.26 are very interesting examples of particle distribution in a wellstructured vortex of Marangoni and natural convections. All of these cases have a Marangoni number (Ma) of $4.3 \times 10^{5}$ with value of convective heat transfer coefficient (h) varying from 5 to $600 \mathrm{~W} / \mathrm{m}^{2} \mathrm{~K}$. Since lower convective heat transfer coefficient significantly decreases the rate of solidification, the particles got sufficient time to follow the high velocity vortex created by convective flow. Also higher Marangoni number produces higher velocity, thus the particles experience sufficient centrifugal force to fall in to the quasi-equilibrium region. Therefore, increase in the convective heat transfer coefficient to $146 \mathrm{~W} / \mathrm{m}^{2} \mathrm{~K}$ (Figures 5.23 and 5.24) and even at $600 \mathrm{~W} / \mathrm{m}^{2} \mathrm{~K}$ (Figures 5.255.26), could not restrict particle movement and thus creates a much defined distribution. Different initial positions of particle distribution did not impact too much on this behavior since the velocity was sufficiently large enough to extract the particles from their well-confined concentrated initial distribution. 

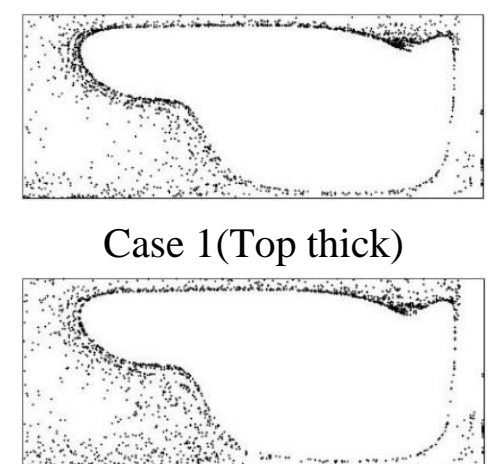

Case 5(Top thin)

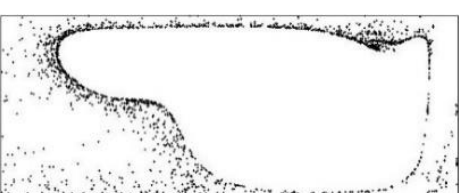

Case 2(Bottom thick)

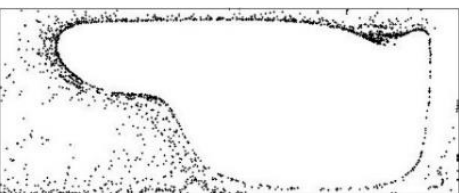

Case 6(Bottom thin)

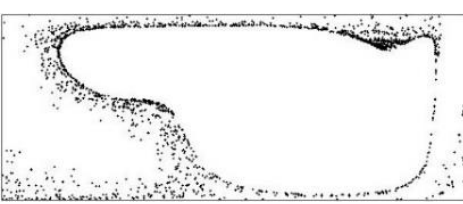

Case 3(Left thick)

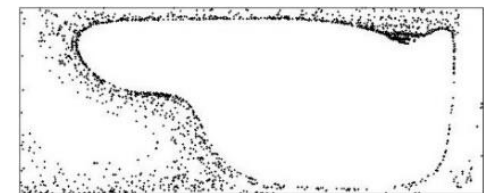

Case 7(Left thin)

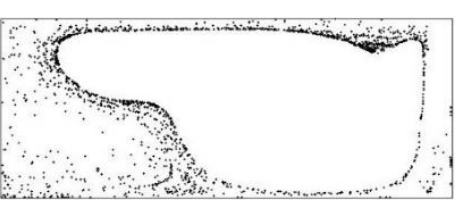

Case 4(Right thick)

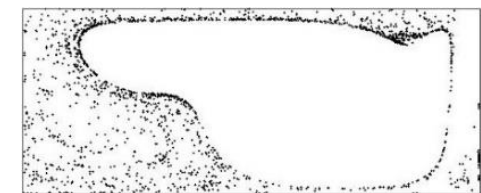

Case 8(Right thin)

Figure 5.21. Final particle distribution at $\mathrm{h}=5 \mathrm{~W} / \mathrm{m}^{2} \mathrm{~K}, \mathrm{Ma}=4.3 \times 10^{5}$ and insulated bottom wall

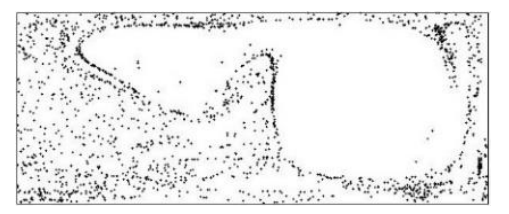

Case 1(Top thick)

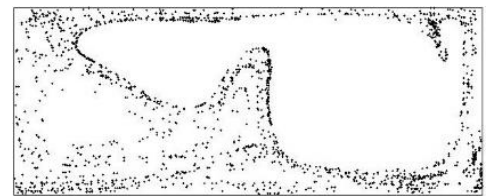

Case 5(Top thin)

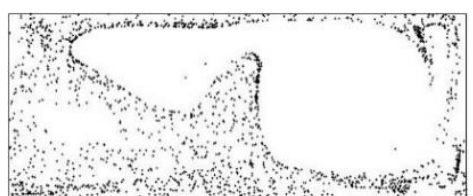

Case 2(Bottom thick)

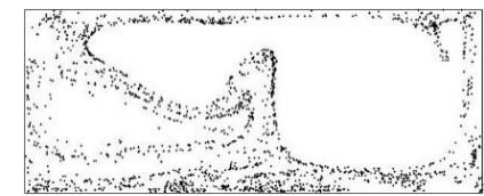

Case 6(Bottom thin)

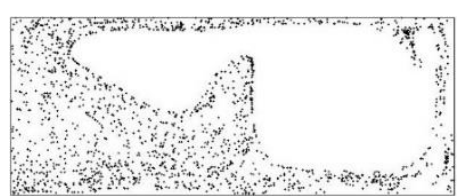

Case 3(Left thick)

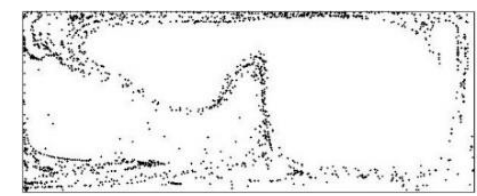

Case 7(Left thin)

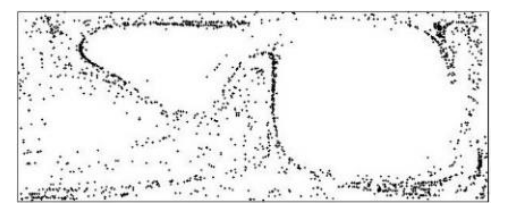

Case 4(Right thick)

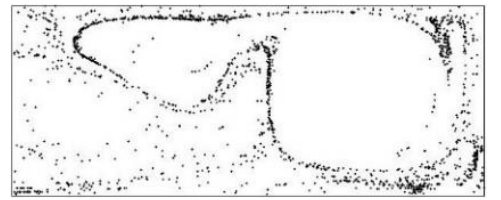

Case 8(Right thin)

Figure 5.22. Final particle distribution at $\mathrm{h}=5 \mathrm{~W} / \mathrm{m}^{2} \mathrm{~K}, \mathrm{Ma}=4.3 \times 10^{5}$ and constant temperature bottom wall 


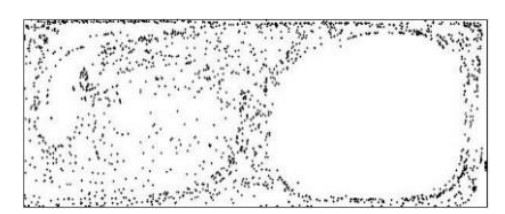

Case 1(Top thick)

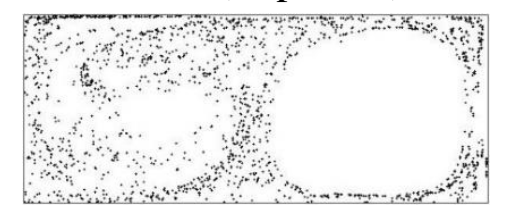

Case 5(Top thin)

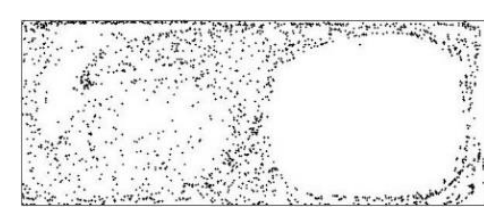

Case 2(Bottom thick)

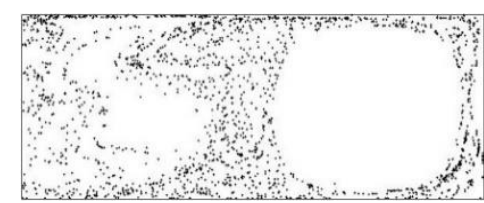

Case 6(Bottom thin)

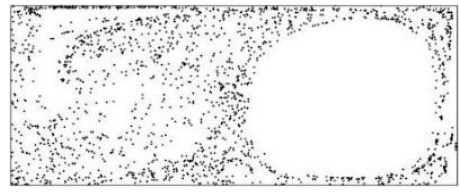

Case 3(Left thick)

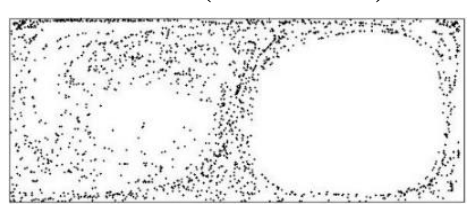

Case 7(Left thin)

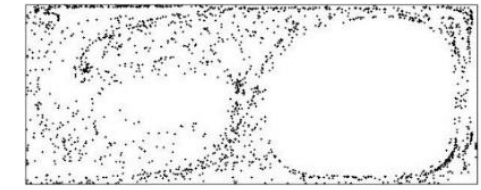

Case 4(Right thick)

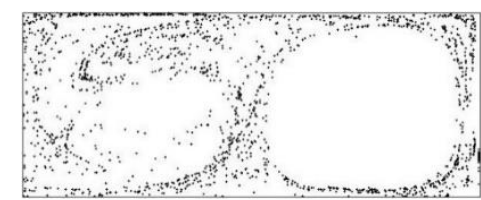

Case 8(Right thin)

Figure 5.23. Final particle distribution at $\mathrm{h}=146 \mathrm{~W} / \mathrm{m}^{2} \mathrm{~K}, \mathrm{Ma}=4.3 \times 10^{5}$ and insulated bottom wall

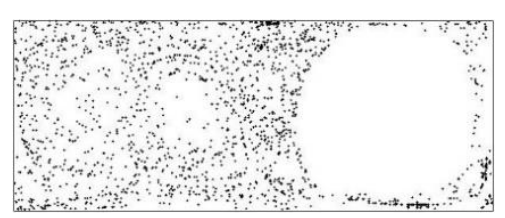

Case 1(Top thick)

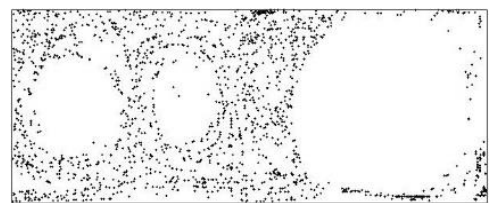

Case 5(Top thin)

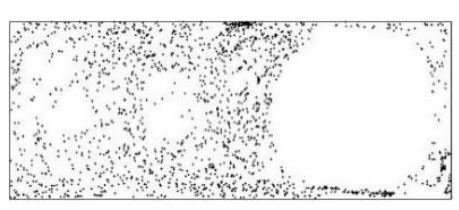

Case 2(Bottom thick)

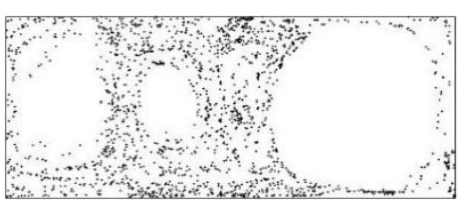

Case 6(Bottom thin)

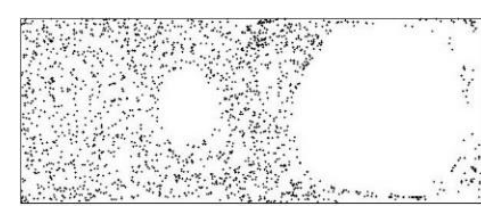

Case 3(Left thick)

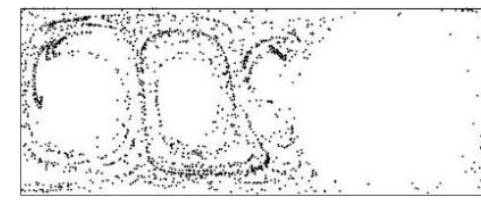

Case 7(Left thin)

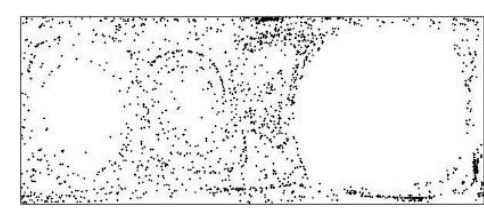

Case 4(Right thick)

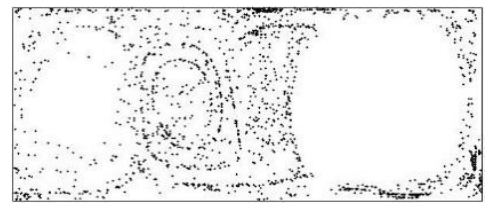

Case 8(Right thin)

Figure 5.24. Final particle distribution at $\mathrm{h}=146 \mathrm{~W} / \mathrm{m}^{2} \mathrm{~K}, \mathrm{Ma}=4.3 \times 10^{5}$ and constant temperature bottom wall 

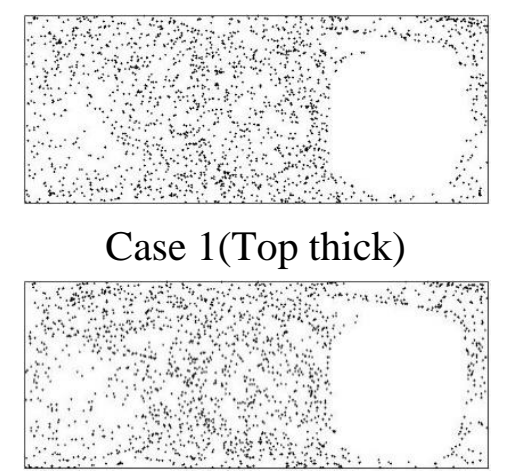

Case 5(Top thin)

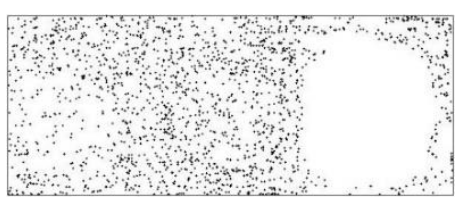

Case 2(Bottom thick)

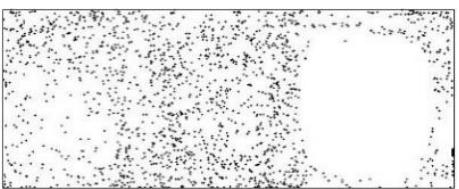

Case 6(Bottom thin)

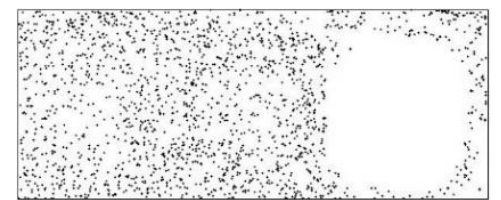

Case 3(Left thick)

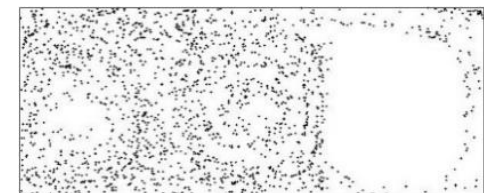

Case 7(Left thin)

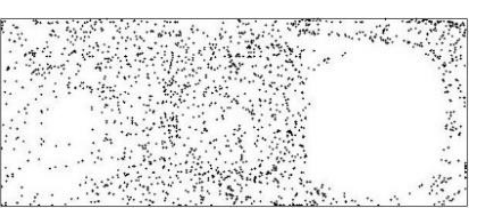

Case 4(Right thick)

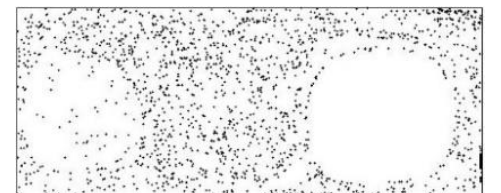

Case 8(Right thin)

Figure 5.25. Final particle distribution at $\mathrm{h}=600 \mathrm{~W} / \mathrm{m}^{2} \mathrm{~K}, \mathrm{Ma}=4.3 \times 10^{5}$ and insulated bottom wall

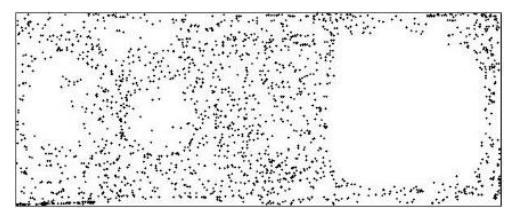

Case 1(Top thick)

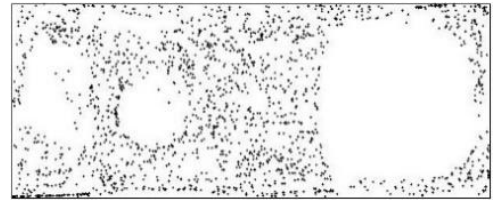

Case 5(Top thin)

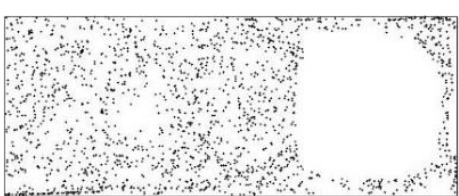

Case 2(Bottom thick)

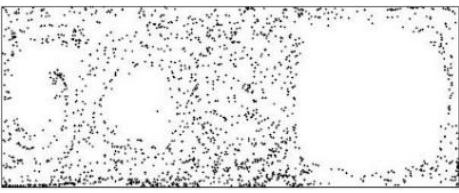

Case 6(Bottom thin)

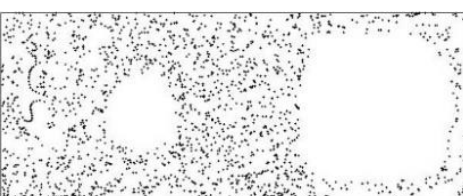

Case 3(Left thick)

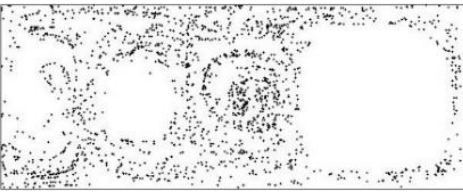

Case 7(Left thin)

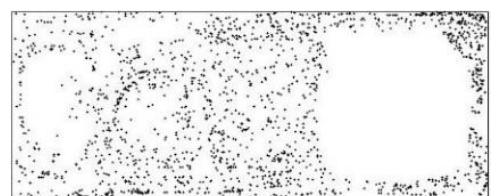

Case 4(Right thick)

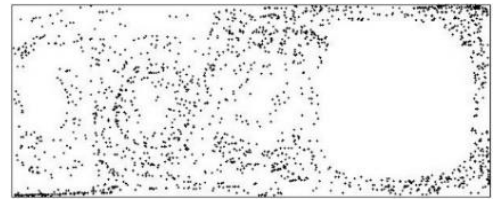

Case 8(Right thin)

Figure 5.26. Final particle distribution at $\mathrm{h}=600 \mathrm{~W} / \mathrm{m}^{2} \mathrm{~K}, \mathrm{Ma}=4.3 \times 10^{5}$ and constant temperature bottom wall 


\section{Quantitative Analysis of Different Parameters}

Figure 5.27 shows the effect of Marangoni number (Ma) and convective heat transfer coefficient (h) on the solidification time. The cases with insulated bottom wall boundary condition are labeled as (i) and constant temperature bottom wall boundary condition are labeled as (c). Different Marangoni numbers (Ma) are also labeled in the figure. This figure truly resemblance the correlation of the above mentioned parameters with the solidification of the geometry. For better presentation and comparison, only three convective heat transfer coefficient (h) values were considered. Those are 5, 146 and $600 \mathrm{~W} / \mathrm{m}^{2} \mathrm{~K}$.

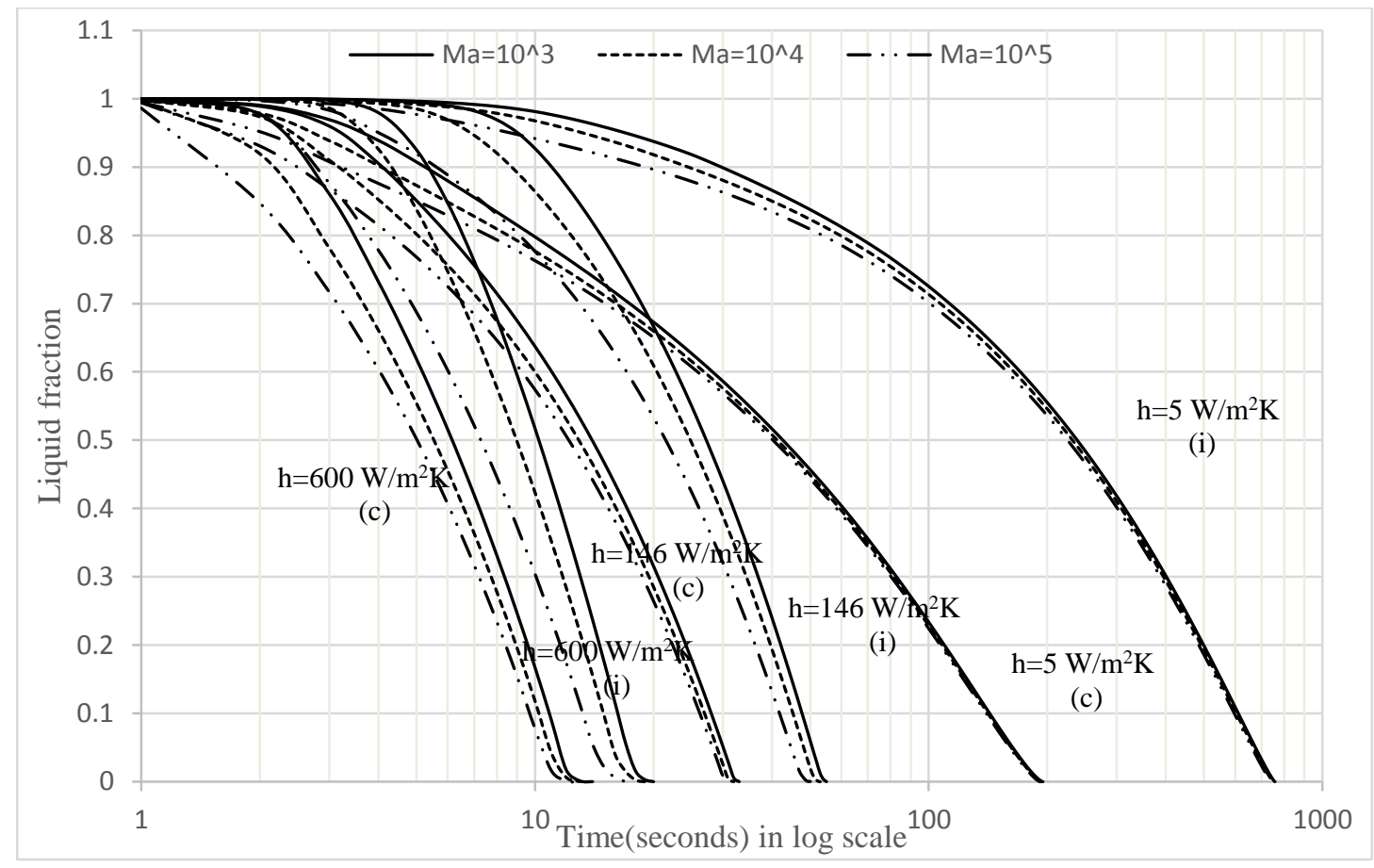

Figure 5.27. Effect of convective heat transfer coefficient (h), Marangoni number (Ma), insulated (i) and constant temperature(c) bottom boundary on liquid fraction 
It can be observed that the effect of increasing the value of convective heat transfer coefficient (h) decreased the solidification time. However, the difference of solidification time between three different Marangoni numbers increased when the value of convective heat transfer coefficient (h) was increased. The main reason behind this phenomena was that the increase in convective heat transfer coefficient $(h)$ value solidifies the top boundary relatively quickly. Thus the rest of the solidification process was solely dependent on the buoyancy effect, where the Rayleigh number was constant for all the cases.

Figures 5.28 and 5.29 include all the convective heat transfer coefficient (h) values and Marangoni numbers (Ma) used in the present study.

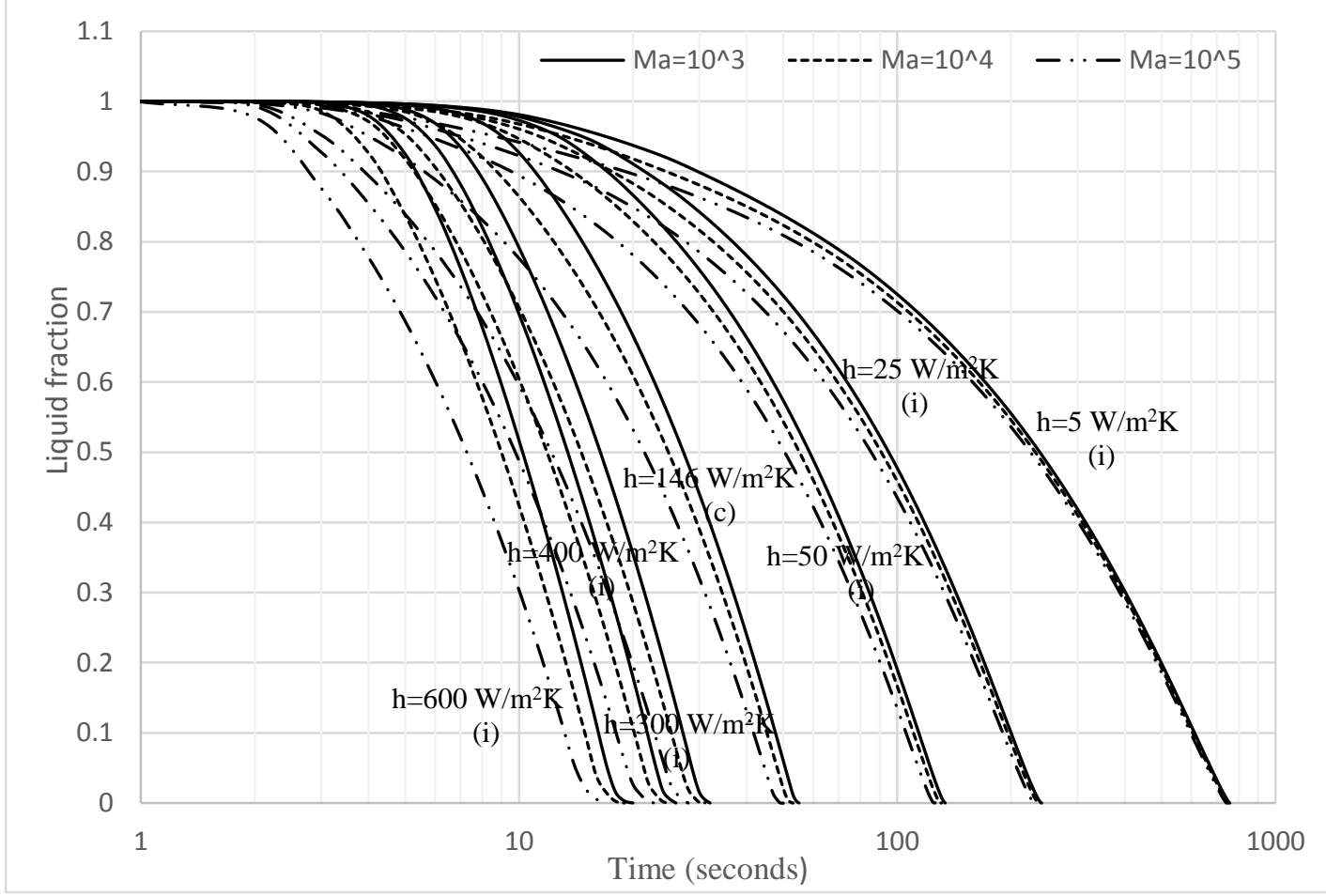

Figure 5.28. Effect of convective heat transfer coefficient (h), Marangoni number (Ma) and insulated (i) bottom boundary on liquid fraction 
Figure 5.28 shows the effect of insulated bottom wall and Figure 5.29 shows the effect of constant temperature bottom wall. Cases with constant temperature bottom wall boundary condition have a significantly higher rate of solidification of the top wall as well as the entire geometry.

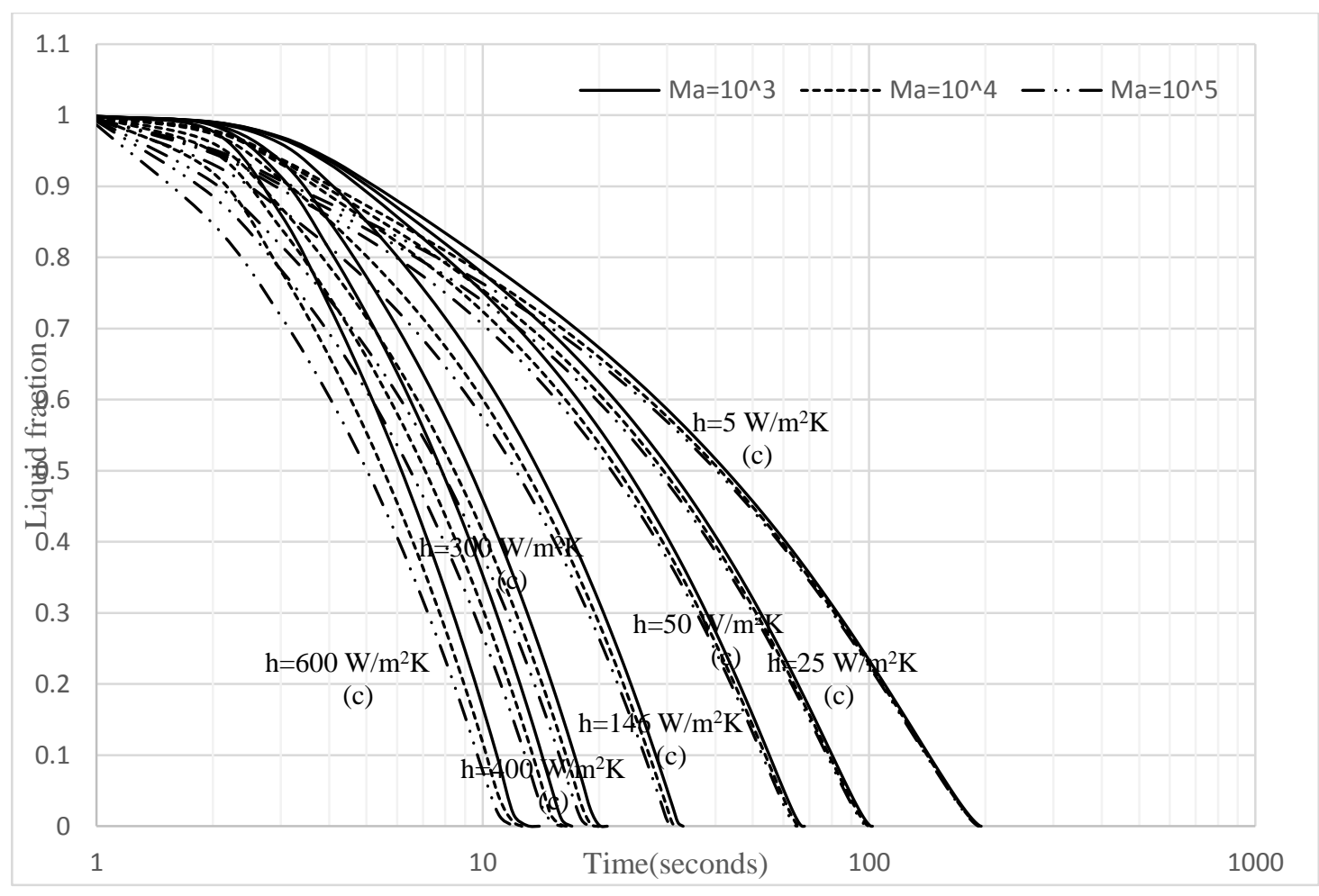

Figure 5.29. Effect of convective heat transfer coefficient (h), Marangoni number (Ma) and constant temperature(c) bottom boundary on liquid fraction

Figures 5.30-5.36 illustrate the heat flux along the top wall vs time. For all the cases in Figure 5.30, the value of convective heat transfer coefficient (h) was fixed at 5 $\mathrm{W} / \mathrm{m}^{2} \mathrm{~K}$. For Figures 5.31 to 5.36 , the values of convective heat transfer coefficient (h) were changed sequentially from 25 to $600 \mathrm{~W} / \mathrm{m}^{2} \mathrm{~K}$. All the convective heat transfer coefficient (h) values used in present study have been illustrated in these figures. 
Marangoni numbers (Ma) are labeled on the figure along with the indication of specific bottom wall boundary condition. The cases with insulated bottom wall boundary condition are labeled as (i) and constant temperature bottom wall boundary condition are labeled as (c). It was observed that with the increase in convective heat transfer coefficient (h), the value of heat flux increased. Since increases in convective heat transfer coefficient (h) also increased the heat transfer between top wall and the ambient, the time required for complete solidification decreased. This trend in the heat flux values can be observed by looking at the $\mathrm{x}$ and y-axis values for Figures 5.30-5.36. The higher heat transfer coefficient (h) value created a steeper slope which indicates relatively higher rate of heat transfer.

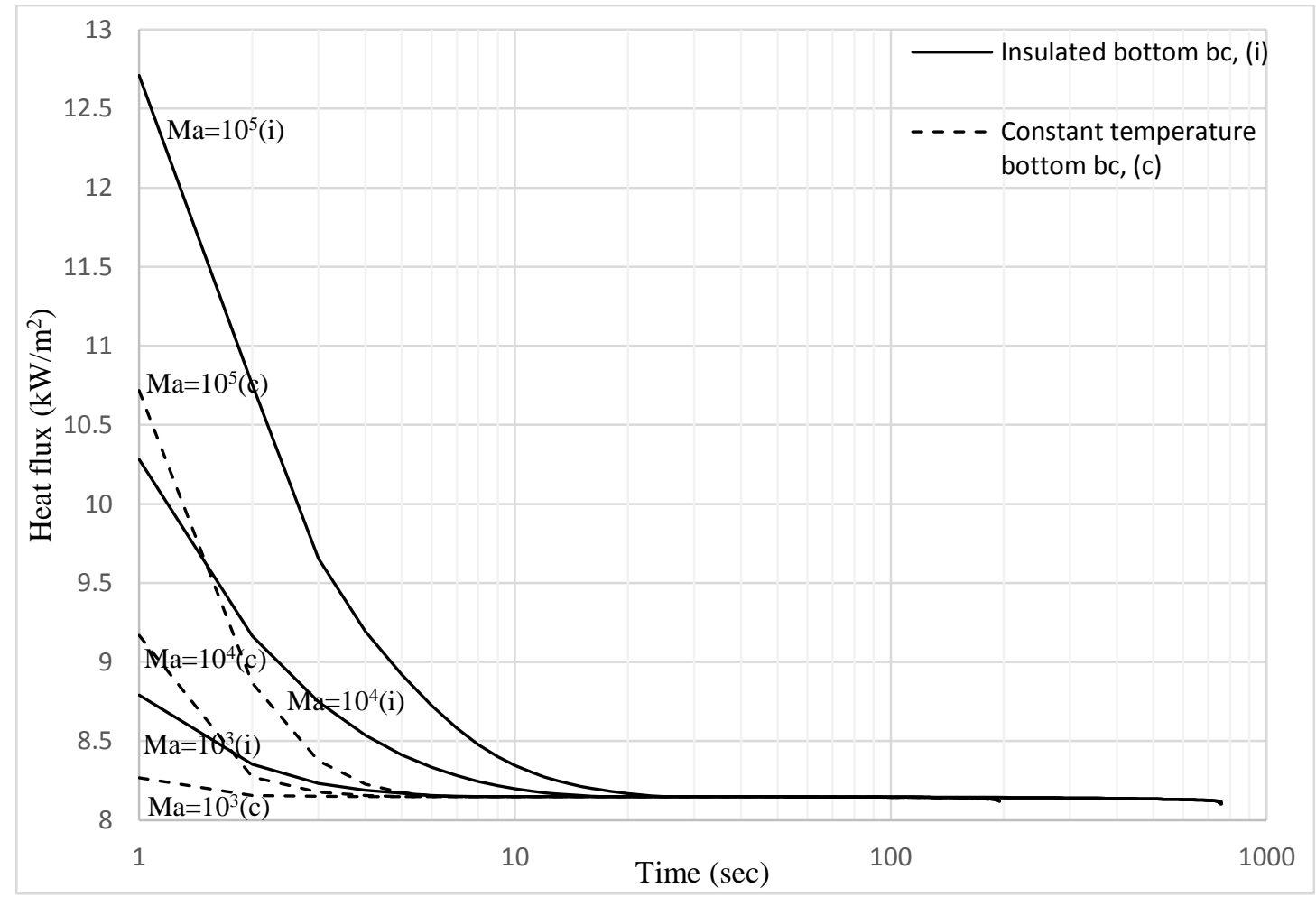

Figure 5.30. Effect of Marangoni number (Ma), insulated (i) and constant temperature(c) bottom boundary condition on top wall heat flux at $h=5 \mathrm{~W} / \mathrm{m}^{2} \mathrm{~K}$ 
For Figure 5.30, after a certain period of time when the top wall solidified, the variation of heat flux along different Marangoni numbers decreased. This can be observed when the lines in Figure 5.30 dropped to a heat flux of roughly $8.4 \mathrm{~kW} / \mathrm{m}^{2}$. The reason behind this phenomena was solely due to the fact that after solidification of the top wall, Marangoni convection stopped due to the absence of free surface on top wall of the geometry. Thus the convective heat transfer coefficient (h) value of $5 \mathrm{~W} / \mathrm{m}^{2} \mathrm{~K}$ did not make a lot of differences in terms of change in heat flux on top wall due to its low value, after the solidification of the top wall.

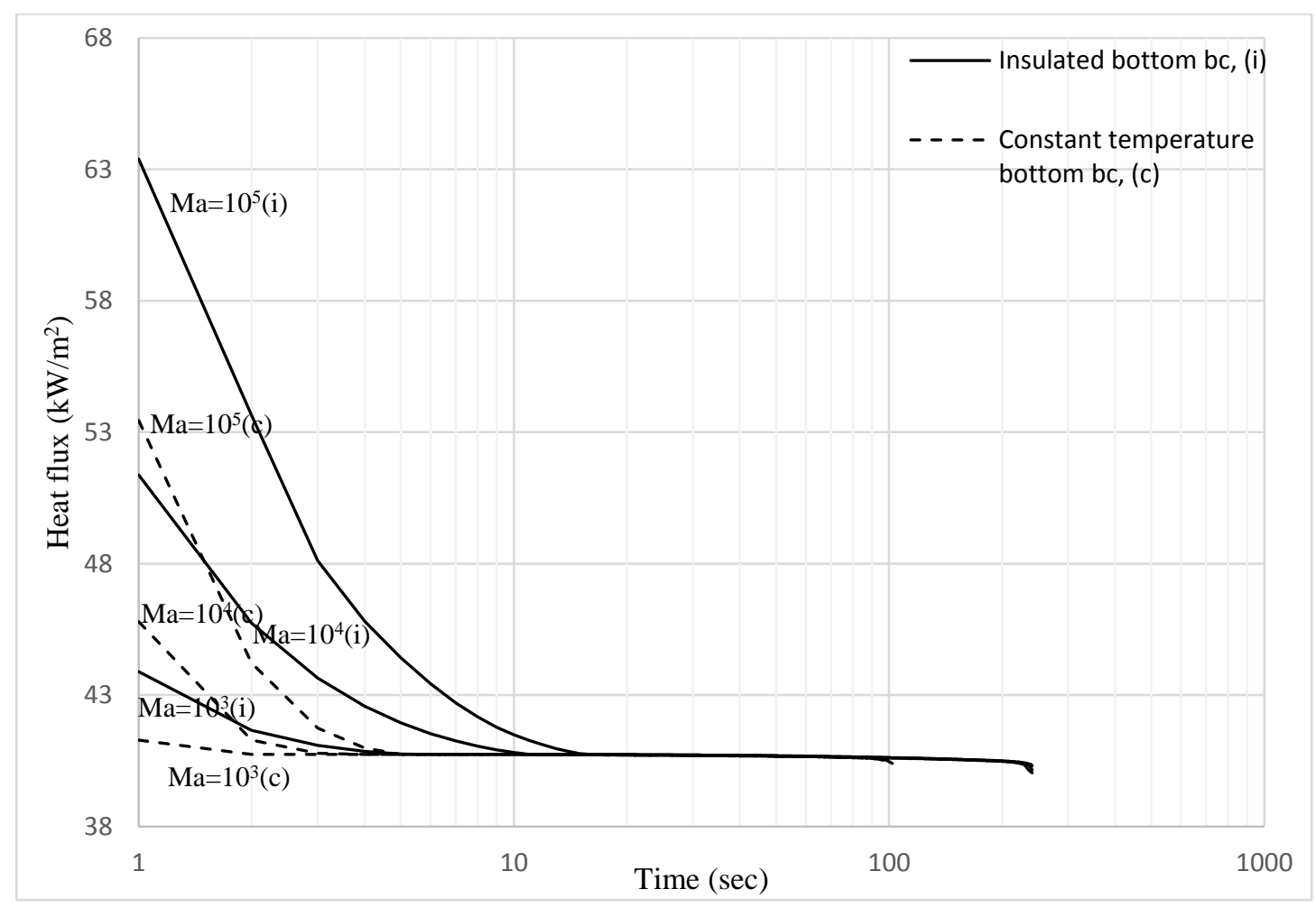

Figure 5.31. Effect of Marangoni number (Ma), insulated (i) and constant temperature(c) bottom boundary condition on top wall heat flux at $h=25 \mathrm{~W} / \mathrm{m}^{2} \mathrm{~K}$ 
Constant temperature bottom wall contributed the most for the solidification process and has more prominent effect on decreasing the temperature of whole geometry whenever the convective heat transfer coefficient value is low. However, with the increase of convective heat transfer coefficient, the changes in the heat flux values between different Marangoni numbers become more prominent which indicates that increasing the value of convective heat transfer coefficient $(\mathrm{h})$ will eventually accelerate the heat transfer even after the top boundary is solidified. Figures 5.31 and 5.32 have similar concept as Figure 5.30. Only the convective heat transfer coefficients (h) were considered as 25 and $50 \mathrm{~W} / \mathrm{m}^{2} \mathrm{~K}$, respectively.

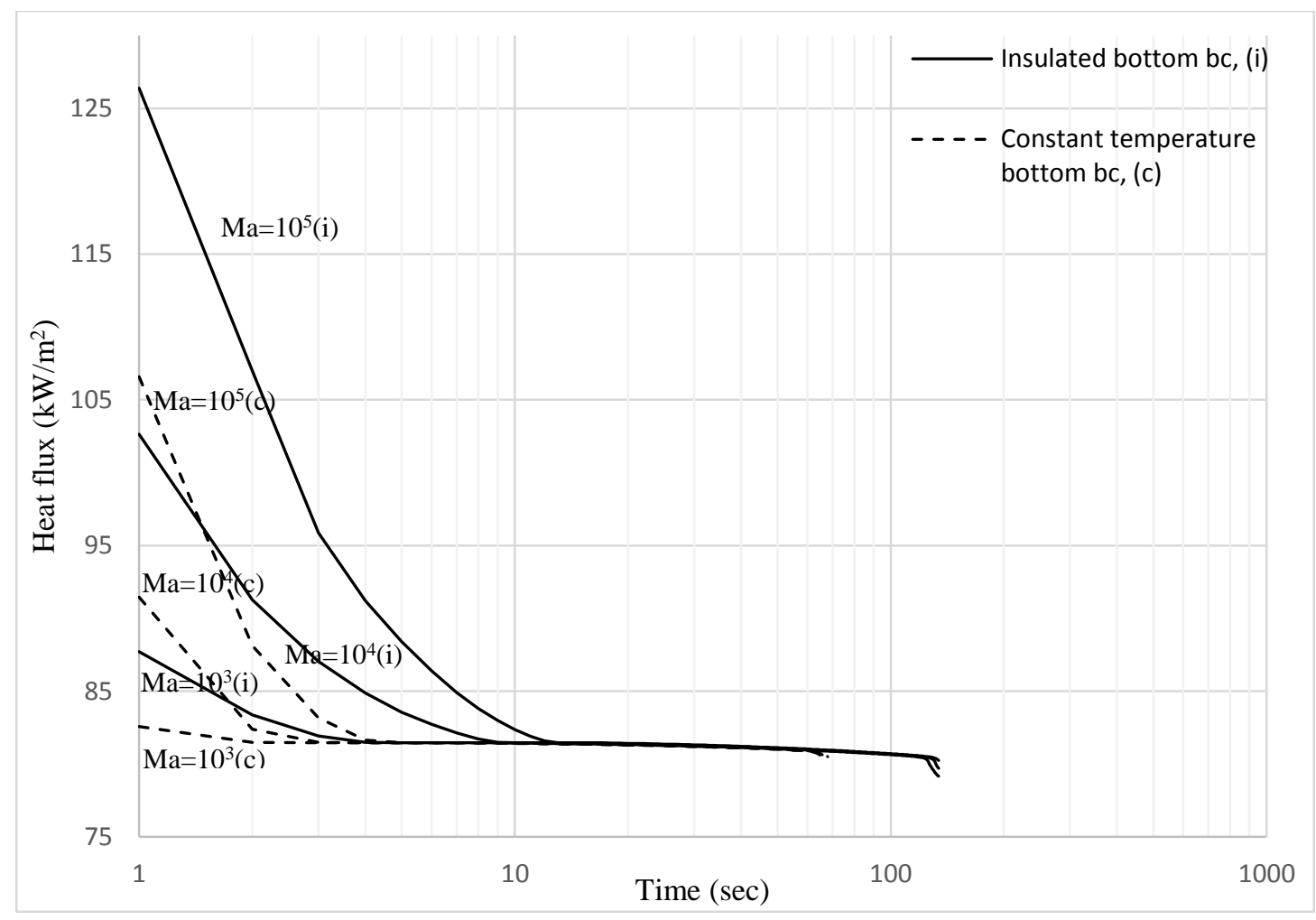

Figure 5.32. Effect of Marangoni number (Ma), insulated (i) and constant temperature(c) bottom boundary condition on top wall heat flux at $\mathrm{h}=50 \mathrm{~W} / \mathrm{m}^{2} \mathrm{~K}$ 
Due to increase in convective heat transfer coefficient (h) value, the variation of heat flux increased between different Marangoni numbers. Since higher value of convective heat transfer coefficient (h) increased the heat flux on top wall, the difference of heat flux between different Marangoni numbers can be observed by looking at y-axis (heat flux) values.

The overall time required for solidification of entire geometry decreased with an increase in convective heat transfer coefficient value, which can be observed by comparing the x-axis (time) of Figures 5.30-5.32. The change in heat flux remained very similar between different Marangoni numbers after the top wall has been solidified. The estimated time of solidification of top wall can be observed by looking at the point in the figures where the difference in heat flux values became very similar between different Marangoni numbers and showed a region where all the different lines are amalgamated and formed a somewhat linear line.

With the increase in convective heat transfer coefficient (h) value to $146 \mathrm{~W} / \mathrm{m}^{2} \mathrm{~K}$, it can be observed that the slope of the almost horizontal line, after roughly around $t=10$ seconds (observable in Figures 5.30-5.32), increased at $h=146 \mathrm{~W} / \mathrm{m}^{2} \mathrm{~K}$. This can be clearly seen by comparing the region roughly after $t=10$ seconds between Figures 5.305.32 and Figure 5.33. 


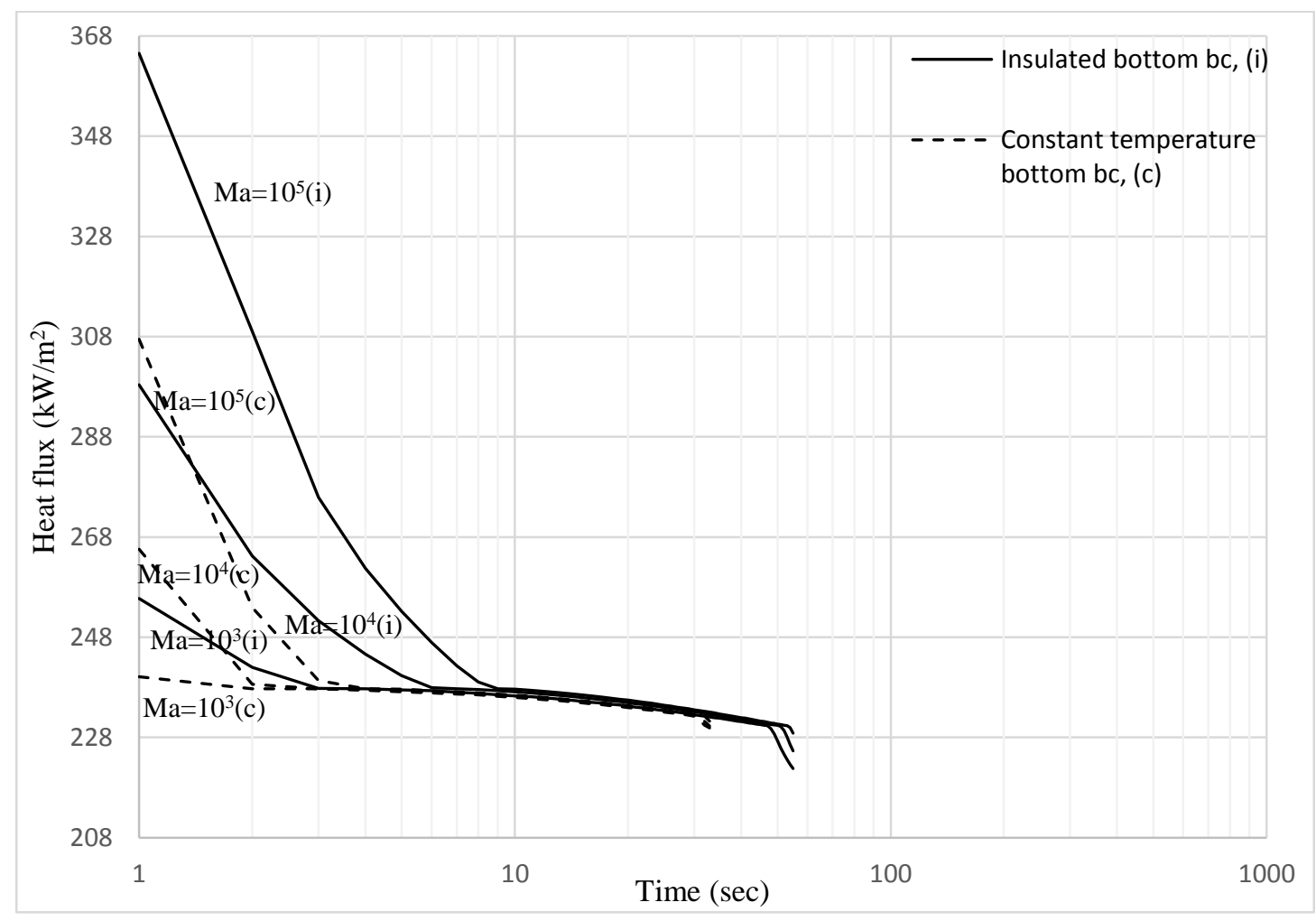

Figure 5.33. Effect of Marangoni number (Ma), insulated (i) and constant temperature(c) bottom boundary condition on top wall heat flux at $\mathrm{h}=146 \mathrm{~W} / \mathrm{m}^{2} \mathrm{~K}$

This indicates that when convective heat transfer coefficient (h) is $146 \mathrm{~W} / \mathrm{m}^{2} \mathrm{~K}$, the overall decrease in heat flux was slightly quicker than cases with low convective heat transfer coefficient values (Figures 5.30-5.32). And this progressive decrease in heat flux after solidification of the top wall can also be seen in Figures 5.34 and 5.35. Figures 5.34 and 5.35 have convective heat transfer coefficient values of 300 and $400 \mathrm{~W} / \mathrm{m}^{2} \mathrm{~K}$.

For these cases, the difference in heat flux values between different Marangoni numbers becomes more dominant even after solidification of the top wall. Previously it was seen that the difference in heat flux values for all the Marangoni numbers juxtaposed in a small region and continued to be fairly linear till the end of solidification process (Figures 5.30-5.33). 


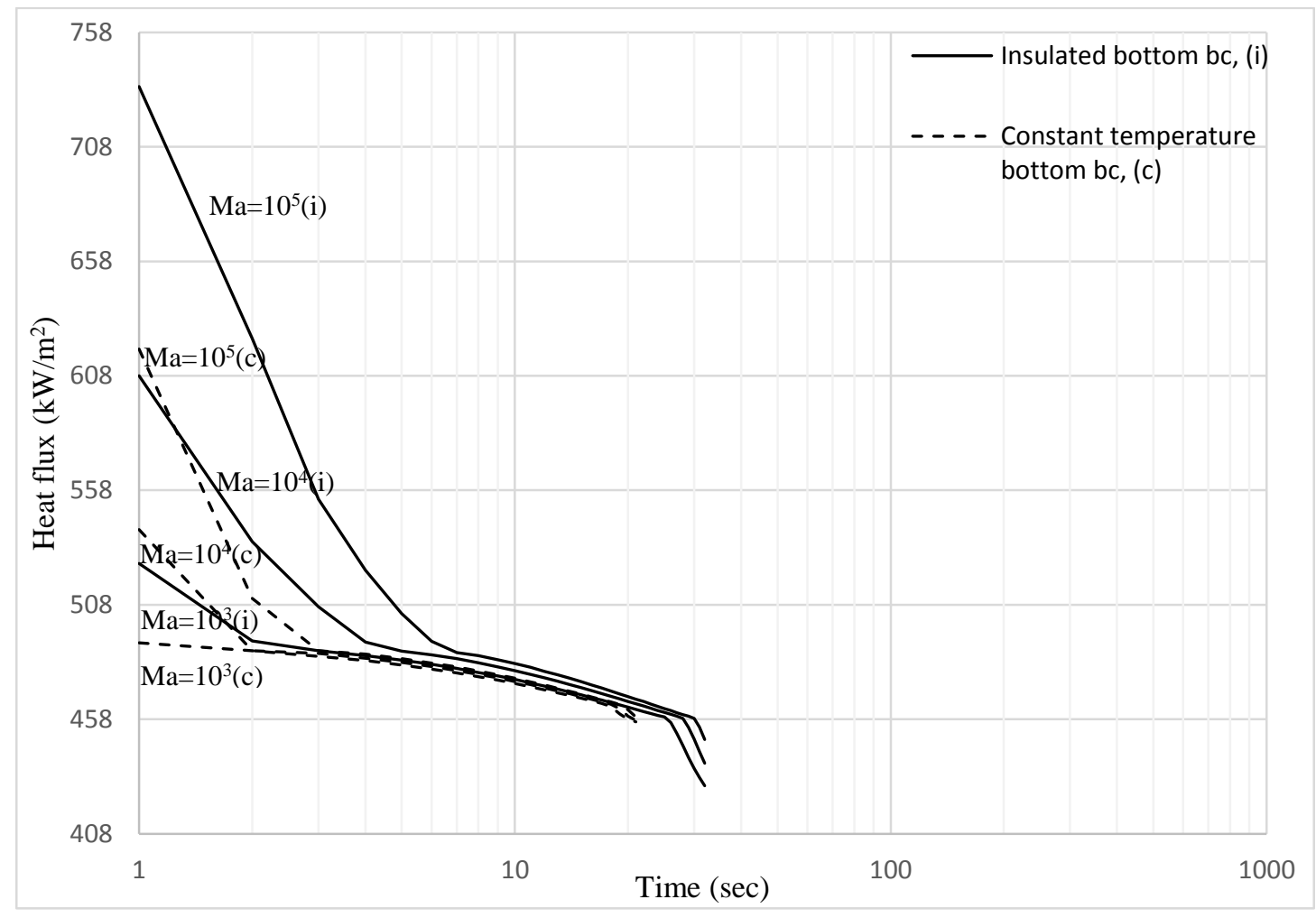

Figure 5.34. Effect of Marangoni number (Ma), insulated (i) and constant temperature(c) bottom boundary condition on top wall heat flux at $\mathrm{h}=300 \mathrm{~W} / \mathrm{m}^{2} \mathrm{~K}$

But with value of convective heat transfer coefficient (h) at 300 and $400 \mathrm{~W} / \mathrm{m}^{2} \mathrm{~K}$, the heat flux of the top wall kept decreasing and thus a clear difference of heat fluxes on the top wall between different Marangoni numbers was visible. The increases in heat transfer on the top wall due to higher convective heat transfer coefficient (h) was solely responsible for this phenomena. 


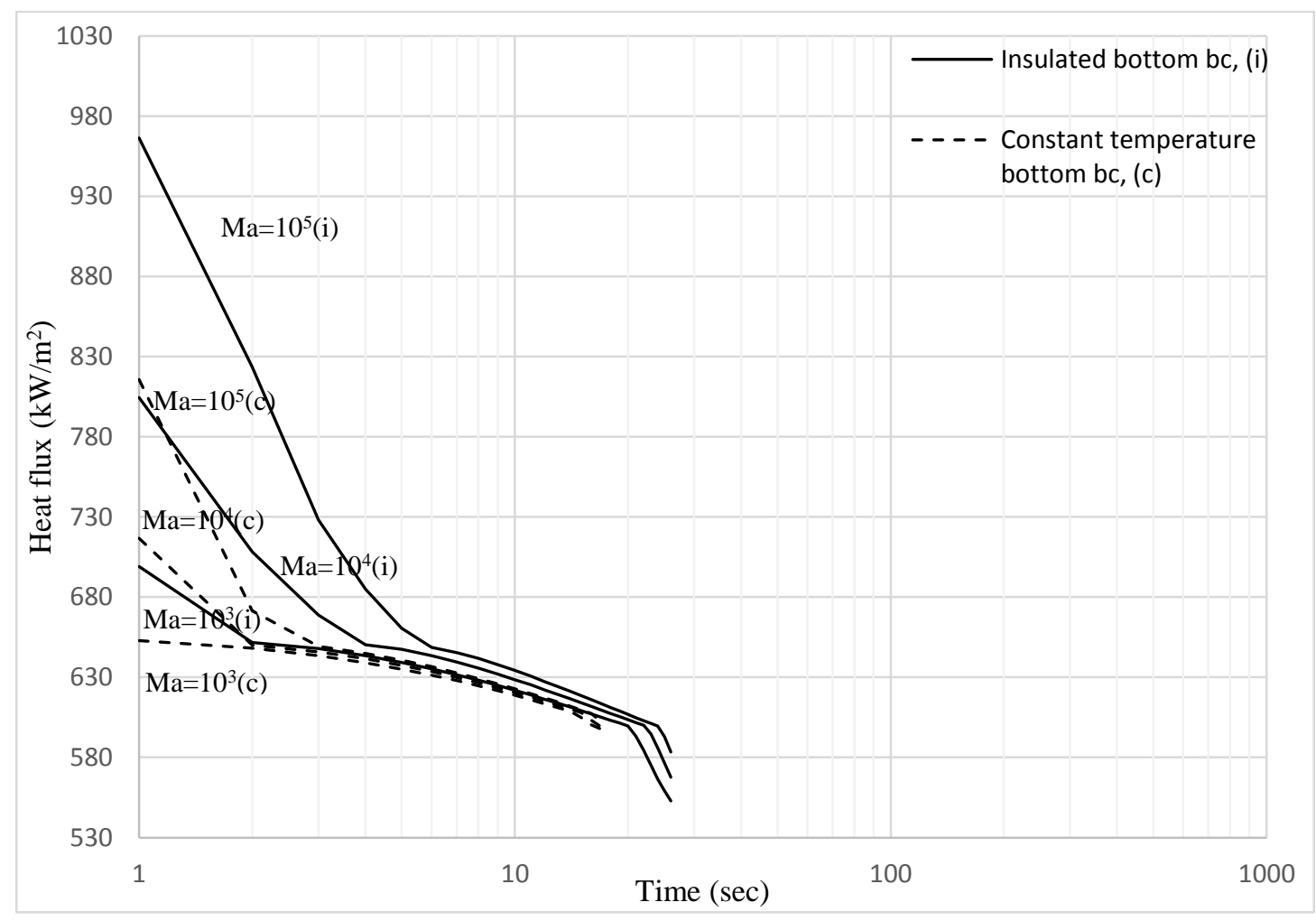

Figure 5.35. Effect of Marangoni number (Ma), insulated (i) and constant temperature(c) bottom boundary condition on top wall heat flux at $\mathrm{h}=400 \mathrm{~W} / \mathrm{m}^{2} \mathrm{~K}$

For convective heat transfer coefficient (h) of $600 \mathrm{~W} / \mathrm{m}^{2} \mathrm{~K}$ (Figure 5.36), the differences in heat flux values between different Marangoni numbers became even more dominant. For a lower Rayleigh number case, this will not have any impact on the movement of the particles. However, significant movement in particle distribution will occur if the Rayleigh number is sufficiently high. Higher Rayleigh number will provide higher fluid velocity. Hence even after the top wall is solidified, the high Rayleigh number high buoyancy induced flow will be responsible for further movement of the particles. 


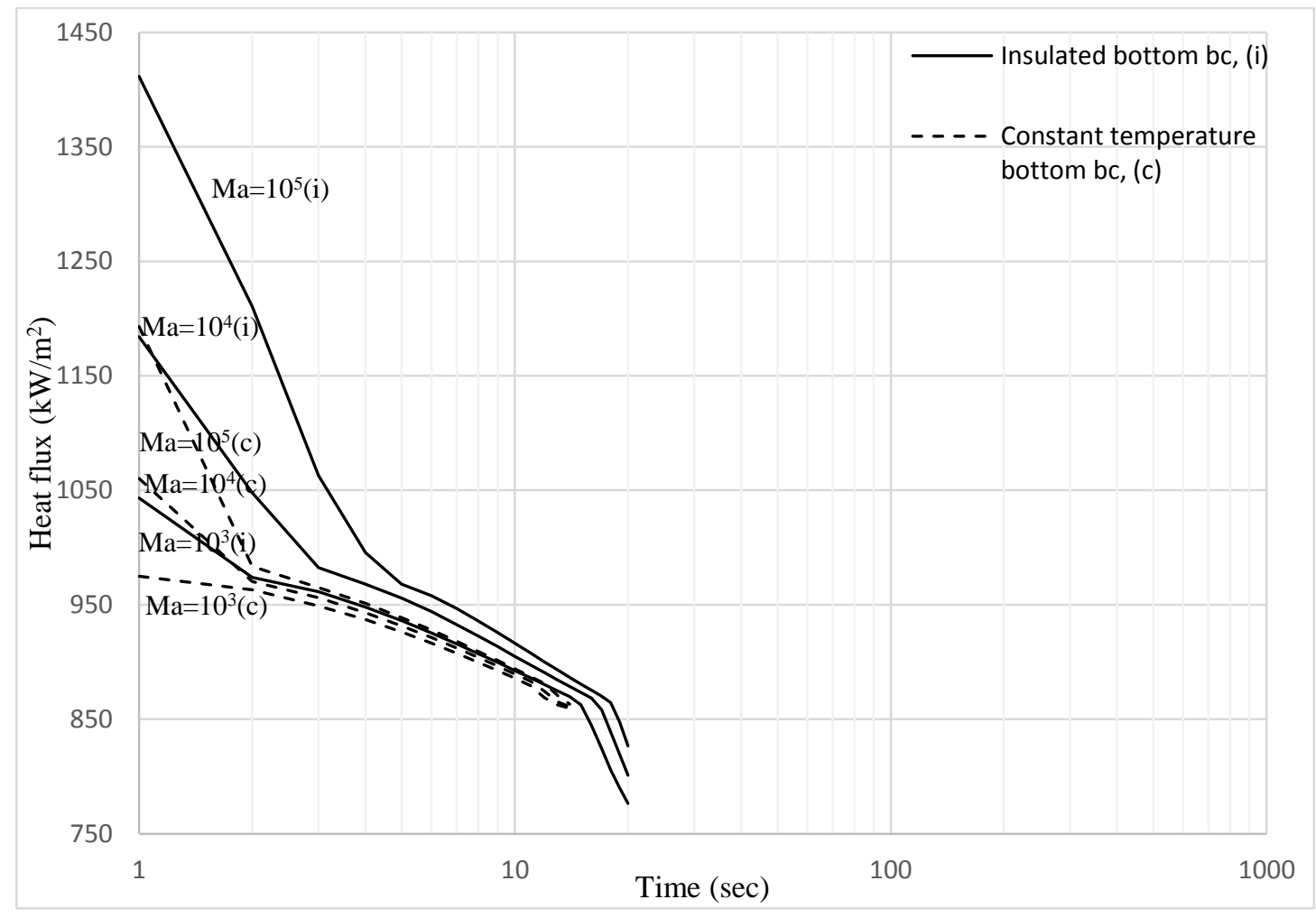

Figure 5.36. Effect of Marangoni number (Ma), insulated (i) and constant temperature(c) bottom boundary condition on top wall heat flux at $h=600 \mathrm{~W} / \mathrm{m}^{2} \mathrm{~K}$

To further investigate the relationship between convective heat transfer coefficient and time required for solidification of the top wall, equations were generated by curve fitting and are shown in Figure 5.37. Different Marangoni number and bottom wall boundary conditions were used. The $\mathrm{r}^{2}$ (variance) for the corresponding equations were in a range of 0.9667 to 0.9936. 


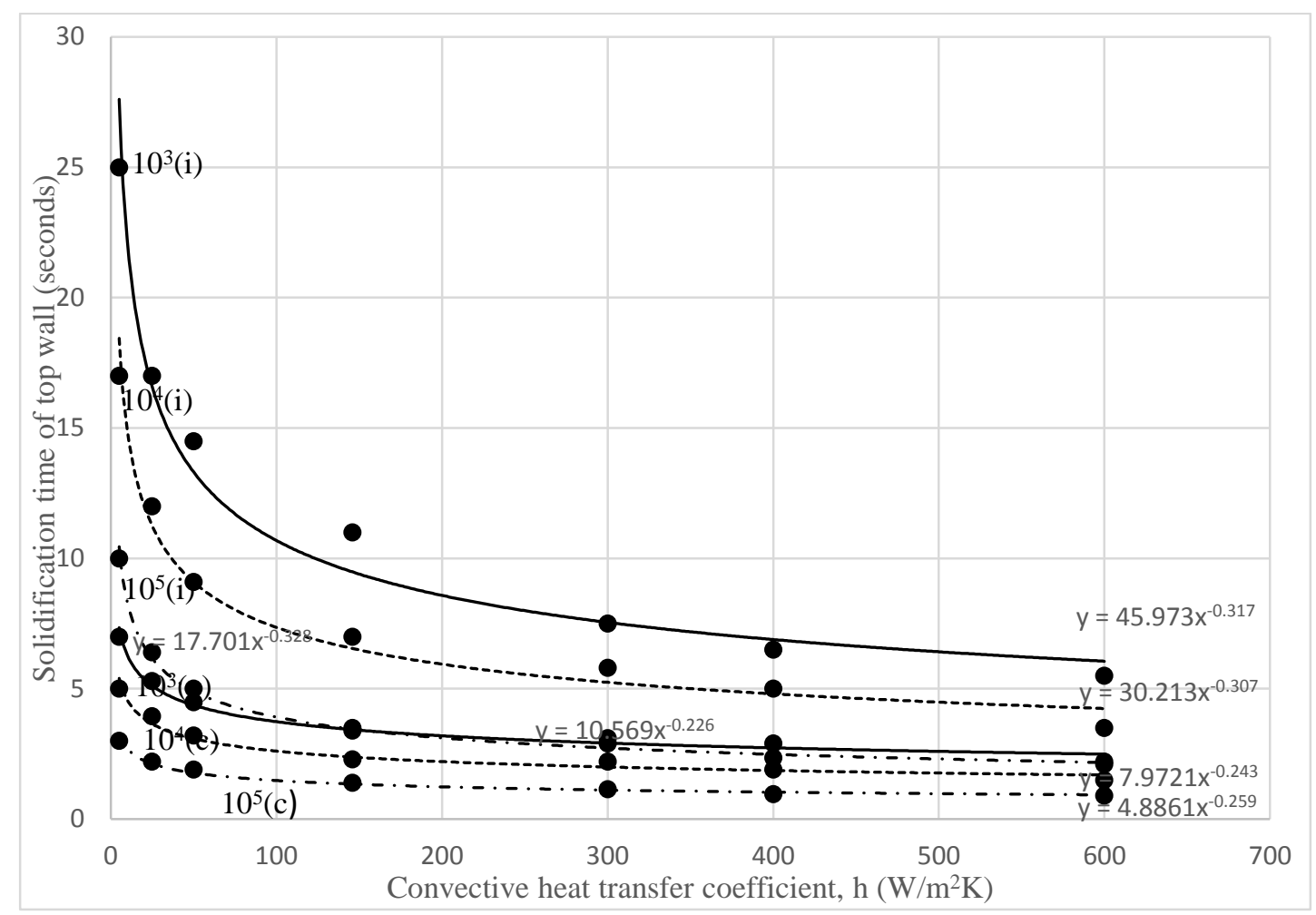

Figure 5.37. Power law curve fit for top wall's solidification time vs $h$ at different Marangoni number (Ma), insulated (i) and constant temperature(c) bottom wall

The values of variance equal to unity when polynomial curve fit is done.

However, power law curve fit was used due to its usefulness in practical applications. As it was evident from previous discussion, lowering the value of convective heat transfer coefficient (h) increases the time required for top wall solidification. Also increasing the Marangoni number (Ma) decreases the solidification time. Constant temperature bottom boundary condition takes less amount of solidification time due to increase in heat transfer in the geometry. It was interesting to observe that the solidification time is very similar for $\mathrm{Ma}=10^{5}$ insulated bottom wall and $\mathrm{Ma}=10^{3}$ constant temperature bottom wall cases, when the convective heat transfer coefficient is higher than $200 \mathrm{~W} / \mathrm{m}^{2} \mathrm{~K}$. 
Figure 5.37 can be used to calculate the required time for top wall solidification at different convective heat transfer coefficient along with different Marangoni number and bottom wall condition. For any given set of parameters within the parametric range of this study, the top wall's solidification time can give an estimation of the particle distribution in the geometry since the solidification time is one of the most important factors dictating particle's final distribution.

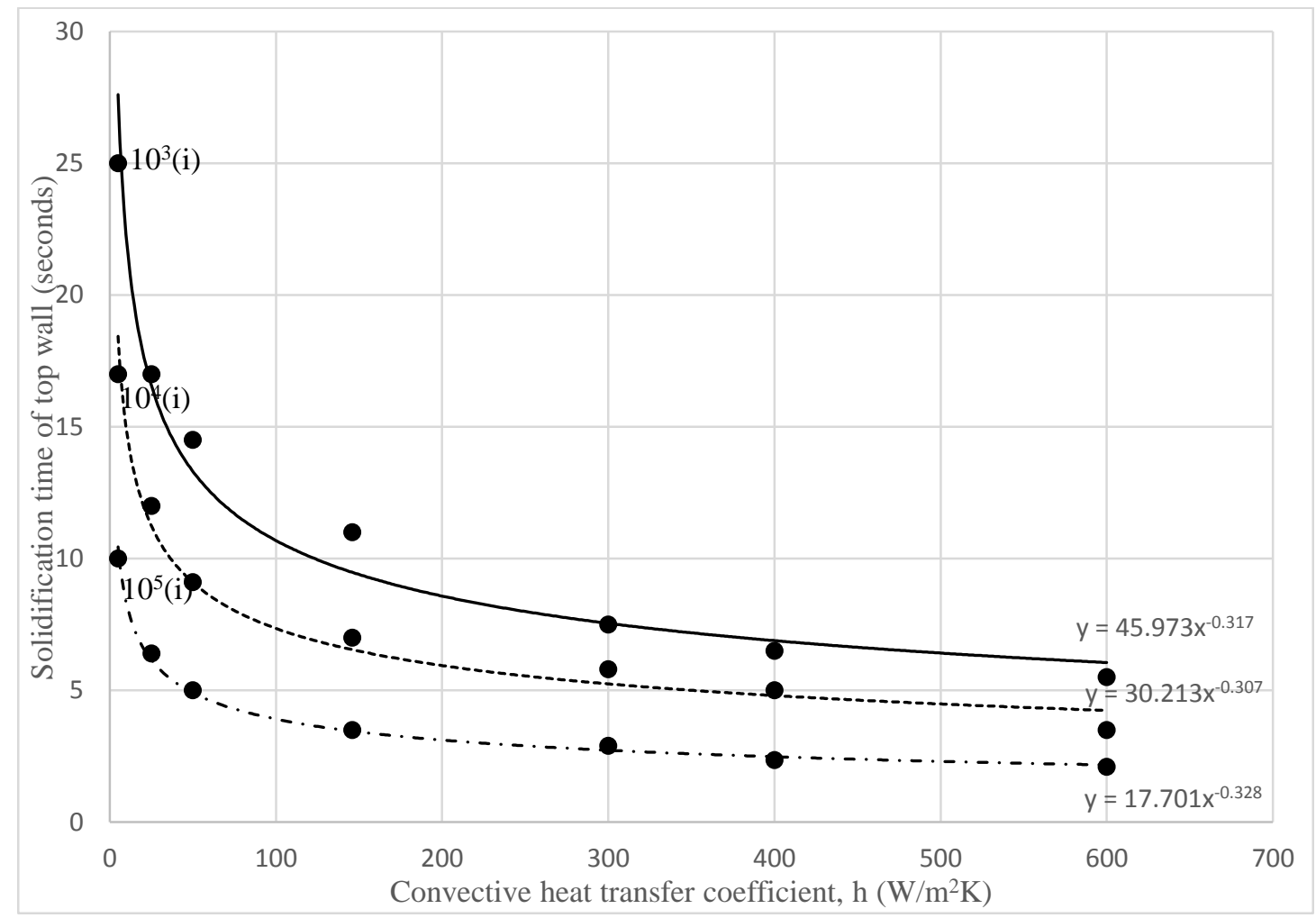

Figure 5.38. Power law curve fit for top wall's solidification time vs h at different Marangoni number (Ma) and insulated (i) bottom wall

Figures 5.38 and 5.39 illustrate similar concept as Figure 5.37. Figure 5.38 considers the insulated bottom wall condition and Figure 5.39 considers the constant temperature bottom wall condition. It can be clearly observed that the difference in time 
between each of the curve fits significantly decreased when the bottom wall was at constant temperature boundary condition. Constant low temperature wall increased the heat transfer in the geometry, which decreased the overall temperature of the geometry. Thus the top wall also got affected by this heat transfer and solidified quickly.

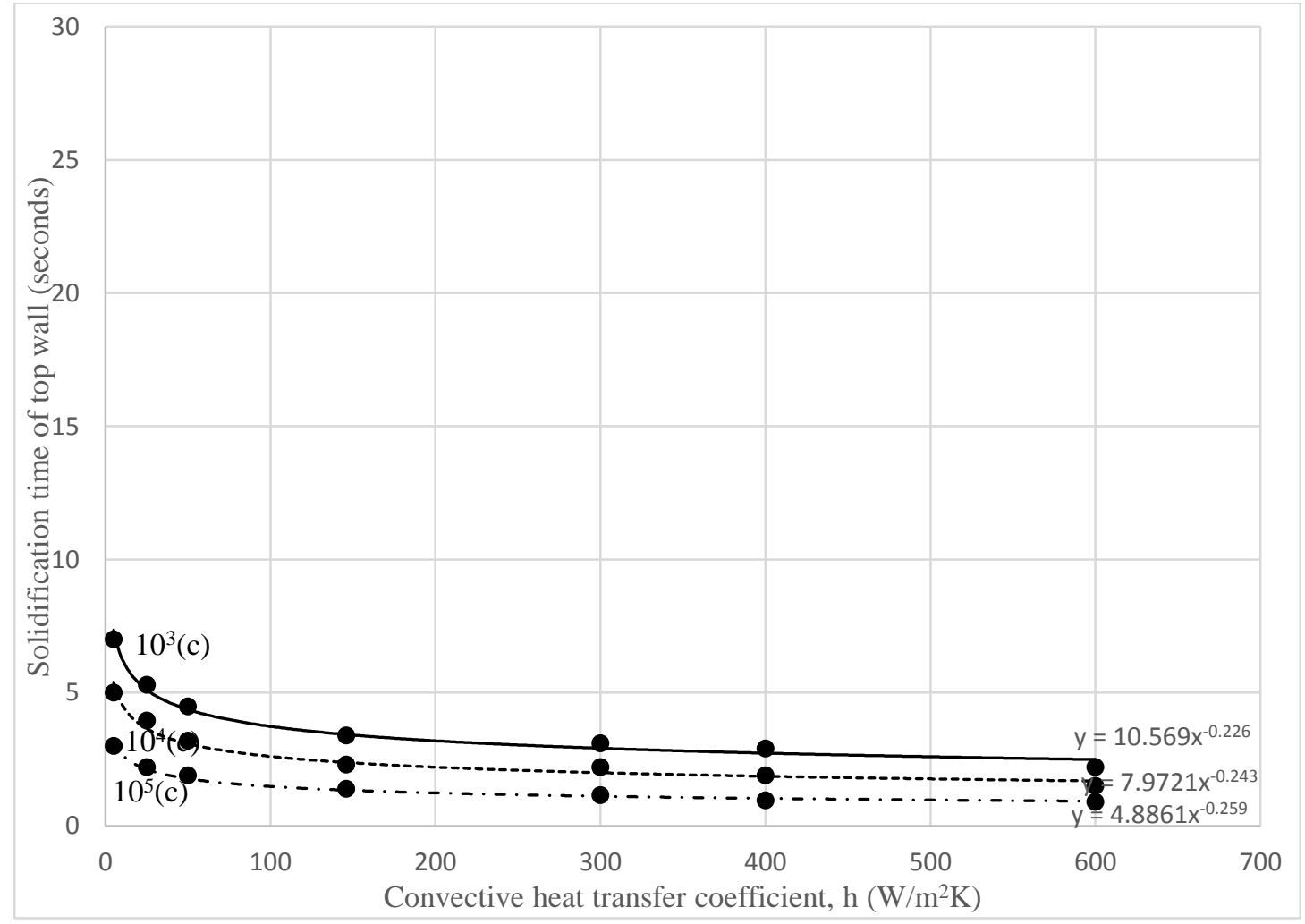

Figure 5.39. Power law curve fit for top wall's solidification time vs h at different Marangoni number (Ma) and constant temperature(c) bottom wall

Figures 5.40-5.42 compare between different Marangoni numbers along the same concept. Increase in Marangoni number significantly increases the velocity of the flow. 


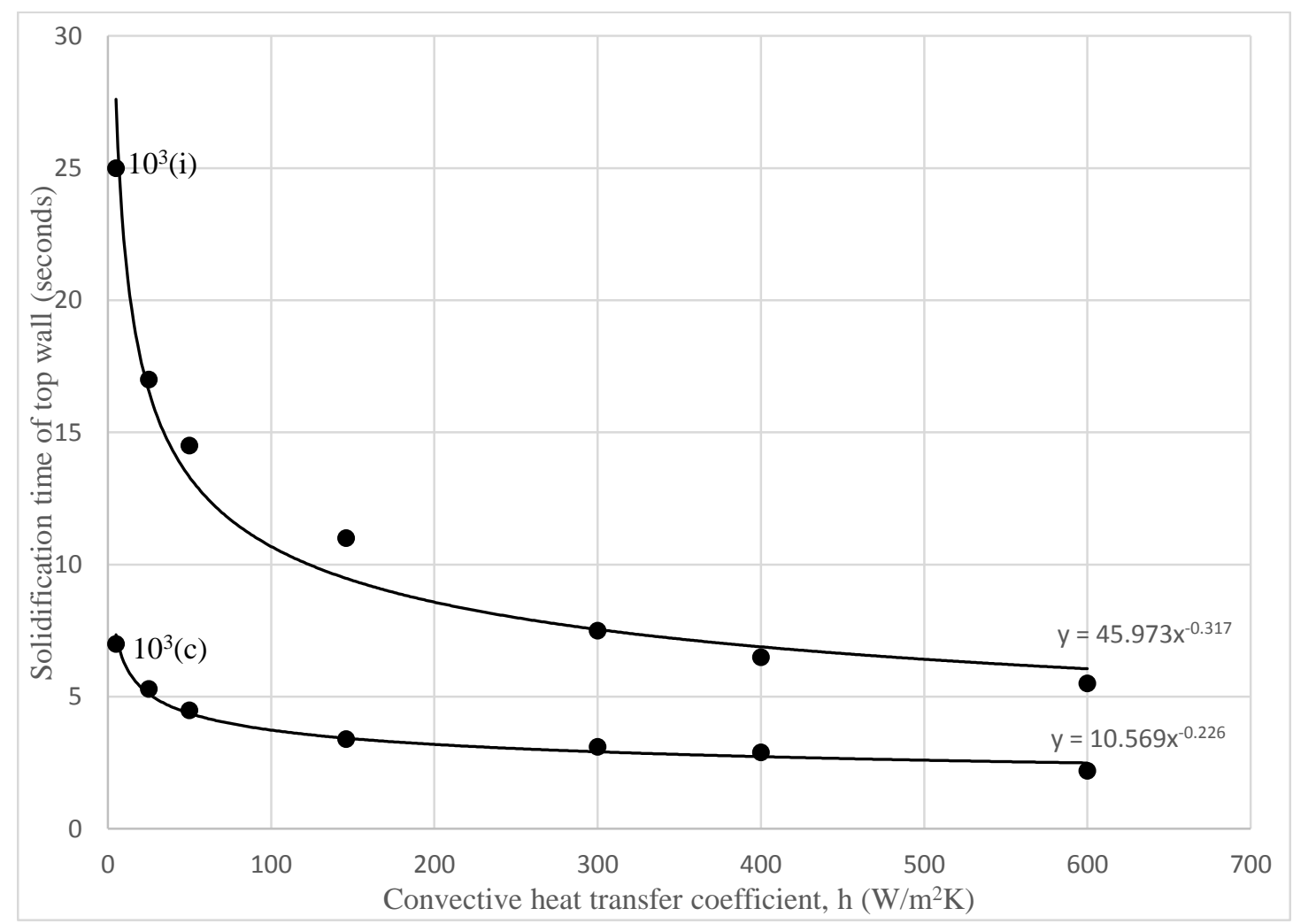

Figure 5.40. Power law curve fit for top wall's solidification time vs $\mathrm{h}$ at $\mathrm{Ma}=4.3 \times 10^{3}$ along with insulated (i) and constant temperature(c) bottom wall

Thus the overall heat transfer in the geometry increased. As a result, top wall got solidified even quicker. Higher Marangoni number produced less difference in time between curve fit of cases with insulated and constant temperature bottom wall, which can be observed by comparing the difference in time between the two lines in Figures 5.40-5.42. 


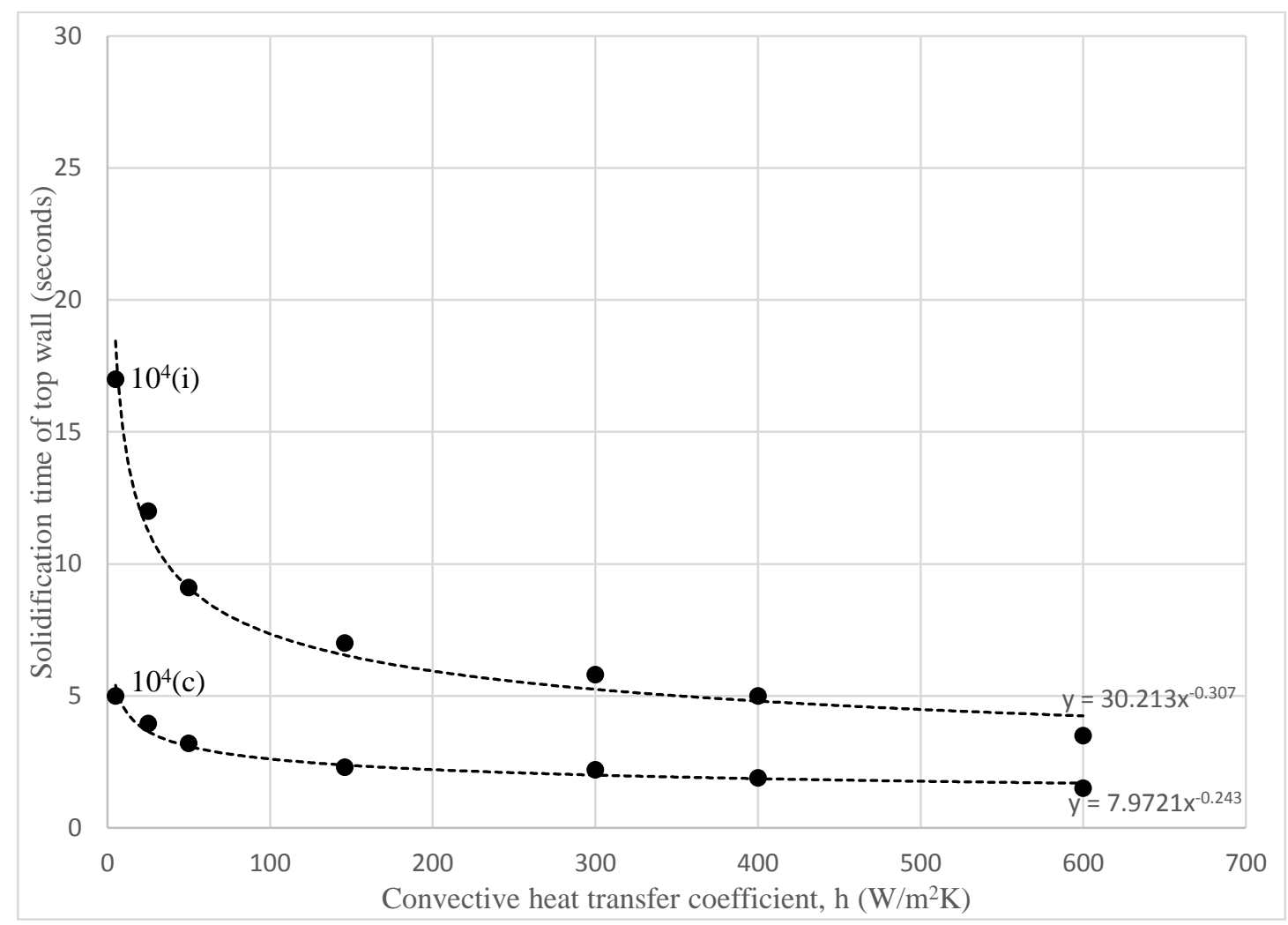

Figure 5.41. Power law curve fit for top wall's solidification time vs $\mathrm{h}$ at $\mathrm{Ma}=4.3 \times 10^{4}$ along with insulated (i) and constant temperature(c) bottom wall

To further investigate the problem, a linear relationship between time required for solidification of top wall and total time required for solidification of the entire geometry is shown in Figure 5.43. Each individual line contains three data points corresponding to three Marangoni number which are shown in the figure. Labels showing different Marangoni number has only been mentioned once for the line of convective heat transfer coefficient, (h) of $5 \mathrm{~W} / \mathrm{m}^{2} \mathrm{~K}$ with insulated bottom wall. Rest of the lines follows the same order of Marangoni number where Marangoni number of $10^{3}$ takes the longest time to solidify and the highest Marangoni number $10^{5}$ takes the least time. 


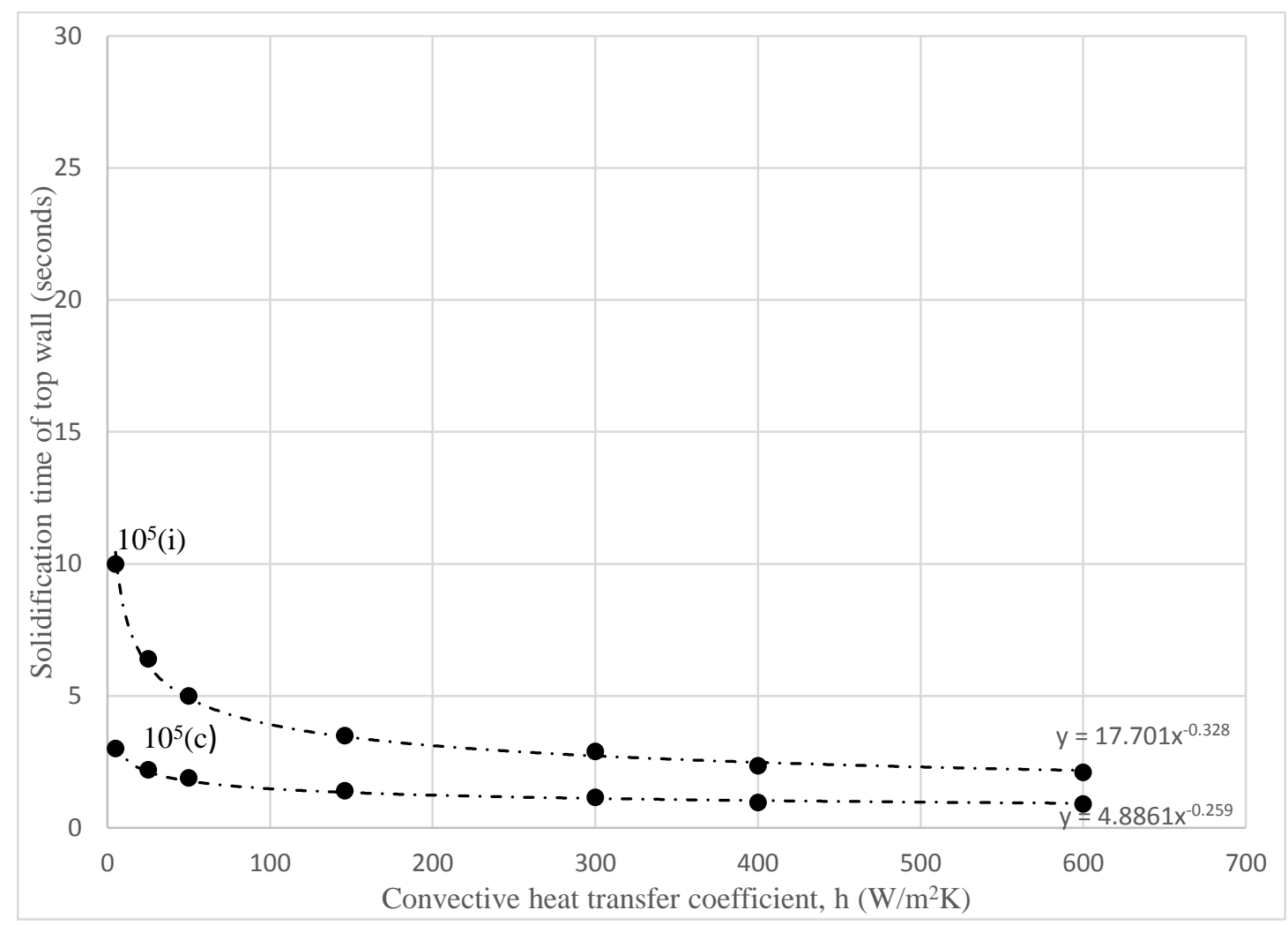

Figure 5.42. Power law curve fit for top wall's solidification time vs $\mathrm{h}$ at $\mathrm{Ma}=4.3 \times 10^{5}$ along with insulated (i) and constant temperature(c) bottom wall

It was interesting to discover that the relationship between different Marangoni numbers are linear for every single cases. If the total solidification time of the geometry can be measured, the corresponding time required for solidification of the top wall can be calculated by using these equations. The solidification time of top wall is of high importance since it controls the Marangoni convection. Thus an estimated final distribution of particles can be obtained by using the equations from Figure 5.43 and comparing the results with Figure 5.2-5.26 which showed how the solidification time was directly related with particle distribution. 


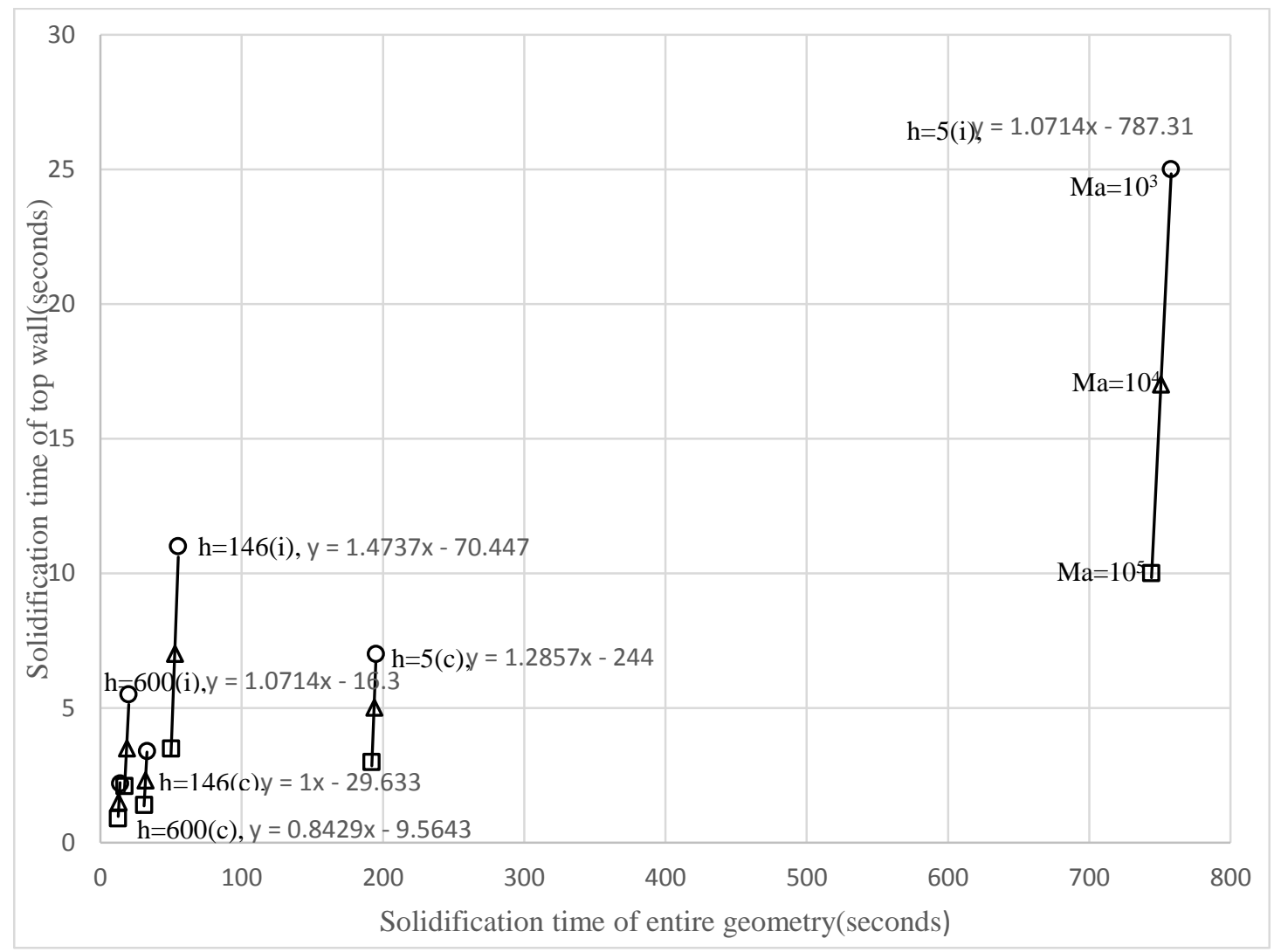

Figure 5.43. Linear curve fit for variation of top wall's solidification time vs the entire geometry's solidification time at different Ma and h.

Figures 5.44-5.50 were used to show the effect of each convective heat transfer coefficient (h) individually while comparing top wall's solidification time vs the entire geometry’s solidification time at different Marangoni numbers (Ma) and bottom wall thermal boundary conditions. These figures provide better visual representation of the relationship between time required of solidification and the effect of bottom wall boundary conditions (insulated or constant temperature). It can be observed that increase in convective heat transfer coefficient (h) decreases the difference of solidification time between different Marangoni numbers and also between cases with different bottom wall thermal boundary conditions. 


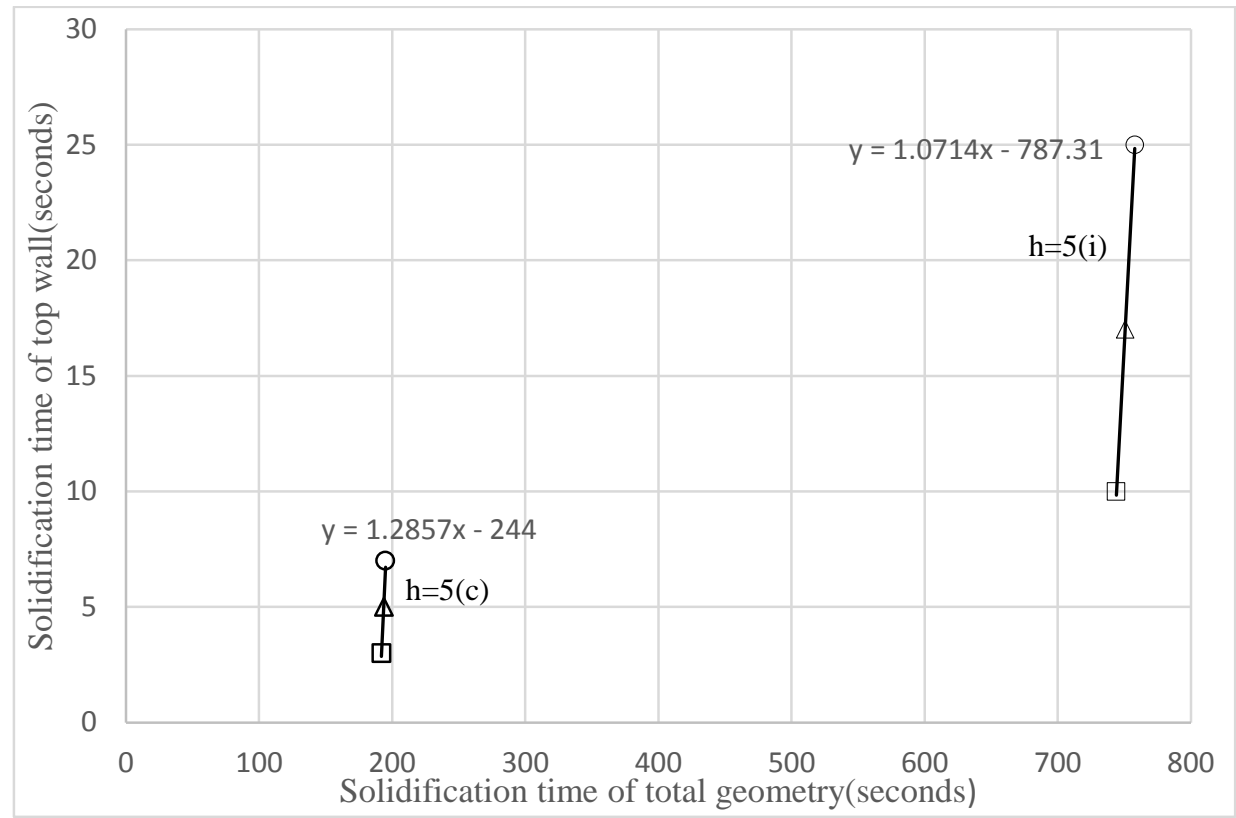

Figure 5.44. Linear curve fit for variation of top wall's solidification time vs the entire geometry's solidification time at different $\mathrm{Ma}$ and $\mathrm{h}=5 \mathrm{~W} / \mathrm{m}^{2} \mathrm{~K}$.

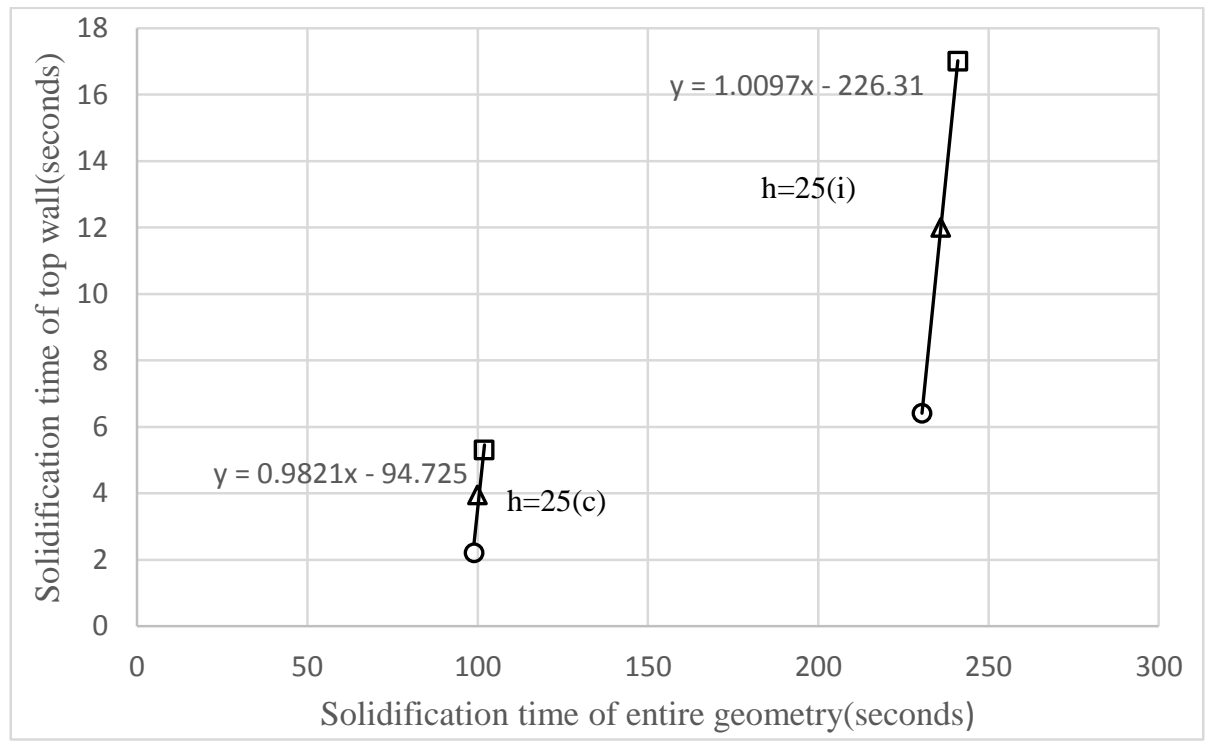

Figure 5.45. Linear curve fit for variation of top wall's solidification time vs the entire geometry's solidification time at different $\mathrm{Ma}$ and $\mathrm{h}=25 \mathrm{~W} / \mathrm{m}^{2} \mathrm{~K}$. 


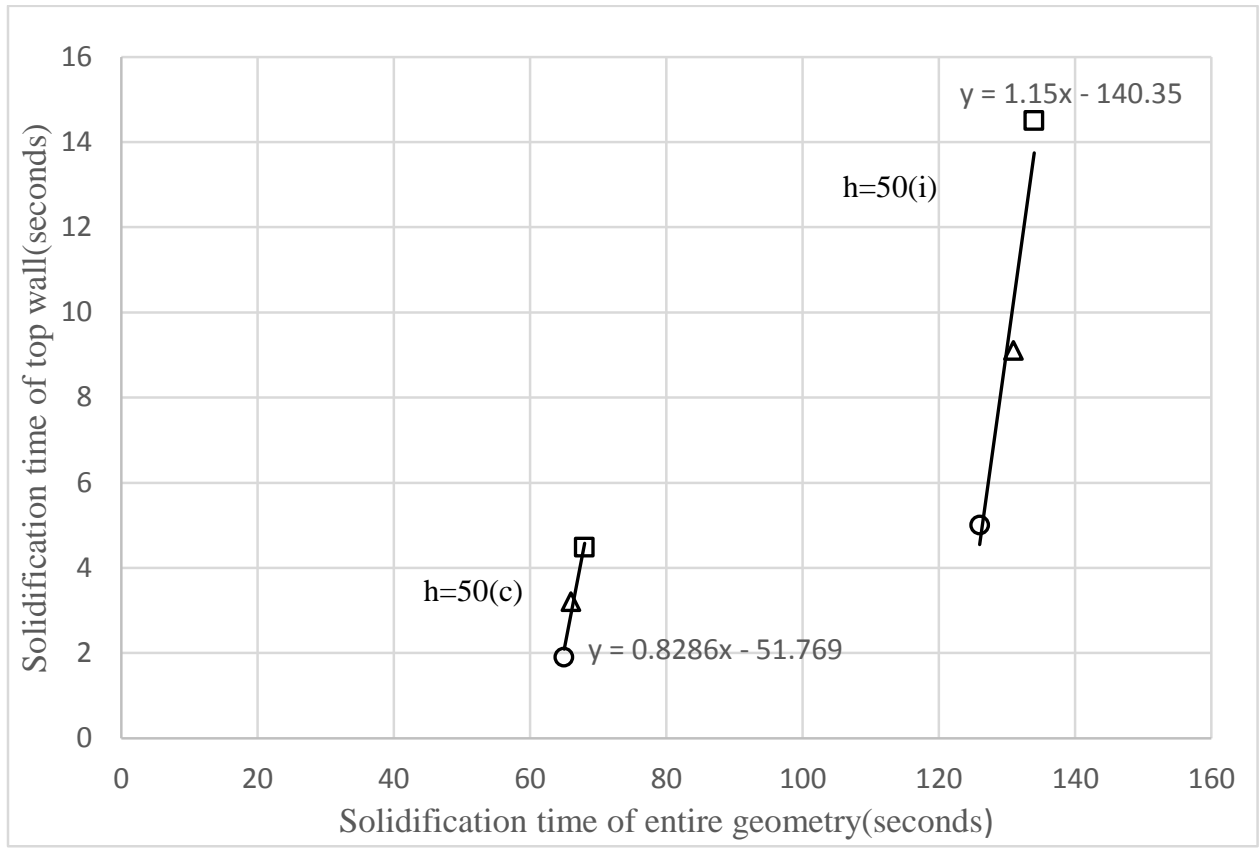

Figure 5.46. Linear curve fit for variation of top wall's solidification time vs the entire geometry's solidification time at different $\mathrm{Ma}$ and $\mathrm{h}=50 \mathrm{~W} / \mathrm{m}^{2} \mathrm{~K}$.

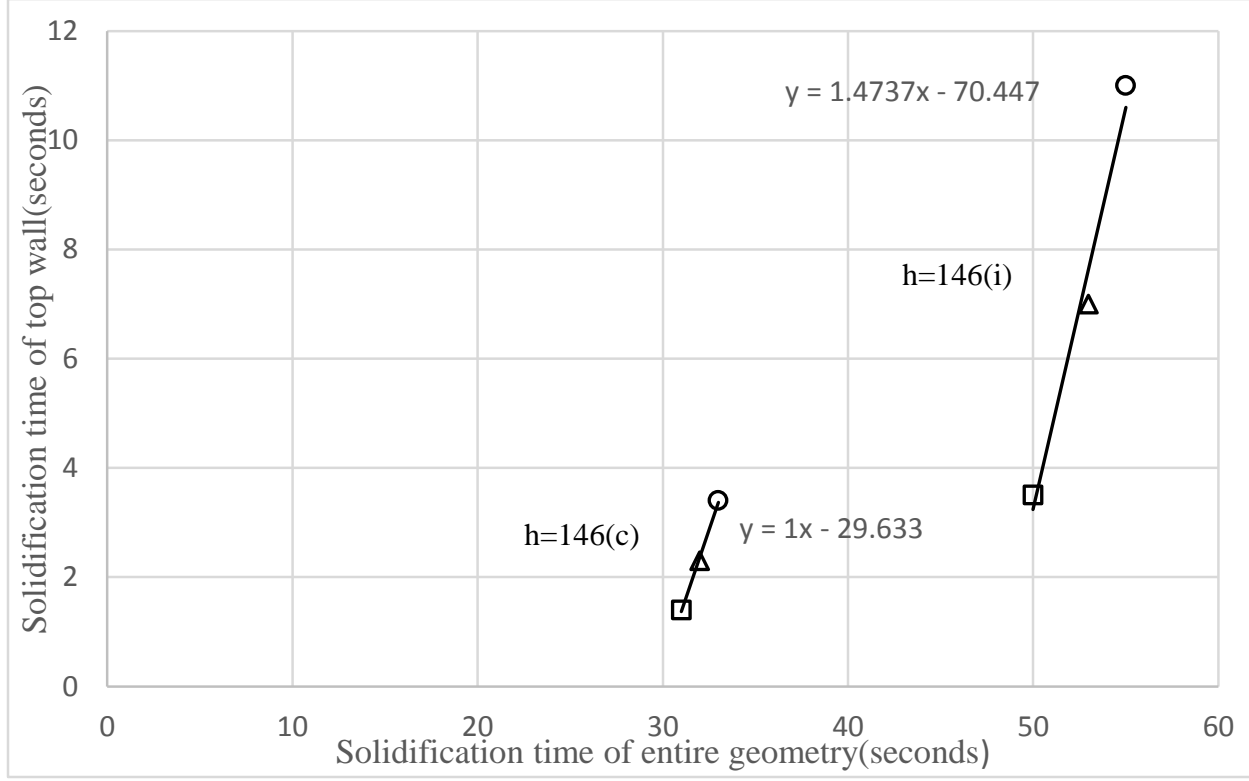

Figure 5.47. Linear curve fit for variation of top wall's solidification time vs the entire geometry's solidification time at different $\mathrm{Ma}$ and $\mathrm{h}=146 \mathrm{~W} / \mathrm{m}^{2} \mathrm{~K}$. 


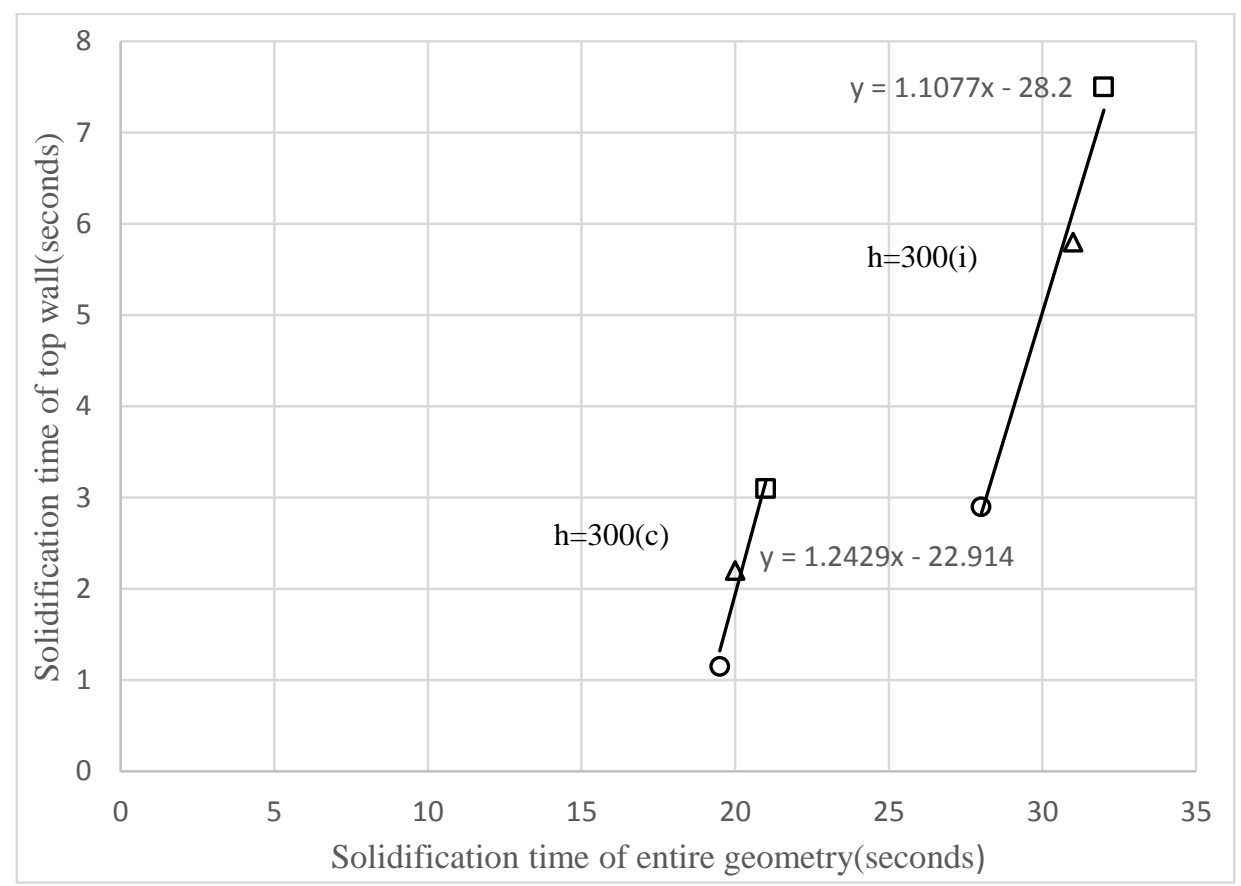

Figure 5.48. Linear curve fit for variation of top wall's solidification time vs the entire geometry's solidification time at different $\mathrm{Ma}$ and $\mathrm{h}=300 \mathrm{~W} / \mathrm{m}^{2} \mathrm{~K}$.

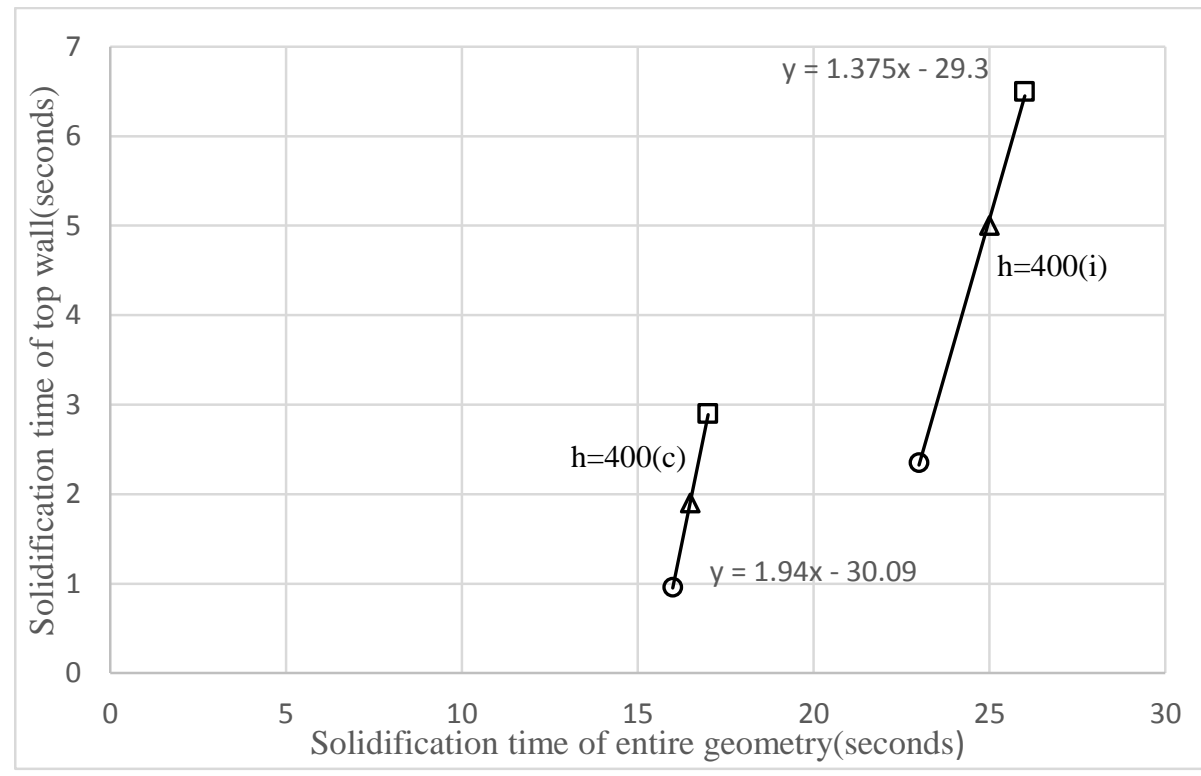

Figure 5.49. Linear curve fit for variation of top wall's solidification time vs the entire geometry's solidification time at different $\mathrm{Ma}$ and $\mathrm{h}=400 \mathrm{~W} / \mathrm{m}^{2} \mathrm{~K}$. 
98

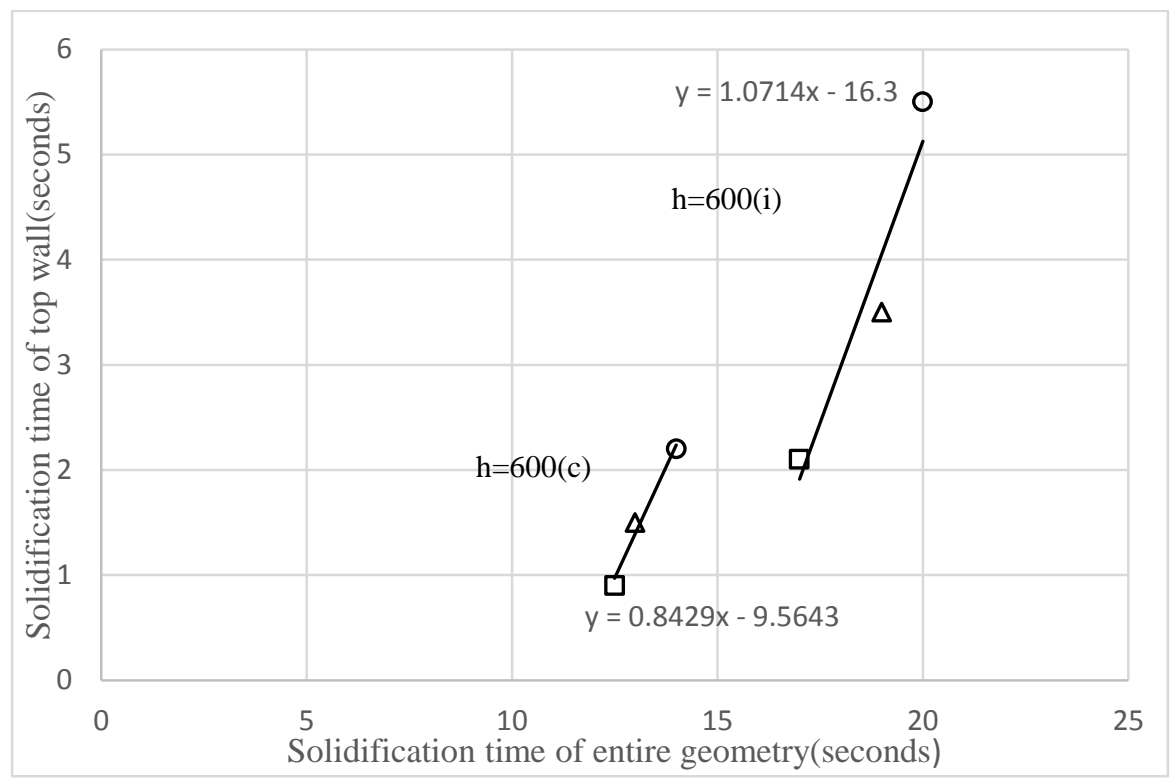

Figure 5.50. Linear curve fit for variation of top wall's solidification time vs the entire geometry's solidification time at different Ma and $\mathrm{h}=600 \mathrm{~W} / \mathrm{m}^{2} \mathrm{~K}$.

Similar equations were generated by power law curve fit to depict the relationship for the solidification time of the top wall vs. the solidification time for the entire geometry for different values of convective heat transfer coefficient (h), while the Marangoni number was kept constant. Figures 5.51-5.53 show the relationships for $\mathrm{Ma}=$ $4.3 \times 10^{3}, 4.3 \times 10^{4}$ and $4.3 \times 10^{5}$ respectively. These equations will be useful to predict the solidification time for the entire geometry for different values of convective heat transfer coefficient (h). 


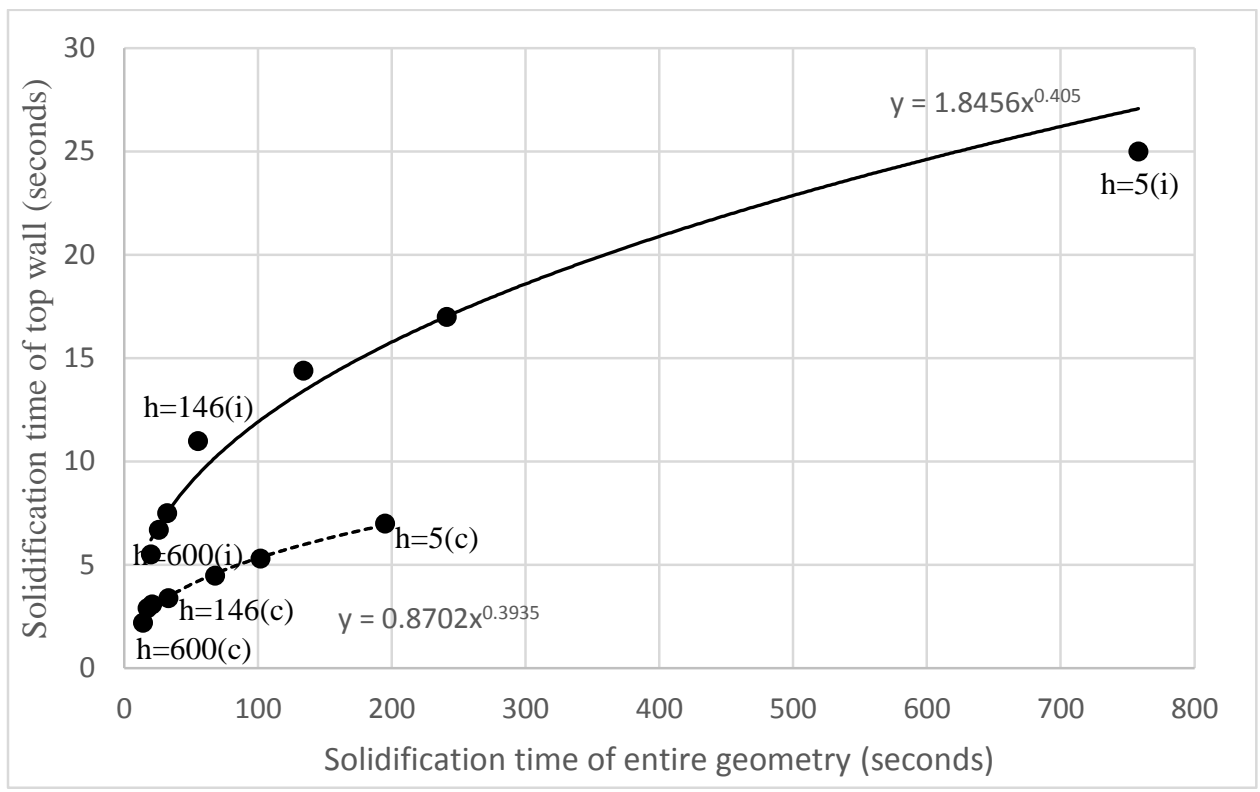

Figure 5.51. Power law curve fit for variation of top wall's solidification time vs total geometry's solidification time at different values of $\mathrm{h}$ and $\mathrm{Ma}=4.3 \times 10^{3}$

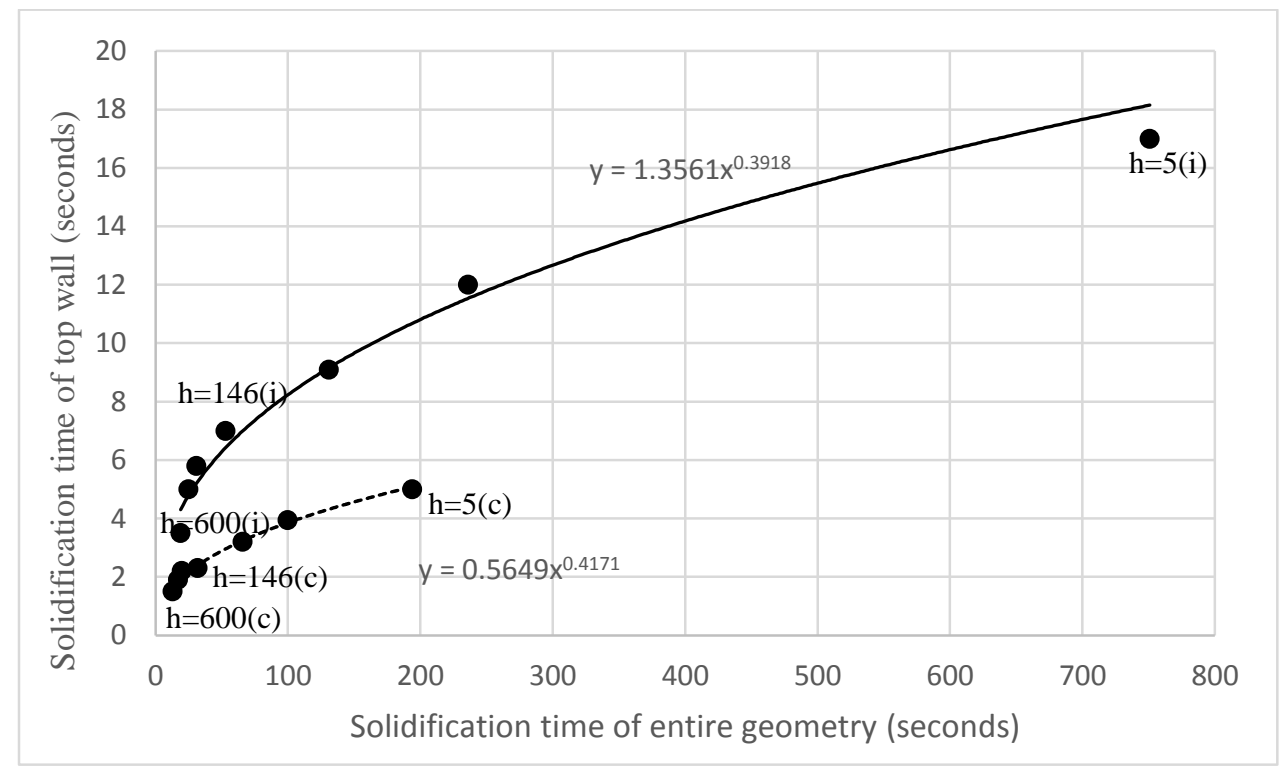

Figure 5.52. Power law curve fit for variation of top wall's solidification time vs total geometry's solidification time at different values of $\mathrm{h}$ and $\mathrm{Ma}=4.3 \times 10^{4}$ 


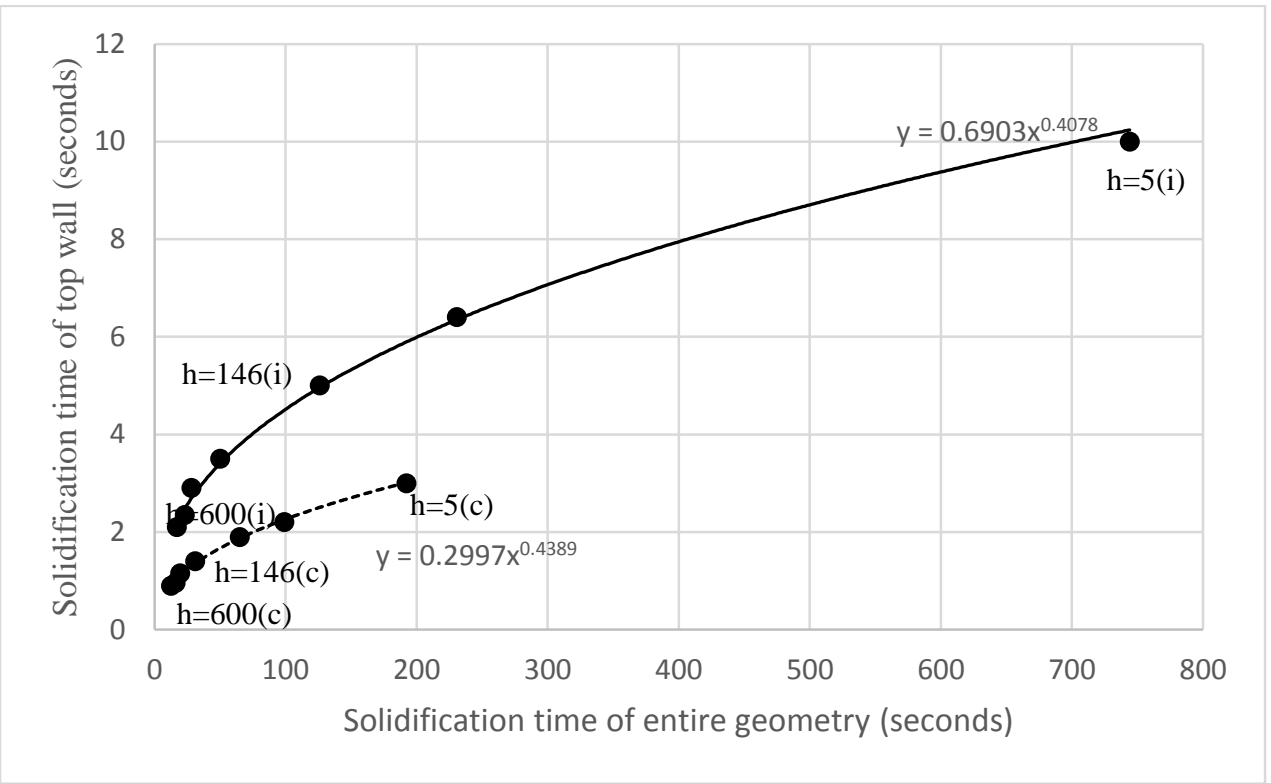

Figure 5.53. Power law curve fit for variation of top wall's solidification time vs total geometry's solidification time at different values of $\mathrm{h}$ and $\mathrm{Ma}=4.3 \times 10^{5}$ 


\section{CHAPTER 6}

\section{CONCLUSION / RECOMMENDATIONS}

The transport and distribution of nanoparticles were investigated considering both the effects of buoyancy and Marangoni convection. Euler-Lagrangian approach was incorporated to couple Marangoni and buoyancy convection along with solidification and particle tracking. Different initial distribution of particles, Marangoni number, convective heat transfer coefficient and thermal boundary condition of the bottom wall were investigated. It was observed that the overall distribution of the particles is strongly affected by the amount of heat transfer occurring in the geometry as well as the solidification time of the top wall (free surface). The comparison of the results for different value of the parameters demonstrate a major difference in the final particle distribution. Higher Marangoni number generally yield a very dominant recirculating pattern in the fluid flow, as well as the higher distribution of the particles in the quasiequilibrium region. Effectiveness of Marangoni convection highly depends on the amount of time it takes to solidify the top wall. The impact of high Marangoni number was clearly visible even when the top wall solidifies relatively faster, in which the particle flow in the quasi-equilibrium region. In case of low Marangoni number, particles do not move in a very well defined quasi-equilibrium recirculating region due to lower fluid velocity. With the increase of convective heat transfer coefficient value, this movement becomes more restricted. With the increase in Marangoni number, fluid flow 
achieves higher velocity thus it becomes easier for the nanoparticles to travel and follow a much defined recirculating region mainly because of the centrifugal force.

Initial distribution of particles also have a huge impact on the final distribution of particles after complete solidification. At lower Marangoni number, highly concentrated initially distributed particles have a tendency to remain concentrated during the solidification process. This creates empty spaces with no particles in there and highly concentrated particles in the quasi-equilibrium region. For high Marangoni number, it was observed that even at a higher rate of solidification, particles move and get distributed in a well-defined quasi equilibrium region. Particle distribution was not affected that much by the rate of solidification for the cases with $\mathrm{Ma}=4.3 \times 10^{5}$. Since the Rayleigh number was constant for this study, natural convection was not very effective in particle transportation, compared to Marangoni convection.

Effects of Marangoni number, convective heat transfer coefficient and varying bottom wall boundary condition have been evaluated on the solidification time of the geometry as well as the heat flux at the top wall. Increase in convective heat transfer coefficient resulted a stepper slope for the total heat flux on top wall versus time plot, which indicates a higher rate of heat transfer between the top wall and the ambient. Also at low convective heat transfer coefficient, the differences in heat fluxes between different Marangoni numbers were significantly lower compared to the same Marangoni numbers at high convective heat transfer coefficient. This difference increased with increase in convective heat transfer coefficient. It indicates that high convective heat transfer coefficient value significantly increased the heat transfer on the top wall. Notable 
increase in heat flux can also be observed between different Marangoni numbers at high convective heat transfer coefficient even after the solidification of the top wall.

Marangoni convection terminates after the solidification of the top wall. Thus convective heat transfer coefficient was solely responsible for the increase in heat transfer on top wall. Relationship between convective heat transfer coefficient, Marangoni number, solidification time of top wall and total geometry have been analyzed and quantified by using multiple equations.

Future work could include the following aspects:

- Different geometries with different aspect ratios should be explored. Different aspect ratio should change the rate of solidification with a different motion and position of the solidification front, which in terms can change the final distribution of particles after solidification.

- Three dimensional problem formulation could give interesting insight to the particle movement phenomena. Particle movement in $\mathrm{z}$ direction could alter the concentrated distribution in quasi steady region experienced in present study.

- Different materials for governing fluid and nanoparticles could be incorporated. Generally, nanoparticles flow with the velocity contour of the fluid. However, if the density of nanoparticle is significantly different than the density of governing fluid, particles will either float to the top or deposit at the bottom of the geometry. And if the rate of solidification is very high, they can get trapped in the solidified region while traveling towards the top or bottom and distribute at different places of the geometry. 
- The continuous velocity induces by moving of laser cladding injector and substrate requires further research. Present study assumed that the particles were initially distributed either uniformly, or as a concentrated entity in the geometry. But during deposition of clad layer, the fluid will experience some additional velocities due to the movement of cladding injector or movement of the substrate. Amount of velocity introduced will also vary depending on the powder flow rate and the electrical power used by the laser. Higher laser power will results in a larger molten surface. If the applied powder flow rate is less, this will introduce larger melt pool in the substrate. However if the powder flowrate is high, it will create larger melt pool in the clad layer. Higher flowrate of powder will also significantly increase the initial velocity experienced by particles.

- The deformation on the free surface induced by surface tension should be explored. Generally, gravitational acceleration damps the free surface deformation. However, deformation can be an issue when Marangoni number is significantly larger than Rayleigh number (Ma >> Ra). Deformed top wall could change the velocity streamline which could result in a different distribution of particles. The deformation on the free surface has significant implication at microgravity. 


\section{REFERENCES CITED}


Abboud, J. H. and West, D. R. F., In situ production of Ti-TiC composites by laser melting, Journal of Materials Science Letters, Vol. 11, pp. 1675-1677, 1992.

Abboud, J. H. and West, D. R. F., Microstructure of titanium injected with SiC particles by laser processing, Journal of Material Science Letters, Vol. 10, pp. 1149-1152, 1991.

Akbar, M. K., Rahman. M. and Ghiaasiaan, S.M., Particle transport in a small square enclosure in laminar natural convection, Aerosol Science, Vol. 40, pp. 747-761, 2009.

ANSYS Reference manual, Release 14.5, SAS IP Inc., 2014.

Ayers, J. D. and Tucker, T. R., Particulate-TiC-hardened steel surfaces by laser melt injection, Thin solid films, Vol. 73, Issue 1, pp. 201-207, 1980.

Baker, T. N., Xin, H., Hu, C. and Mridha, S., Design of surface in-situ metal-ceramic composite formation via laser treatement, Material Science Technology, Vol. 10, pp. 536-544, 1994.

Brechet, Y., Embury, J.D.,Tao, S., and Luoi, L., Damage initiation in metal matrix composites, Journal of Acta Metallurgica et Materialia, Vol. 39, No. 8, pp. 17811786, 1991.

Brent, A. D., Voller, V. R. and Reid, K. J., Enthalpy-porosity technique for modeling convection-diffusion phase change, International Journal of numerical method, Vol. 24, pp. 271-284, 1987.

Capello, E., Colombo, D. and Previtali, B., Repairing of sintered tools using laser cladding by wire, Journal of Materials Processing Technology, Vol. 164-165, pp. 990-1000, 2005.

Chandrasekhar, S., Stochastic problems in physics and astronomy, Reviews of Modern Physics, Vol. 15 (1), pp. 1-89, 1943.

Chen, F., C. M., Simon and Lai, A. C. K., Modeling particle distribution and deposition in indoor environments with a new drift-flux model, Journal of atmospheric environment, Vol. 40, pp. 357-367, 2006.

Choi, J., Han, L. and Hua, Y., Modeling and experiments of lase cladding with droplet injection, ASME journal of heat transfer, Vol. 127, pp. 978-986, 2005.

Chorin, A. J., Numerical solution of Navier-Stokes equations. Mathematics of Computation, Vol. 22, pp. 745-762, 1968. 
De Mestral, F. and Thevenot, F., In the Physics and Chemistry of Carbides, Nitrides and Borides, ed. R. Freer. Kluwer, Dordrecht, 1989.

Ehlen, G., Ludwig, A. and Sahm, P. R., Simulation of Time-Dependent Pool Shape during Laser Spot Welding: Transient Effects, Metallurgical and materials transactions A, Vol. 34A, pp. 2947-2961, 2003.

European Nuclear Society Encyclopedia, 2014.

Fan, H.G., Tsai, H. L. and Na, S. J., Heat transfer and fluid flow in a partially or fully penetrated weld pool in gas tungsten arc welding, International Journal of heat and mass transfer, Vol. 44, pp. 417-428, 2001.

Feng, Z., Feng, Y. and Andersson, M., Shape effects on the drag force and motion of nano and micro particles in low Reynolds number flow, ASME International mechanical engineering congress and exposition, Houston, TX. Paper number: IMEC2012-89469, November 10-15, 2012.

Gadgil, A. and Gobin, D., Analysis of two dimensional melting in rectangular enclosures in the presence of convection, International Journal of Heat and Mass Transfer, Vol. 106, pp. 20-26, 1984.

Gebhart, B., Jaluria, Y., Mahajan, R.L., and Sammakia, B., Buoyancy-Induced Flows and Transport, Hemisphere, Cambridge, 1988.

Giangi, M., Stella, F., Leonardi, E., and de Vahl Davis, G., A numerical study of solidification in the presence of a free surface under microgravity conditions, Numerical Heat Transfer, part A, Vol. 41, pp. 579-595, 2002.

Golkarfard, V. and Talebizadeh, P., Numerical comparison of airborne particles deposition and dispersion in radiator and floor heating systems, Advanced powder technology, Vol. 25, Issue 1, pp. 389-397, 2013.

Hashim, J., Looney, L. and Hashmi, M.S.J., Particle distribution in cast metal matrix composites-Part I, Journal of Materials Processing and Technology, Vol. 123, pp. 251-257, 2002.

Hinds, W. C., Aerosol Technology, Properties, Behavior, and Measurement of Airborne Particles, John Wiley \& Sons, New York, 1998.

Kloosterman, A. B., Kooi, B.J., and De hosson, J. TH. M., Electron microscopy of reaction layers between $\mathrm{SiC}$ and Ti-6Al-4V after laser embedding, Journal of ActaMetallurgica et Materialia, Vol. 46, No.17, pp. 6205-6217, 1998. 
Kovalev, O. B., Popov, A.N., Smirnova, E.M. and Smurov, I., Numerical Study of Concentration and Thermocapillary Melt Convection under Pulsed Laser Alloying, Physical Procedia, Vol. 12, pp. 478-489, 2011.

Leduc, S., Fredriksson, C. and Hermansson, R., Particle tracking option in Fluent validated by simulation of a low-pressure impactor, Advanced powder technology, Vol. 17, pp. 99-111, 2006.

Lei, Y. P., Murakawa, H., Shi, Y. W. and Li, X. Y., Numerical analysis of the competitive influence of Marangoni flow and evaporation on the heat surface temperature and molten pool shape in laser surface remelting, Computational Material Science, Vol. 21, pp. 276-290, 2001.

Li, A. and Ahmadi, G., Dispersion and Deposition of Spherical Particles from Point Sources in a Turbulent Channel Flow, Aerosol Science and Technology, Vol. 16, pp. 209-226, 1992.

Liu, A., Voth, T. E. and Bergman, T. L., Pure material melting and solidification with liquid phase buoyancy and surface tension forces, International Journal of Heat and Mass Transfer, Vol. 36, No. 2, pp. 411-422, 1993.

Mezhericher, M., Brosh, T. and Levy, A., Modeling of particle pneumatic conveying using DEM and DPM methods, Journal of particulate science and technology, Vol. 29, pp. 197-208, 2011.

Mills, A. F., Heat Transfer, Second Edition, Prentice-Hall, New Jersey, 1999.

Mridha, S. and Baker, T. N., Metal matrix composite layer formation with $3 \mu \mathrm{m} \mathrm{SiCp}$ powder on IMI318 titanium alloy surfaces through laser treatment, Journal of Materials Processing Technology, Vol. 63, Issue 1-3, pp. 432-437, 1997.

Ookawara, S., Agrawal, M., Street, D. and Ogawa, K., A numerical study of the influence of particle density on lift force-induced separation in a micro-separator/classifier by a macroscopic particle model, Journal of chemical engineering of Japan, Vol. 40, pp. 986-992, 2007.

Ounis, H., Ahmadi, G. and McLaughlin, J. B., Brownian Diffusion of Submicrometer Particles in the Viscous Sublayer. Journal of Colloid and Interface Science, Vol. 143, No. 1, pp. 66-277, 1991.

Pal, D. and Joshi, Y. K., Melting in a side heated tall enclosure by a uniformly dissipated heat source, International Journal of Heat and Mass Transfer, Vol. 44, pp. 375387, 2001. 
Pirker, S., Kahrimanovic, D., Kloss, C., Popoff, B. and Braun, M., Simulating coarse particle conveying by a set of Eulerian, Lagrangian and hybrid particle models, Advanced Powder technology, Vol. 204, pp. 203-213, 2010.

Ramachandran,N., Gupta, J. R. and Jalunu, Y., Thermal and fluid flow effects during solidification in a rectangular cavity, International Journal of Heat and Mass Transfer, Vol. 25, pp. 187-194, 1982.

Rhie, C. M. and Chow, W. L., Numerical Study of the Turbulent Flow Past an Airfoil with Trailing Edge Separation, AIAA Journal, Vol. 21, No. 11, pp. 1525-1532, 1983.

Robinson, R., Snyder, P. and Oldham, M., Comparison of Particle Tracking Algorithms in Commercial CFD Packages: Sedimentation and Diffusion, Journal of Inhalation toxicology, Vol. 19, pp. 517-531, 2007.

Saffman, P. G., The Lift on a Small Sphere in a Slow Shear Flow. Journal of Fluid Mechanics, Vol. 22, pp. 385-400, 1965.

Sahoo, P., Debroy, T. and McNallan, M.J., Surface Tension of Binary Metal Surface Active Solute Systems under Conditions Relevant to Welding Metallurgy, Journal of metallurgical transactions B, Vol. 19 B, pp. 483-491, 1988.

Shyy, W. and Chen, M., Interaction of thermocapillary and natural convection flows during solidification: normal and reduced gravity conditions, Journal of Crystal Growth, Vol. 108, pp. 247-261, 1991.

Swaminathan, C. R. and Voller, V. R., A general enthalpy method for modeling solidification processes. Metallurgical Transactions B, Vol. 23, No. 5, pp. 651664, 1992.

Tan, L. H., Leonardi, E., Barber, T. J. and Leong, S. S., Experimental and numerical study of Marangoni convection in shallow liquid layers, International Journal of Computational Fluid Dynamics, Vol. 19, No. 6, pp. 457-473, 2005.

Tan, L. H., Leong, S. S., Barber, T. J. and Leonardi, E., Simulation of solidification with Marangoni effect using a multiphase approach, $16^{\text {th }}$ International symposium on transport phenomena, ISTP-16, Prague, 2005.

Villers, D., Platten, J. K., Coupled buoyancy and Marangoni convection in acetone: experiments and comparison with numerical simulations, Journal of Fluid Mechanics, Vol. 234, pp. 487-510, 1991. 
Voller, V. R., and Prakash. C., A Fixed-Grid Numerical Modeling Methodology for Convection-Diffusion Mushy Region Phase-Change Problems, International Journal of Heat and Mass Transfer, Vol. 30, pp. 1709-1720, 1987.

White, Frank M. Viscous fluid flow, Second Edition, McGraw-Hill Inc., 1991.

Wolff, F. and Viskanta, R., Solidification of pure metal at a vertical wall in the presence of liquid superheat, International journal of heat and mass transfer, Vol. 31, pp. 1735-1744, 1988.

Xu, Y. L., Dong, Z. B., Wei, Y. H. and Yang, C.L., Marangoni convection and weld shape variation in A-TIG welding process, Theoretical and Applied Fracture Mechanics, Vol. 48, pp. 178-186, 2007.

Zhao, B., Zhang, Y., Li, X., Yang, X. and Huang, D., Comparison of indoor aerosol particle concentration and deposition in different ventilated rooms by numerical method, Journal of building and environment, Vol. 39, pp. 1-8, 2003.

Zhou, X. and Huai, X., Numerical Investigation of Thermocapillary Convection in a Liquid Layer with Free Surface, Microgravity Science and Technology, Vol. 25, pp. 335-341, 2014. 